\title{
Strategic party formation on a circle \& the role of social proximity in job referrals
}

Citation for published version (APA):

Yüksel, A. M. (2015). Strategic party formation on a circle \& the role of social proximity in job referrals. [Doctoral Thesis, Maastricht University]. Datawyse / Universitaire Pers Maastricht. https://doi.org/10.26481/dis.20151125ay

Document status and date:

Published: 01/01/2015

DOI:

10.26481/dis.20151125ay

Document Version:

Publisher's PDF, also known as Version of record

\section{Please check the document version of this publication:}

- A submitted manuscript is the version of the article upon submission and before peer-review. There can be important differences between the submitted version and the official published version of record.

People interested in the research are advised to contact the author for the final version of the publication, or visit the DOI to the publisher's website.

- The final author version and the galley proof are versions of the publication after peer review.

- The final published version features the final layout of the paper including the volume, issue and page numbers.

Link to publication

\footnotetext{
General rights rights.

- You may freely distribute the URL identifying the publication in the public portal. please follow below link for the End User Agreement:

www.umlib.nl/taverne-license

Take down policy

If you believe that this document breaches copyright please contact us at:

repository@maastrichtuniversity.nl

providing details and we will investigate your claim.
}

Copyright and moral rights for the publications made accessible in the public portal are retained by the authors and/or other copyright owners and it is a condition of accessing publications that users recognise and abide by the legal requirements associated with these

- Users may download and print one copy of any publication from the public portal for the purpose of private study or research.

- You may not further distribute the material or use it for any profit-making activity or commercial gain

If the publication is distributed under the terms of Article $25 \mathrm{fa}$ of the Dutch Copyright Act, indicated by the "Taverne" license above, 


\section{Ayşe Müge Yüksel}

Strategic Party Formation on a Circle

\&

The Role of Social Proximity in Job Referrals 
Strategic Party Formation on a Circle \& The Role of Social Proximity in Job Referrals

(C) Copyright Ayşe Müge Yüksel, Maastricht 2015

All rights reserved. No part of this publication may be reproduced, stored in a retrieval system, or transmitted, in any form, or by any means, electronic, mechanical, photocopying, recording or otherwise, without the prior permission in writing from the author.

This book was typeset by the author using $\mathrm{IATEX}_{\mathrm{E}}$.

Cover design by Ayşe Müge Yüksel.

Published by Universitaire Pers Maastricht

ISBN 9789461594839

Printed in the Netherlands by Datawyse 


\title{
Strategic Party Formation on a Circle \& The Role of Social Proximity in Job Referrals
}

\author{
Proefschrift \\ ter verkrijging van de graad van doctor \\ aan de Universiteit Maastricht, \\ op gezag van Rector Magnificus, \\ Prof. dr. L.L.G. Soete,
}

volgens het besluit van het College van Decanen,

in het openbaar te verdedigen

op woensdag 25 November 2015, om 16:00 uur

door

Ayşe Müge Yüksel

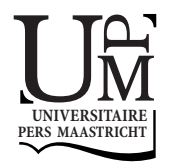




\section{Promotor:}

Prof. dr. Arno Riedl

\section{Copromotores:}

Dr. Ronald Peeters

Dr. Rene Saran

\section{Beoordelingscommissie:}

Prof. Dr. Jean-Jacques Herings (voorzitter)

Prof. Dr. Robert Dur (Erasmus University Rotterdam)

Dr. Martin Strobel

Dr. Franziska Tausch (Max Planck Institute for Research on Collective Goods) 


\section{Acknowledgements}

A PhD Project is a long, tough journey one cannot finish by herself. Mine was a bit longer I admit, but it would have never been possible if it was not for all the great people who were there for me. I therefore would like to take this opportunity to thank them for their help that has meant so much to me.

First and foremost, I would like to thank Ronald Peeters who always devoted time for our discussions generously, guided me in every level from the sketch of an idea to the tiniest detail of the work. He brought good mood to every meeting, never stopped encouraging and inspiring me. It's his vision and experience which brought this work to its current standard.

I am immensely grateful to Arno Riedl, Rene Saran and Amrita Dhillon, working with them was a pleasure and their feedback was most valuable. I undoubtedly learned a great deal from them.

I would also like to express my gratitude for Marco Battaglini who made my five month research visit to Princeton possible.

In addition, I address my thanks to Elke Lucas, Nicole Hulsman and Sylvia Beenen for their excellent administrative support, and to the METEOR Research School for their financial support.

This has not been years of nerdiness only but also years of traveling, growing, sharing joy and friendship. I would like to thank all my colleagues and friends for all of it. I would like to thank Attila Korpos, Arkadi Predtetchinski, Michael Yang, Audrey Picard, Franziska Tausch, Lavinia Gotovan, Fortuna Casoria and Murat Öztürk, in particular. Then there is the "Turkish community" of course.

I started this journey with Engin and Gülçin Menteşoğlu, who encouraged me to apply in the first place and supported me in every possible way. 
Selin Özsoy , Feyzan Ersoy and Esra Çetiner never gave up cheering me up. Without Seher Fazlioğlu and Jessie Lemmens it would not have been the same. Not even close.

The people who deserve my utmost gratitude is my family. They have given me love, courage and strength. I am forever indebted to them. I consider myself the luckiest person for Kutay Cingiz also recently joined my family. I dedicate this book to my family.

Ayşe Müge Yüksel

Maastricht, 2015 


\section{Contents}

1 Introduction 1

1.1 Part I: Political economy . . . . . . . . . . . . . . . . . . 1

1.2 Part II: Behavioral economics . . . . . . . . . . . . 5

2 Strategic Party Formation on a Circle $\quad 7$

2.1 Introduction . . . . . . . . . . . . . . . 7

2.2 Model . . . . . . . . . . . . . . . . . . . . . . . 10

2.3 Plurality Rule . . . . . . . . . . . . . . . . . . 15

2.4 Proportional Rule . . . . . . . . . . . . . . . . . 24

2.5 Summary . . . . . . . . . . . . . . . . . 28

2.6 Proofs . . . . . . . . . . . . . . . . . . . 29

3 Equilibrium Concepts for a Party Formation Setting 41

3.1 Introduction . . . . . . . . . . . . . . . . . 41

3.2 Model . . . . . . . . . . . . . . . . . . . . 42

3.3 Equilibrium Refinements . . . . . . . . . . . . . . . . 43

3.4 Summary . . . . . . . . . . . . . . . . . . 54

4 Overcoming Moral Hazard with Social Networks $\quad 57$

4.1 Introduction . . . . . . . . . . . . . . . 57

4.2 Conceptual framework . . . . . . . . . . . . . . 61

4.3 The experiment . . . . . . . . . . . . . . 65

4.4 Results. . . . . . . . . . . . . . . . . 68

4.5 Discussion and conclusion . . . . . . . . . . 80 
5 Workplace Referrals and Gift Exchange 83

5.1 Introduction . . . . . . . . . . . . . . . . . 83

5.2 The experiment . . . . . . . . . . . . . 85

5.3 Results . . . . . . . . . . . . . . . . . . . . . 89

5.4 Discussion and conclusion . . . . . . . . . . . . . 97

$\begin{array}{ll}\text { Appendix } 1 & 101\end{array}$

$\begin{array}{ll}\text { Appendix } 2 & 109\end{array}$

$\begin{array}{ll}\text { Bibliography } & 117\end{array}$

$\begin{array}{ll}\text { Valorization } & 123\end{array}$

$\begin{array}{ll}\text { Curriculum Vitae } & 129\end{array}$ 


\section{Chapter 1}

\section{Introduction}

This work consists of two parts; the first part is a game theoretical approach to political economy. We ask the questions of how the electoral system affects the outcome of an election, how many parties are formed and which political agendas are supported. We model this setting in an alternative way and then discuss which equilibrium notion would be the most appropriate to use in this model.

The second part contributes to behavioral economics. This part consists of two experiments in labor theory. We investigate the advantages of the use of referrals in the workplace. An obvious advantage is inducing worker discipline and overcoming moral hazard. Workers expend much more effort when they are hired through a referrer rather than via random matching in a spot market. We elicit the motivations behind this behavior and investigate how the effort level chosen by the worker differs with the social proximity between the worker and the referrer.

\subsection{Part I: Political economy}

By picking the election method one can immensely affect the outcome of the elections. There are two major voting rules that constitute the basis of election systems today. Pluralistic voting is the basis of the voting systems in France, the UK, Canada and the United States. It is also known as winner-takes-all, since the party that receives the most number of votes 
wins the elections. On the other hand, under proportional representation the number of seats won by a party is proportionate to the number of votes received. This electoral rule is the basis of the voting systems in the Netherlands, Switzerland, Israel and Spain.

Plurality rule gives the government an advantage in upcoming elections since the government can arrange the voting districts in such a way that opposition votes are divided and distributed to areas that dominantly support the incumbent party. Moreover, voters may choose to vote for the candidate they favor most among those who have a higher chance to win even when it is not their true preference, because otherwise their votes will have no impact on the outcome and therefore be wasted. Extremist political agendas and minorities are represented very limitedly under pluralistic voting. In cases of low voter turnout during plurality type elections, a party might gain political power disproportionate to its voter base. Under proportional voting rule minorities get better representation, but after-election politics gain much more importance. Parties form a coalition government and minorities might even get too much power by strategic coalition formation. In our analyses, we will leave after-election politics and welfare implications aside and investigate how the choice of the electoral rule affects the number of parties formed and which agendas those parties would support.

Duverger's law is a principle in political science that asserts a twoparty system will be formed when pluralistic voting rule is used when given enough time. Duverger also has a hypothesis that proportional voting rule leads to multipartyism. Our findings support these widely accepted predictions.

Up to this point the political agenda space has been modeled as a line, that is the standard Downsian model. The Downsian model and many of its extensions mostly have nonrealistic convergence results, especially to the median, under plurality voting. To get rid of one-party equilibria some restrictive assumptions are introduced such as a restricted number of parties joining the elections. Some other extensions of the model suffer from a lack of equilibrium or existence of multiple equlibria and therefore cannot predict much.

Although we are used to picturing the political agenda space as a line, political ideology cannot be observed directly but can only be observed 
through its consequences. The political agenda space does not need to be linear. The line that represents the agenda space is bounded from both ends. This implies that there is a very extreme position at which point you cannot be any more extreme and where two extreme positions are furthest away from each other. However, political psychology describes extremism as a personality attribute rather than a political stance. Extreme positions may in fact not be so far away from each other. For example, take Iran on the far-right and North Korea on the far-left, which nevertheless share common points. Similarities of Nazism and Stalinism have also long been discussed. Bringing the edges together, a circle is a good alternative for a policy space. Another advantage of the circle is that it does not have a median or edge players, hence it does not have the disadvantages we mentioned above.

In our model, the political agenda space is the circumference of a circle of unit length. Any number of purely office-seeking politicians join the elections and pick their agenda simultaneously. Any agenda supported by one or more politicians is referred to as a party and incumbent politicians cannot reject an entry of other politicians into the party. Voters are uniformly distributed on the agenda space and they sincerely vote for their most preferred agenda. Under pluralistic voting, political power is divided equally by the winning parties. Under proportional voting rule, the political power of a party is proportional to the votes it receives. Under both rules, this power is divided equally among the politicians in a given party, which results in the personal gain of the politicians that they try to maximize.

A characterization for the set of Nash equilibria in this model is presented, however under plurality voting this set is quite wide and further refinement is necessary for making a sharper prediction. Established equilibrium refinement notions, strong Nash equilibrium and coalition-proof Nash equilibrium do not help much. The set of strong Nash equilibria is empty under both election rules so this refinement seems too strong for this setting. The set of CPNE is also empty under plurality rule and this characterization is very complicated to undertake under proportional voting rule.

Besides being too strong, these equilibrium concepts must also be tailored to the specific needs of the party formation setting. Party formation 
is a dynamic process, however we do not see all sorts of deviations. We see a shift in a party's political agenda, a group splitting from a party and starting a new party, merger of parties, but we do not see coordinated deviation of actors moving towards two distinct agendas. We alter the strong Nash equilibrium notion and the CPNE notion by allowing only these types of deviations.

The alteration of strong Nash equilibrium, namely Party-formation restricted strong Nash equilibrium is already an improvement by making a nonempty selection of equilibria. However the exact number of parties and the existence of an equilibrium are not robust, they depend heavily on the exact number of competing politicians. Finally the alteration of CPNE, namely defection-proof Nash equilibrium makes robust predictions consistent with real electoral outcomes.

The first two chapters of this thesis investigate the effects of the electoral rule on the number of parties formed and the agendas that are supported. In chapter two existing literature is discussed, a formal model is developed, and Nash equilibria and defection-proof Nash equilibria characterizations are presented. Chapter three is devoted to the discussion of other equilibrium concepts in party formation setting. We exhibit which equilibria are selected by strong Nash, Pf-restricted strong Nash, CPNE and defectionproof Nash and address why defection-proof Nash equilibrium is the most suitable equilibrium refinement for our study.

Our main contributions in this part is the use of a circle as a unidimensional political agenda space, defining a party-formation specific equilibrium concept and finding game-theoretical support for Duverger's predictions. Circular political agenda space can further be utilized in researching post-election politics. When a bill is put up to a vote for passing into law, some parties will be for and some will be against it. While this can be modeled in a very restricted way on the unit interval, it is much more flexible on a circle since there are many more ways to divide a circle into two parts. Defection-proof Nash equilibrium is also a new useful tool for the analysis of party formation in a wide range of models including those where the political agenda space is the unit interval. 


\subsection{Part II: Behavioral economics}

Google makes the claim that "Good people know other good people. Our best employees have been hired through referrals. Google encourages you to recommend candidates for opportunities here and will award you a $\$ 2000$ bonus if your referral accepts our offer and remains employed for at least 60 days." Microsoft, Cisco, Accenture and many more use these employee referral programs. The use of social networks in the workplace has also been documented by many authors, although the reasons for their widespread prevalence are less well known.

Employee referrals are considered to be the most commonly used and best source for new hires today. They shorten the search time and make it less expensive for the employer since every employee has her personal network to pool from and is equipped with the best information about the candidate, job and the company hiring. This is advantageous compared to one recruiter going over hundreds of applications none of whom she knows personally. Jobvite, a recruitment website, announced that when an employee is hired through referral she tends to stay longer in the company as well. On the downside, employee referrals may compromise diversity of the workforce and leave out excellent candidates who happen to be outside the reach of the employees' social networks.

For certain jobs talent and expertise are not the issue; trustworthiness is what the employer is looking for. We want to know if employee referrals are still relevant in these cases and if we can reduce moral hazard, induce discipline and reduce monitoring costs by exploiting social connections between newly hired workers and employee referrers. Even when there is no established social connection, if hiring is carried out by an employee referrer, can this affect the newly hired worker positively compared to random hiring at the spot market by the employer? Can the job offer be perceived as a gift and be reciprocated?

In chapter four, we present evidence based on a combined field-laboratory experiment where social networks are used by employers to reduce worker moral hazard. The worker chooses an effort level given a fixed wage under different settings of social proximity. Social proximity is captured using actual Facebook friendship information revealed anonymously to subjects 
once they have been recruited. Since employers themselves do not have access to social connections, they delegate the decision to referrers who can select among workers with different degrees of social proximity to themselves. We show that employers choose referrals over anonymous hiring about $80 \%$ of the time. In keeping with our predictions, referrers also choose workers with a greater social proximity to themselves and workers who are closer to referrers indeed pay back more to the referrer. The advantage of the lab setting is that we can isolate egalitarianism and directed altruism as the main driving forces for these results.

We use the theoretical model of job referrals from Dhillon et al. (2013) and test its predictions. The experiment is not a standard lab experiment since it makes use of the real life information obtained through an online networking website. This provides us with more reliable data compared to those studies where a friendship relation is artificially created in the lab setting. We asked participants for permission to access their Facebook accounts and extract the information about their mutual friendship status and the number of common friends they have. Revealing the identities of the subjects would not have allowed us to disentangle the effect of pure friendship, prospects for future interactions or an attractive profile picture. We supplied the participants with only the relevant information (and kept them in separate rooms to avoid a guessing game), this way we could be sure that any difference in participants' behavior could confidently be attributed to those aspects.

In chapter five, we present the results of our second experiment which was carried out in a very similar fashion to the first one. We show that even when social connections are non-existent, hiring through referral pays off. If a worker can attribute a job offer to the volitional choice of a referrer, she is more likely to exert higher levels of effort compared to random hiring.

Those two lab experiments were done with students with a general equilibrium approach of testing the full mechanism of job referrals, including the employer, the referrer, the worker, their interactions and strategies, not just the worker-referrer relationship. 


\section{Chapter 2}

\section{Strategic Party Formation on a Circle}

\section{$2.1 \quad$ Introduction}

In democratic societies, collective decisions are made in legislatures. The legislators are often grouped into parties. Party representation and configuration in turn depend on the political framework ( Rae (1971), Lijphart (1990) and Taagepera and Shugart (1989)) and the particular strategies adopted by the politicians, parties and voters within that framework. One natural question is, how electoral systems affect the number of parties that form and their respective positions? ${ }^{1}$

Two famous predictions about the effect of electoral systems on political party formation are attributed to the political scientist, Maurice Duverger (1954). Duverger's law states that plurality voting favors a two-party system. According to Duverger's hypothesis, proportional representation favors multi-partyism. Therefore, the Duvergerian comparative prediction is that the number of parties is larger under proportional representation than under plurality voting (Riker (1982), Morelli (2004)).

Cox (1987), Palfrey (1989), Feddersen (1992) and Fey (1997) find the-

\footnotetext{
${ }^{1}$ This chapter is based on a paper jointly written by Ronald Peeters, Rene Saran and Ayşe Müge Yüksel, which has been released as Meteor Research Memorandum (number $10 / 045)$.
} 
oretical support for Duverger's law when the voters avoid wasting their vote on "hopeless" candidates. Rivière (1998), and Osborne and Tourky (2008) focus on economies of party size to explain the formation of political parties. Other papers that explain the existence of parties, without particularly focusing on one of Duverger's predictions, include Osborne and Slivinski (1996), Besley and Coate (1997), Jackson and Moselle (2002), Snyder and Ting (2002), and Levy (2004).

Morelli (2004) is the first to addresses both the law and hypothesis. He shows that more than two parties may be active in a multi-district election with plurality voting when there is sufficient heterogeneity in policy preferences across districts. In addition, when the distribution of preferences is more aligned, the number of "effective" parties under proportional representation must be less than three. Thus, Morelli (2004) finds that the Duvergerian comparative prediction may be violated in a multi-district setting.

In this paper, we are interested in game-theoretic foundations of Duverger's law and hypothesis. Unlike the previous theoretical literature on Duverger's predictions, we study a spatial model of multi-candidate competition. ${ }^{2}$ The Downsian model of electoral competition (Downs (1957)), where the set of agendas equals the unit interval, is not suitable for this research. In this standard framework, a pure-strategy equilibria does not exist under the proportional rule; whereas, the incentive to attract the median voter generates a single party in the pluralistic system when considering refinements that allow movements on party-level. This motivates our point of departure from the standard framework: we instead assume that the set of agendas equals the unit circle. ${ }^{3}$ We hereby follow in the success of the industrial organization literature in studying multi-firm competition by moving from Hotelling's linear city (Hotelling (1929)) to Salop's circular city (Salop (1979)). ${ }^{4}$

\footnotetext{
${ }^{2}$ We solely focus on the pre-election process of strategic party formation. In particular, we ignore policy and welfare implications, and the impact of post-election coalition formation on actual power.

${ }^{3}$ Some justification of using the circle as agenda space is provided in Section 2.2 in which we present the model.

${ }^{4}$ According to Persson and Tabellini (2000, p.5), "It is hard to model the outcome of multiparty competition ...". As we will see, the transition to a circular agenda space may
} 
The summary description of the model is as follows. There are a finite number of politicians that simultaneously and independently choose to promote agendas in the elections, where the set of agendas is the unit circle. Politicians promoting the same agenda form a party. Hence, the party structure follows directly from the politicians' decisions to promote agendas. We assume that the voters are uniformly distributed over the unit circle, with each voter's most preferred agenda coinciding with her location on the circle. Furthermore, voters are assumed to vote sincerely, i.e., support the party closest to their most preferred agendas. This assumption results in the vote share of each party to be proportional to its distance to the two adjacent parties. Next, the electoral system determines a mapping from the distribution of votes to the distribution of "power". In the pluralitarian system, the parties with the highest vote share gain all power (winner takes all); in the proportional system, the power of each party equals its vote share. We assume that the politicians belonging to a party share equally in its power, and each politician is opportunistic (officemotivated), trying to maximize her individual power. Hence, in general, each politician prefers to become a member of a party with a high vote share but as few other members as possible.

We provide a full characterization of the sets of pure-strategy Nash equilibria in both the pluralitarian and proportional systems, and show that these sets are nonempty. Typically, both systems possess a rich set of Nash equilibria. ${ }^{5}$ Therefore, we define the notion of defection-proofness to refine the Nash equilibrium predictions.

Defection-proof Nash equilibrium is similar in motivation to coalitionproof Nash equilibrium (Bernheim et al., 1987), but only allows for particular deviations, which we call defections. ${ }^{6}$ The defections include deviations

be a step forward.

${ }^{5} \mathrm{~A}$ high multiplicity of (types of) equilibria is also found in a two-stage locationquantity game along the circle's circumference in Gupta et al. (2004).

${ }^{6}$ The set of defection-proof Nash equilibria includes the set of strong Nash equilibria (Aumann (1959)). However, there is no logical relation between the sets of coalition-proof Nash equilibria and defection-proof Nash equilibria. A defection-proof Nash equilibrium is immune to self-enforcing or credible defections by any coalition (i.e., defections from which there are no further credible defections by any subcoalition). On the other hand, a coalition-proof Nash equilibrium is immune to credible deviations by any coalition 
by a coalition of politicians that are typically observed in reality; for instance, shifts in agenda, mergers of parties, and a set of politicians splitting from their original parties and forming a new party or joining an existing one. ${ }^{7}$

In the pluralitarian system, we show that Nash equilibria that generate strictly more than three parties are not defection-proof, whereas only multiple parties are supported as defection-proof Nash equilibrium under the proportional rule. Our defection-proof Nash equilibrium predictions are only partially consistent with Duvergers law - we predict either two or three parties under pluralitarian system - but they fully support Duvergers hypothesis and the Duvergerian comparative prediction.

In Section 2.2, we present the details of the model and the definition of defection-proofness. In Sections 2.3 and 2.4, we present, respectively, the equilibrium analysis for the pluralitarian and proportional systems. We conclude in Section 2.5 by summarizing our results. Proofs are collected in Section 2.6.

\section{$2.2 \quad$ Model}

There is a finite set of politicians, $I$, with $|I| \geq 3 .^{8}$ The set of agendas, $A$, is the circumference of a circle of unit length. An agenda is denoted by $a$. The politicians simultaneously choose to support agendas. We restrict attention to pure strategies. Therefore, $A$ is the set of strategies for each politician. A strategy profile is denoted by $s$. For any $J \subseteq I, s_{J}$ denotes

(i.e., deviations from which there are no further credible deviations by any subcoalition). The set of possible defections by a coalition is a subset of the set of deviations by that coalition. Nevertheless, the set of credible defections by a coalition is not necessarily a subset or superset of the set of credible deviations.

${ }^{7}$ Duverger already reasoned that the field of parties is trimmed to just two by the forces of "fusion" and elimination (Fey (1997)). According to Kaminski (2006), "party politics revolves around the emergence of new parties [and] electoral splits and coalitions." In Eguia (2010), the stability of a party configuration or voting bloc in an assembly is defined with respect to immunity of the current configuration against fourteen classes of deviations. Our definition of defections includes twelve of these classes - exception being classes D1 and D3 in which a subset of politicians deviate to become independents or singleton parties. Hence, considering only defections does not seem to be too restrictive.

${ }^{8}|X|$ is the cardinality of set $X$. 
the strategy profile $\left(s_{i}\right)_{i \in J}$ and $s_{-J}$ denotes the strategy profile $\left(s_{i}\right)_{i \in I \backslash J}$.

A strategy profile $s$ defines a partition $\mathcal{P}(s)$ of the set of politicians, where each $P \in \mathcal{P}(s)$ is such that for some agenda $a, s_{i}=a$ for all $i \in P$ and $s_{j} \neq a$ for all $j \notin P$. That is, every politician who belongs to $P$ supports the same agenda $a$ in the profile $s$ and none of the politicians outside $P$ support the agenda $a$. We will refer to any $P \in \mathcal{P}(s)$ as a party. Hence, $\mathcal{P}(s)$ is the set of all parties formed in the strategy profile $s$. The agenda supported by a party $P \in \mathcal{P}(s)$ is the unique agenda supported by every politician who belongs to $P$. For any $P \in \mathcal{P}(s)$, let $R^{s}(P)$ be the first party that is supporting an agenda in the clockwise direction starting at the agenda supported by $P$. Similarly, let $L^{s}(P)$ be the first party that is supporting an agenda in the counterclockwise direction starting at the agenda supported by $P$. Any two parties $P, P^{\prime} \in \mathcal{P}(s)$ are adjacent if $P^{\prime} \in\left\{L^{s}(P), R^{s}(P)\right\}$.

Voters are uniformly distributed on $A .^{9}$ Each voter's location on $A$ is her most-preferred agenda. Voters are assumed to vote sincerely for the party supporting the agenda closest to her most-preferred agenda; in case there are two such parties, she votes for each with equal probability - there cannot be more than two such parties since the set of agendas is a circle.

Before we continue with introducing further definitions and concepts, we believe a justification for using the circle as agenda space is needed. First, it is not uncommon for voters on the extreme-left and on the extreme-right to agree on some political issues (often called the horseshoe theory, Faye (1996)). Both extremes typically disapprove immigration; labor unions because aliens take their jobs and white supremacists because they don't like aliens. They also share a similar distaste for foreign aid; left because foreign aid usually ends up in the hands of corrupt elites and bolsters pro-market policies and right because it bolsters inefficient public sector. Moreover, even on issues where extreme political positions do not coincide, political psychology tells us that extremists choose from one of the extremes rather than a closer moderate position (Nozick (1997)).

The weight of a party $P \in \mathcal{P}(s)$, denoted by $w_{P}(s)$, is the proportion

\footnotetext{
${ }^{9}$ This assumption is restrictive and not necessarily realistic but it provides us a manageable tool to demonstrate the connecting and splitting forces created as basic implications of pluralistic and proportional rules.
} 
of voters who vote for party $P$. We term the length of the arc between the agenda supported by $P$ and agenda supported by $L^{s}(P)$ as the left distance of party $P$ and denote it by $l^{s}(P)$. Similarly, the length of the arc between the agenda supported by $P$ and agenda supported by $R^{s}(P)$ will be called the right distance of party $P$ and denoted by $r^{s}(P)$. It is straightforward to show that $w_{P}(s)=\frac{l^{s}(P)+r^{s}(P)}{2}$ (see Figure 2.1). Note that $w_{P}(s) \geq 0$ for all $P \in \mathcal{P}(s)$ and $\sum_{P \in \mathcal{P}(s)} w_{P}(s)=1$. Then $w(s)=\left(w_{P}(s)\right)_{P \in \mathcal{P}(s)}$ is the distribution of weights under the strategy profile $s$.

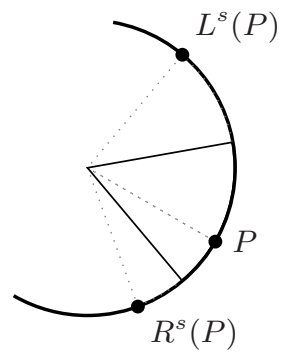

Figure 2.1: $P$ is an arbitrary party, $L^{s}(P)$ and $R^{s}(P)$ denote the first parties located in each direction from $P$. The dotted lines demarcate arcs that define the distance between adjacent parties. The thick lines demarcate arcs that define each party's voter base or weight. The weight of a party is the average of its left and right distances.

A rule $\rho$ defines for every strategy profile $s$, the power $\rho_{P}(w(s))$ of each party $P \in \mathcal{P}(s)$ as a function of the distribution of weights $w(s)$. We assume that the politicians belonging to a party share equally in its power. Furthermore, politicians receive utility equal to their individual power - such office-motivated politicians are standard in the literature. Hence, the utility of politician $i$ in strategy profile $s$ is $u_{i}(s)=\frac{\rho_{P}(w(s))}{|P|}$, where $i \in P \in \mathcal{P}(s)$.

For any rule $\rho$, a strategy profile $s$ is a Nash equilibrium if there do not exist $i \in I$ and $s_{i}^{\prime} \in A$ such that $u_{i}\left(s_{i}^{\prime}, s_{-i}\right)>u_{i}\left(s_{i}, s_{-i}\right)$. Thus, Nash equilibrium strategies are stable against unilateral deviations by a single politician. However, Nash equilibrium disregards the possibility of coordinated deviations or defections by a coalition of politicians.

Definition 1 (Defection). A defection (or a strictly beneficial defection) 
from a strategy profile $s$ by a coalition $J \subseteq I$ is a strategy profile for coalition $J, s_{J}^{\prime} \in A^{|J|}$, such that $s_{j} \neq s_{j}^{\prime}=a$ for all $j \in J$, and $u_{j}\left(s_{J}^{\prime}, s_{-J}\right)>$ $u_{j}\left(s_{J}, s_{-J}\right)$ for all $j \in J .^{10}$

Thus, a defection is a deviation from a strategy profile by a coalition of politicians that satisfies two requirements: first, all the members of the coalition deviate to the same agenda and second, all the members of the coalition must strictly improve their utilities after the deviation. The following are some examples of defections:

- Shift in a party's agenda: All the politicians in a party decide to shift the agenda supported by their party.

- Split in a party: A subset of politicians belonging to a party forms a new party by supporting a different agenda.

- Merger of parties: All the politicians in two or more parties choose to support a new common agenda.

- A set of politicians split from their original parties and merge at a new or some previously supported agenda.

Such defections are quite common in politics and therefore, we allow for them in our model. However, unless binding agreements are possible among the defecting coalition, the defection must be self-enforcing or credible.

Definition 2 (Credible Defection).

(i) A credible defection from a strategy profile $s$ by a politician $j \in I$ is a $s_{j}^{\prime} \in A$ such that $s_{j}^{\prime}$ is a defection from $s$ by politician $j$.

\footnotetext{
${ }^{10}$ It is standard to assume that while contemplating a deviation, a coalition considers the strategy of the complement as fixed. Moreover, one could imagine a stronger notion of defection that requires that in case the defecting coalition chooses an agenda that is already supported by another party, then the politicians in the latter party should also be better off. The resulting notion of defection-proof Nash equilibrium can easily be shown to make precisely the same selection among Nash equilibria. However, this stronger definition of defection is not consistent with Nash equilibrium. After all, in Nash equilibrium, we consider defections by single politicians but do not care in case such a defection makes the party that this single politician joins worse off. Therefore, we stick with the current weaker notion of defection.
} 
(ii) A credible defection from a strategy profile $s$ by a coalition $J \subseteq I$ such that $|J|>1$ is a strategy profile for coalition $J, s_{J}^{\prime} \in A^{|J|}$, such that $s_{J}^{\prime}$ is a defection from $s$ by coalition $J$ and there does not exist any subcoalition $J^{\prime} \subset J$ with a credible defection from $\left(s_{J}^{\prime}, s_{-J}\right)$.

Thus, a credible defection by a coalition is such that no further credible defection is possible by any proper subcoalition.

Definition 3 (Defection-Proof Nash Equilibrium). A defection-proof Nash equilibrium is a strategy profile $s$ such that there is no credible defection from $s$ by any coalition $J \subseteq I$.

Defection-proof Nash equilibria are stable against credible defections by any coalition. Clearly, the set of defection-proof Nash equilibria is a subset of the set of Nash equilibria.

We restrict attention to two specific rules, plurality rule and proportional rule. Under the plurality rule, all parties with the maximum weight share power equally whereas any party with less than the maximum weight gets zero power. ${ }^{11}$ Formally, for any strategy profile $s$, the plurality rule defines the power of any $P \in \mathcal{P}(s)$ as

$$
P l_{P}(w(s)) \equiv \begin{cases}\frac{1}{\left\lceil\arg \max _{P^{\prime} \in \mathcal{P}(s)} w_{P^{\prime}}(s) \mid\right.} & \text { if } P \in \arg \max _{P^{\prime} \in \mathcal{P}(s)} w_{P^{\prime}}(s) \\ 0 & \text { otherwise. }\end{cases}
$$

Under the proportional rule, the power of a party equals its weight. Hence, for any strategy profile $s$, the proportional rule defines the power of any $P \in \mathcal{P}(s)$ as

$$
\operatorname{Pr}_{P}(w(s)) \equiv w_{P}(s) .
$$

In the following two sections, we characterize the Nash equilibria and defection-proof Nash equilibria for the games induced by these two voting rules. We have also investigated alternative refinements of Nash equilibrium, like strong Nash equilibrium and coalition-proof Nash equilibrium

\footnotetext{
${ }^{11}$ More than one parties winning the elections under plurality rule, i.e. receiving exactly the same amount of votes, practically do not happen. We define this case for the sake of completeness and utilities can be interpreted as expected utilities having equal chances of winning.
} 
(CPNE). Under both voting rules, the set of strong Nash equilibria is empty. For the proportional voting rule, we find that in any CPNE, all parties are singleton, i.e., have only one politician. A characterization of CPNE under plurality rule is technically challenging. The reason is that CPNE allows for too many coalitional deviations, some of which we regard implausible (i.e., deviations for which we did not find any empirical support) in the present context. ${ }^{12}$ Our notion of defection-proof Nash equilibrium aims to implement the notion of CPNE while restricting coalitional deviations to the plausible ones. ${ }^{13}$

\subsection{Plurality Rule}

We begin with the characterization of the set of Nash equilibria under the plurality rule.

Theorem 1. Under plurality rule, a strategy profile $s$ is a Nash equilibrium if and only if the numbers of politicians in any two parties in $\mathcal{P}(s)$ differ by at most 1, and exactly one of the following holds:

(i) $|\mathcal{P}(s)|=2$ and $\min \left\{l^{s}(P), r^{s}(P)\right\}>\frac{1}{3}$ for some $P \in \mathcal{P}(s)$.

(ii) $3 \leq|\mathcal{P}(s)| \leq \frac{|I|}{2}$ and all parties have equal weights.

(iii) $3 \leq|\mathcal{P}(s)| \leq 4,|\mathcal{P}(s)|>\frac{|I|}{2}$ and all parties are equidistant from each other.

(iv) $5 \leq|\mathcal{P}(s)| \leq 6,|\mathcal{P}(s)|>\frac{|I|}{2}$, all parties are equidistant from each other, and there does not exist any pair of singleton parties that are adjacent.

Thus, whether $s$ is a Nash equilibrium or not depends only on two factors: first, the respective distances between the agendas supported in $s$ - which determine the weights of the parties - and second, the numbers of politicians

\footnotetext{
${ }^{12}$ One difference to CPNE concept is the assumption Defection-proof NE makes about the behavior of politicians. Coordinated moves of politicians are expected to be made to the same political agenda, which is a conceivable assumption in the political setting.

${ }^{13}$ Calculations are available upon request.
} 
in the parties formed in $s$. Hence, if $s$ is a Nash equilibrium, then the strategy profile $s^{\prime}$ obtained by either shifting the agendas supported by all politicians by a fixed constant or permuting the identities of the politicians will also be a Nash equilibrium. This is obviously because of the particular specification of the utilities of the politicians.

An important property of Nash equilibrium under the plurality rule is that all parties formed in equilibrium have equal weight (see Lemma 9 in Proofs section). This is because only those parties with the maximum weight obtain positive power. Hence, if a party has less than the maximum weight, then a politician belonging to that party obtains zero utility but could obtain positive utility by deviating to an agenda supported by some party (more precisely, any party with the highest weight in the hypothetical situation in which the set of politicians is $I \backslash\{i\}$, where $i$ is the deviating politician, and these politicians choose agendas according to the strategy profile $s_{-i}$ ). The weight of a party is the average of its left and right distances. Thus, it follows that the sums of the left and right distances of all parties formed in equilibrium are equal. Since the right (left) distance of party $P^{k}$ is trivially equal to the left (right) distance of $R^{s}\left(P^{k}\right)\left(L^{s}\left(P^{k}\right)\right)$, it follows that the left (right) distance of a party $P^{k}$ equals the right (left) distance of party $R^{s}\left(P^{k}\right)\left(L^{s}\left(P^{k}\right)\right)$. Therefore, if $\left\{P^{1}, \ldots, P^{n}\right\}$ is the set of parties that form in Nash equilibrium and, without loss of generality, $P^{k+1}=R^{s}\left(P^{k}\right)$ for all $k=1, \ldots, n-1$, then we obtain the following two sequences of equalities:

$$
\begin{aligned}
& l^{s}\left(P^{1}\right)=r^{s}\left(P^{2}\right)=l^{s}\left(P^{3}\right)=r^{s}\left(P^{4}\right)=\ldots \\
& l^{s}\left(P^{n}\right)=r^{s}\left(P^{1}\right)=l^{s}\left(P^{2}\right)=r^{s}\left(P^{3}\right)=\ldots
\end{aligned}
$$

In words, if we move along the circle in the clockwise direction, then every other arc defined by the set of agendas supported in equilibrium has the same length.

The property that all parties have equal weights in equilibrium, generates two possible configurations of parties in equilibrium:

(i) An odd number of parties form in equilibrium. Then all parties must be equidistant from each other. To see this, suppose $n=5$, i.e., five parties $P^{1}, \ldots, P^{5}$ form in equilibrium (see Figure 2.2(1)). Using 
(2.1), we obtain

$$
\begin{gathered}
l^{s}\left(P^{1}\right)=r^{s}\left(P^{2}\right)=l^{s}\left(P^{3}\right)=r^{s}\left(P^{4}\right)=l^{s}\left(P^{5}\right)=r^{s}\left(P^{1}\right) \\
r^{s}\left(P^{1}\right)=l^{s}\left(P^{2}\right)=r^{s}\left(P^{3}\right)=l^{s}\left(P^{4}\right)=r^{s}\left(P^{5}\right) .
\end{gathered}
$$

Since the parties are equidistant, the set of agendas supported in equilibrium $s$ can be graphically visualized as the vertices of an $n$ sided convex regular polygon (as shown in Figure 2.2(2)).

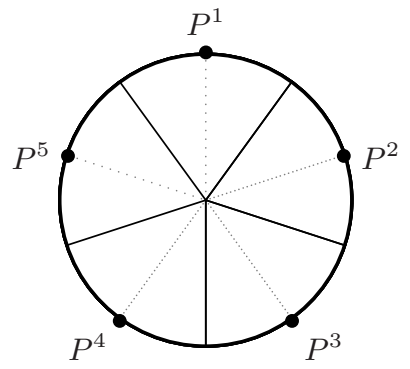

(1)

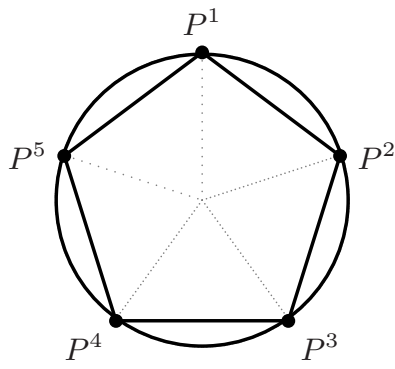

$(2)$

Figure 2.2: Odd number $(>1)$ of parties under plurality rule: (1) All parties have equal weight and are equidistant. (2) The locations of the parties are the vertices of a convex regular polygon.

(ii) An even number of parties form in equilibrium. First, consider the case when more than two parties form. Then both equidistant and non-equidistant configurations are possible. Figure 2.3 shows these configurations with six parties. In general, we can graphically visualize the set of agendas supported in equilibrium as follows. Since the parties have equal weights, we have

$$
l^{s}\left(P^{2}\right)+r^{s}\left(P^{2}\right)=l^{s}\left(P^{4}\right)+r^{s}\left(P^{4}\right)=l^{s}\left(P^{6}\right)+r^{s}\left(P^{6}\right)=\ldots
$$

But $l^{s}\left(P^{2}\right)+r^{s}\left(P^{2}\right)$ is the distance between the agendas supported by parties $P^{1}$ and $P^{3} ; l^{s}\left(P^{4}\right)+r^{s}\left(P^{4}\right)$ is the distance between the agendas supported by parties $P^{3}$ and $P^{5}$ and so on. Hence, all oddnumbered parties $\left(P^{1}, P^{3}, \ldots, P^{n-3}, P^{n-1}\right)$ are equidistant from each other and thus, the agendas supported by these parties are vertices of 
an $\frac{n}{2}$-sided convex regular polygon (as shown in Figure 2.4(2)). Similarly, all even-numbered parties $\left(P^{2}, P^{4}, \ldots, P^{n-2}, P^{n}\right)$ are equidistant from each other and the agendas supported by these parties are also vertices of an $\frac{n}{2}$-sided convex regular polygon (as shown in Figure 2.4(2)). If in addition, all parties are equidistant from each other, then the agendas supported by all parties are vertices of an $n$-sided convex regular polygon (as shown in Figure 2.4(1)).

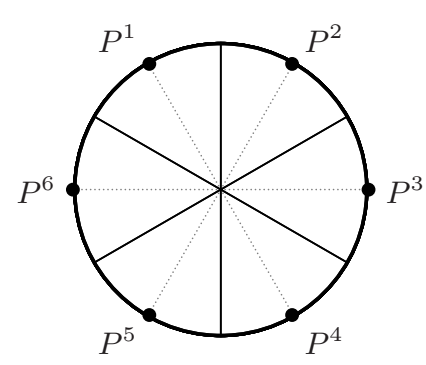

(1)

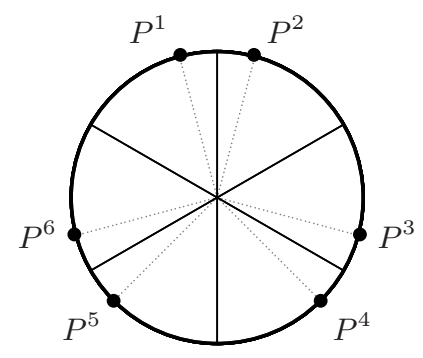

$(2)$

Figure 2.3: Even number $(>2)$ of parties under plurality rule: All parties have equal weight but both equidistant (shown in (1)) and non-equidistant (shown in (2)) configurations are possible. In (2), all even-numbered parties are equidistant from each other and all odd-numbered parties are equidistant from each other.

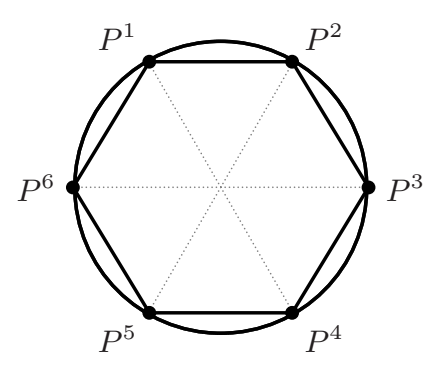

(1)

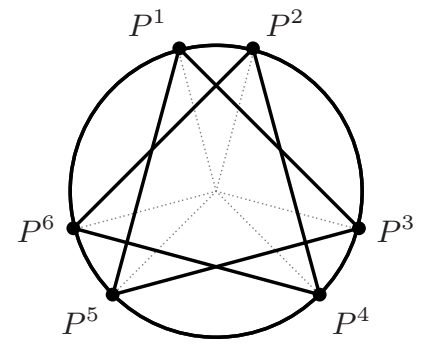

$(2)$

Figure 2.4: Even number $(>2)$ of parties under plurality rule: (1) When all parties are equidistant, their locations are the vertices of a convex regular polygon. (2) When parties are not equidistant, the locations of all even-numbered/oddnumbered parties are the vertices of a convex regular polygon.

When only two parties form in equilibrium, each party has a weight of 
$\frac{1}{2}$. In this case, it must be that the minimum distance between the two parties is greater than $\frac{1}{3}$. Otherwise, a single politician from the party having the larger number of politicians - who obtains a utility of at most $\frac{1}{4}$ as she shares power of $\frac{1}{2}$ with at least one other politician - can deviate to the agenda in the middle of the longer arc between the agendas supported by the two parties. The left and right distances of this new singleton party will be both at least $\frac{1}{3}$ and hence, it will have at least as much weight as the other two parties. Thus, the deviating politician will obtain a utility of at least $\frac{1}{3}$, which is a contradiction.

The utility of a politician is a function both of the weight of her party and the number of other politicians who belong to her party. Since all parties have the same weight in equilibrium, a politician in party $P$ obtains $\frac{1}{P}$ proportion of the weight. If there is another party $P^{\prime}$ such that $|P|>\left|P^{\prime}\right|+1$, then a politician from party $P$ could deviate to the agenda supported by $P^{\prime}$, increasing her utility to $\frac{1}{\left|P^{\prime}\right|+1}$ proportion of the weight. Therefore, the numbers of politicians in any two parties in $\mathcal{P}(s)$ differ by at most 1 in equilibrium.

It also follows from the theorem that the number of parties formed in equilibrium is bounded below by 2 and above by $\max \left\{\frac{|I|}{2}, 6\right\}$. Any strategy profile in which only a single party is formed is not an equilibrium since by deviating to any other agenda, any politician can form a singleton party with the weight of $\frac{1}{2}$ and hence, increase her utility from at most $\frac{1}{3}$ - since $|I| \geq 3$ - to $\frac{1}{2}$. On the other hand, suppose the number of parties formed in equilibrium is greater than both $\frac{|I|}{2}$ and 6. Figure 2.5(1) shows such a strategy profile when $|I|=17$ but nine parties form. Then at least one party, say $P^{2}$, is singleton and the utility of this politician is less than $\frac{1}{6}$ (see figure). Since the numbers of politicians in any two parties cannot differ by more than 1 , both $P^{1}=L^{s}\left(P^{2}\right)$ and $P^{3}=R^{s}\left(P^{2}\right)$ have at most two members. Without loss of generality, let $r^{s}\left(P^{2}\right) \leq l^{s}\left(P^{2}\right)$. If the single politician in $P^{2}$ were to deviate to the agenda supported by $P^{3}$ (as shown in Figure 2.5(2)), then the weight of party $P^{3} \cup P^{2}$ will increase by $\frac{l^{s}\left(P^{2}\right)}{2}$ and the weight of $P^{1}$ by $\frac{r^{s}\left(P^{2}\right)}{2}$, while the weights of all other parties will stay constant as the agendas supported by their respective adjacent parties stay fixed. Since we started with a situation of equal weights, the merged party $P^{3} \cup P^{2}$ will have the maximum weight and hence, through this deviation, 
the politician will obtain a utility of at least $\frac{1}{6}$ as she shares the power of at least $\frac{1}{2}$ with at most two other members, which is a contradiction. The

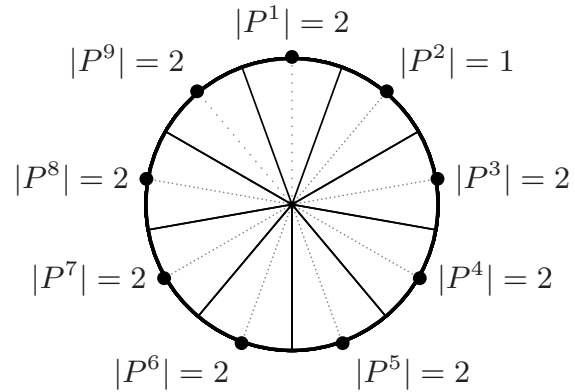

(1)

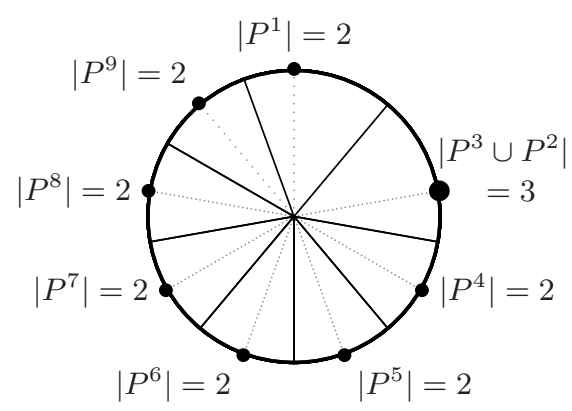

(2)

Figure 2.5: Number of parties is bounded above by $\max \left\{\frac{|I|}{2}, 6\right\}$ : Assume $|I|=17$. (1) A strategy profile in which 9 parties form. (2) A unilateral deviation by the politician in $P^{2}$ that increases her utility.

following corollary immediately follows from the above theorem.

Corollary 2. For any $|I| \geq 3$, there exists a pure-strategy Nash equilibrium under plurality rule.

Indeed, the model under plurality rule has multiple Nash equilibria, with the number of political parties in equilibrium ranging from 2 to $\max \left\{\frac{|I|}{2}, 6\right\}$. Next, we refine our predictions using defection-proofness. The following theorem characterizes the set of defection-proof Nash equilibria.

Theorem 3. Under plurality rule, a strategy profile $s$ is a defection-proof Nash equilibrium if and only if the numbers of politicians in any two parties in $\mathcal{P}(s)$ differ by at most 1 and exactly one of the following holds:

(i) $|\mathcal{P}(s)|=2$ and $\min \left\{l^{s}(P), r^{s}(P)\right\}>\frac{1}{3}$ for some $P \in \mathcal{P}(s)$.

(ii) $|\mathcal{P}(s)|=3$ and all parties are equidistant from each other.

Thus, defection-proofness sharply refines the set of Nash equilibria: only those Nash equilibria in which either two or three parties form are defectionproof Nash equilibria. To see why Nash equilibria with at least four parties are not defection-proof, let's consider a Nash equilibrium $s$ in which parties $P^{1}, \ldots, P^{n}$ form, where $n \geq 4$, and all parties are equidistant, with the 
distance equal to $d$ (the proof takes care of all cases). Let $a$ be the agenda that is the midpoint of the agendas supported by $P^{2}$ and $P^{3}$ (as shown in Figure 2.6(1)). Now, if a coalition consisting of all politicians in $P^{2}$ and $P^{3}$ were to deviate to supporting a, ceteris paribus, then $n-1$ parties, viz. $\left\{P^{1}, P^{2} \cup P^{3}, P^{4}, \ldots, P^{n}\right\}$, will be formed in the resulting profile $s^{\prime}$ (as shown in Figure 2.6(2)). The weight of the party $P^{2} \cup P^{3}$ will be $\frac{3}{2} d$, while the weights of $P^{1}$ and $P^{4}$ will each be $\frac{5}{4} d$, and the weights of all other parties will remain unchanged. Since we started with a situation of equal weights, the merged party $P^{2} \cup P^{3}$ will be the unique party with the maximum weight and hence, each member of the deviating coalition will obtain a utility of $\frac{1}{\left|P^{2}\right|+\left|P^{3}\right|}$ compared to the utility of either $\frac{1}{n\left|P^{2}\right|}$ or $\frac{1}{n\left|P^{3}\right|}$ in profile $s$. Since $n \geq 4$ and the numbers of politicians in parties $P^{2}$ and $P^{3}$ do not differ from each other by more than $1-$ since $s$ is a Nash equilibrium -, we have $n\left|P^{2}\right| \geq 4\left|P^{2}\right|>2\left|P^{2}\right|+1 \geq\left|P^{2}\right|+\left|P^{3}\right|$ and similarly, $n\left|P^{3}\right|>\left|P^{2}\right|+\left|P^{3}\right|$. Thus, each member of the deviating coalition will be strictly better off after the deviation and hence, we have obtained a defection from $s$ by coalition $P^{2} \cup P^{3}$. This defection is in fact credible. Consider any subcoalition $J^{\prime} \subset P^{2} \cup P^{3}$. If starting from $s^{\prime}$, all members of $J^{\prime}$ were to deviate to an agenda like $a^{\prime}$, which lies on the arc between the agendas supported by $P^{1}$ and $P^{4}$ that does not contain $a$ (see Figure 2.6(2)), then at least as many agendas as in $s^{\prime}$ will be supported in the resulting profile $s^{\prime \prime}$. However, the weight of party $P^{2} \cup P^{3} \backslash J^{\prime}$ will not change while the weight of any other party will be at most $\frac{5}{4} d$. Hence, the subcoalition $J^{\prime}$ cannot improve its utility by this deviation. On the other hand, if starting from $s^{\prime}$, all members of $J^{\prime}$ were to deviate to an agenda like $a^{\prime \prime}$ or $a^{\prime \prime \prime}$, which lie between $a$ and the agenda supported by either $P^{1}$ or $P^{4}$ (see Figure 2.6(2)), then the weight of party $J^{\prime}$ will be $\frac{3}{4} d$, which is less than the weight of $P^{2} \cup P^{3} \backslash J^{\prime}$. Thus, $J^{\prime}$ cannot improve its utility by such a deviation. Hence, we conclude that the initial defection from $s$ is a credible defection.

In contrast, all Nash equilibria in which either two or three parties form are defection-proof Nash equilibria. Let's consider a Nash equilibrium $s$ as shown in Figure 2.7(1) with three parties, $P^{1}, P^{2}$ and $P^{3}$ (the argument for two parties is similar). First, consider a defection in which all three parties merge, resulting in $s^{\prime}$ with a single agenda being supported. Since 


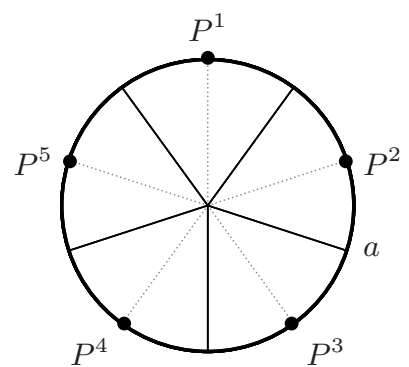

(1)

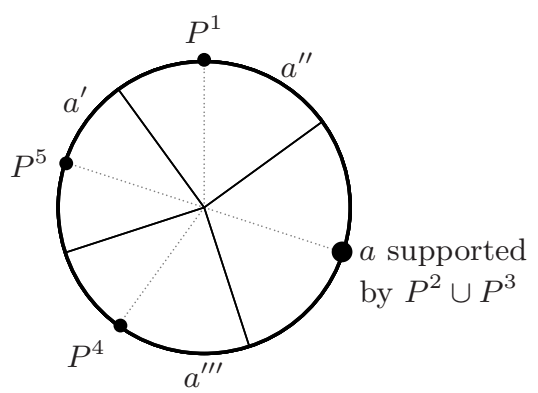

(2)

Figure 2.6: Nash equilibria with more than 3 parties are not defection-proof: (1) A Nash equilibrium with 5 parties. (2) A credible defection by $P^{2} \cup P^{3}$.

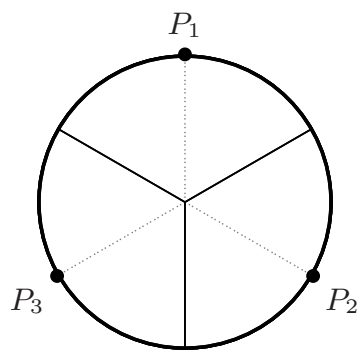

(1)

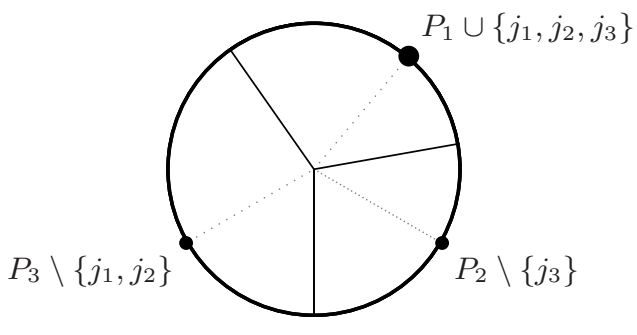

(3)

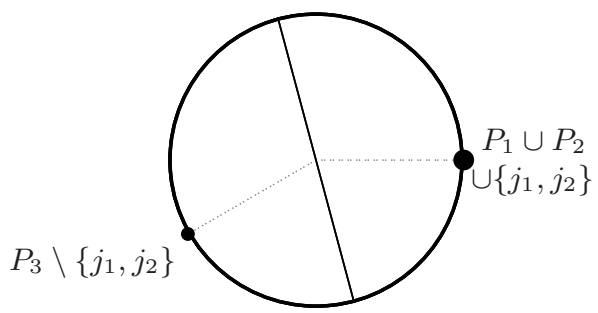

(2)

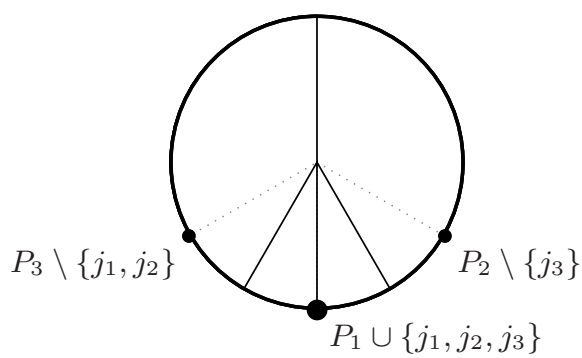

(4)

Figure 2.7: Nash equilibria with 3 parties are defection-proof: (1) A Nash equilibrium with 3 parties. (2) There do not exist defections that result in only two supported agendas. (3) and (4) show that possible defections from (1) which result in three supported agendas are not beneficial to those who defect. 
$s^{\prime}$ is not a Nash equilibrium, there exists a credible defection from $s^{\prime}$ by a single politician belonging to the initial defecting coalition. Thus, the initial defection cannot be credible. Second, consider a defection in which all politicians, except some in say $P^{3}$, merge, resulting in $s^{\prime}$ with two agendas being supported (as shown in Figure 2.7(2)). Thus, instead of $\frac{1}{3\left|P^{1}\right|}$, a defecting politician belonging to $P^{1}$ obtains a utility of at most $\frac{1}{2\left|P^{1}\right|+2\left|P^{2}\right|}$ after the defection. But $2\left|P^{1}\right|+2\left|P^{2}\right| \geq 2\left|P^{1}\right|+\left|P^{2}\right|+1 \geq 3\left|P^{1}\right|$, where the last inequality follows from the fact that the numbers of politicians in parties $P^{1}$ and $P^{2}$ do not differ from each other by more than 1 . Thus, any politician belonging to $P^{1}$ will not improve her utility through this defection, a contradiction. Third, any defection that results in a $s^{\prime}$ in which three agendas are supported must be such that at least two agendas supported in $s$, say those of $P^{2}$ and $P^{3}$, are also supported in $s^{\prime}$. That is, some politicians belonging to $P^{2}$ and $P^{3}$ are not members of the defecting coalition. If the party formed supports an agenda which is different than the agenda supported by $P_{1}$ in $s$, then it has a weight of $\frac{1}{3}$ (Figure 2.7(3)) or $\frac{1}{6}$ (Figure 2.7(4)) depending on the arc on which the agenda is placed. In both cases, there is at least one party with a weight of strictly more than $\frac{1}{3}$. Therefore, the party formed has zero power and so the defection is not beneficial. If the party formed supports the agenda supported by $P_{1}$ in $s$, then all three agendas supported in $s$ are also supported in $s^{\prime}$. But such a defection even by a single politician is not beneficial since $s$ is a Nash equilibrium. Finally, any defection that results in an $s^{\prime}$ in which four agendas are supported must be such that all three agendas supported in $s$ are also supported in $s^{\prime}$ (note that there does not exist a defection that results in five or more supported agendas). But this cannot be beneficial for the same reasoning above. Thus there is no credible defection from $s$ by any coalition.

As a corollary, we easily obtain the following result:

Corollary 4. For any $|I| \geq 3$, there exists a defection-proof Nash equilibrium under plurality rule. 


\subsection{Proportional Rule}

In this section, we study the formation of political parties under the proportional rule. Like in the plurality rule, the vote share or weight of any party is equal to the average of its left and right distances. However, in contrast, now every party has positive power equal to its weight. As the next theorem shows, this substantially alters the configurations of political parties that form in Nash equilibria.

Theorem 5. Under proportional rule, $s$ is a Nash equilibrium if and only if for any party $P \in \mathcal{P}(s)$ either

(i) $|P|=2$ and $l^{s}(P)=r^{s}(P)=\max _{P^{\prime} \in \mathcal{P}(s)}\left\{l^{s}\left(P^{\prime}\right), r^{s}\left(P^{\prime}\right)\right\}$ or

(ii) $|P|=1$ and $l^{s}(P)+r^{s}(P) \geq \max _{P^{\prime} \in \mathcal{P}(s)}\left\{l^{s}\left(P^{\prime}\right), r^{s}\left(P^{\prime}\right)\right\}$.

According to the theorem, all parties have at most two politicians in any Nash equilibrium. ${ }^{14}$ To see this, suppose a party $P$ has at least three politicians in a Nash equilibrium $s$ (as shown in Figure 2.8(1)). The weight of this party equals $\frac{l^{s}(P)+r^{s}(P)}{2}$. Since $P$ has at least three politicians, any politician in $P$ obtains a utility of at most $\frac{l^{s}(P)+r^{s}(P)}{6}$. If any politician in $P$ were to unilaterally deviate to an agenda on the arc corresponding to $\max \left\{l^{s}(P), r^{s}(P)\right\}$, then she would form a new singleton party with weight $\frac{\max \left\{l^{s}(P), r^{s}(P)\right\}}{2}$ (as shown in Figure 2.8(2)). Clearly, $\frac{l^{s}(P)+r^{s}(P)}{6}<$ $\frac{\max \left\{l^{s}(P), r^{s}(P)\right\}^{2}}{2}$. Hence, a strategy profile in which there exists a party with at least three politicians cannot be a Nash equilibrium.

Moreover, in any Nash equilibrium, any party with two politicians must be equidistant from the parties that are adjacent to it, with the distance equal to $d^{*}=\max _{P^{\prime} \in \mathcal{P}(s)}\left\{l^{s}\left(P^{\prime}\right), r^{s}\left(P^{\prime}\right)\right\}$, i.e., the maximum distance between any two adjacent parties. If not, then any politician in such a party $P$ shares a weight of $\frac{l^{s}(P)+r^{s}(P)}{2}<d^{*}$ with the other politician in $P$ and hence, obtains $\frac{l^{s}(P)+r^{s}(P)}{4}<\frac{d^{*}}{2}$. If this politician were to unilaterally deviate to an agenda on any arc corresponding to $d^{*}$, she would increase her utility to $\frac{d^{*}}{2}$, which is a contradiction to Nash equilibrium.

\footnotetext{
${ }^{14}$ In political arenas we do not observe parties with only two or very small number of politicians due to economies of scale. Cost of running for elections is out of our scope; nevertheless this result provides strong evidence on the proportional voting system inducing formation of smaller parties in greater number.
} 


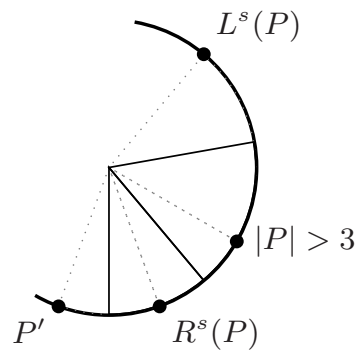

(1)

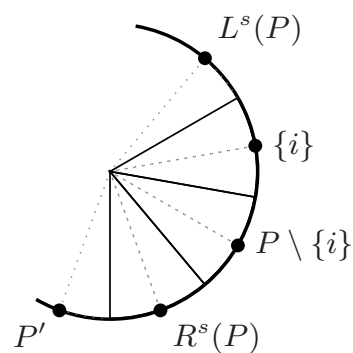

(2)

Figure 2.8: All parties in Nash equilibrium have at most 2 members: (1) A strategy profile with $|P|>3$. (2) A unilateral deviation by some $i \in P$ that increases $i$ 's utility.

Finally, the second condition in the theorem says that any singleton party in any Nash equilibrium must obtain a weight of at least $\frac{d^{*}}{2}$. The politician in a singleton party obtains a utility equal to her party's weight. Therefore, if the second condition were violated, this politician could unilaterally deviate to an agenda on any arc corresponding to $d^{*}$ and increase her utility to $\frac{d^{*}}{2}$.

An upper bound of two on the membership of any party in Nash equilibrium implies that a large number of parties form under the proportional rule when the number of politicians is not too small. In particular, the number of parties in any Nash equilibrium must be at least $\frac{|I|}{2}$, if $|I|$ is even, and at least $\frac{|I|+1}{2}$, if $|I|$ is odd. Furthermore, every integer number of political parties, starting from $\frac{|I|}{2}$ or $\frac{|I|+1}{2}$ up to $|I|$, can be found in some Nash equilibrium. To see this, pick any integer $n$ in the interval $\left[\frac{|I|}{2},|I|\right]$ and construct an $n$-sided regular convex polygon in the unit circle. The agendas corresponding to the vertices of this polygon are equidistant by construction. Therefore, any distribution of the politicians over these agendas such that each agenda has at least one and at most two politicians satisfies the conditions in the theorem and hence, it is a Nash equilibrium (for example, see Figure 2.9(1)). However, it is not necessary that the agendas supported in Nash equilibrium are equidistant. For instance, consider the case when $|I|=10$. Then the following strategy profile with nine parties is a Nash equilibrium: there is a single party with two politicians and at a distance 
of $\frac{2}{11}$ from each of its adjacent parties, and the rest of the eight singleton parties are at a distance of $\frac{1}{11}$ from each other (see Figure 2.9(2)).

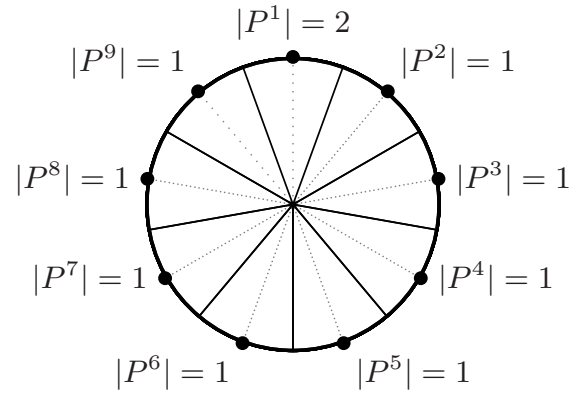

$(1)$

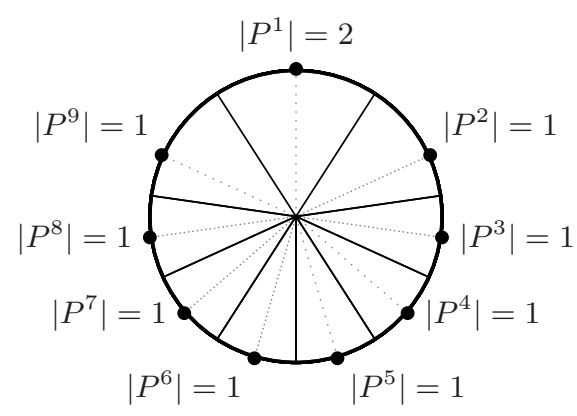

(2)

Figure 2.9: $|I|=$ 10. (1) Nash equilibrium with 9 equidistant parties. (2) Nash equilibrium with 9 parties that are not equidistant.

The following corollary follows from the theorem (see the discussion in the previous paragraph).

Corollary 6. For any $|I| \geq 3$, there exists a pure-strategy Nash equilibrium under proportional rule.

We also have multiple Nash equilibria under the proportional rule, with the number of political parties that can form in Nash equilibrium ranging from $\frac{|I|}{2}$ or $\frac{|I|+1}{2}$ up to $|I|$. Like for the plurality rule, we now use the notion of defection-proofness with the aim of refining the set of Nash equilibria. However, in contrast to the plurality rule, defection-proofness does not narrow down the set of Nash equilibria under the proportional rule.

Theorem 7. Under proportional rule, $s$ is a defection-proof Nash equilibrium if and only if it is a Nash equilibrium.

As we argue in the proof, any defection $s_{J}^{\prime}$ from a Nash equilibrium $s$ by a coalition $J$ to an agenda $a$ such that at least three politicians support $a$ in the resulting strategy profile $\left(s_{J}^{\prime}, s_{-J}\right)$ cannot be credible. This is because of the same reason why any strategy profile in which there exists a party with at least three politicians is not a Nash equilibrium: any politician in the party supporting $a$, and hence in $J$, can unilaterally deviate to improve her utility, which is a credible defection from $\left(s_{J}^{\prime}, s_{-J}\right)$. 


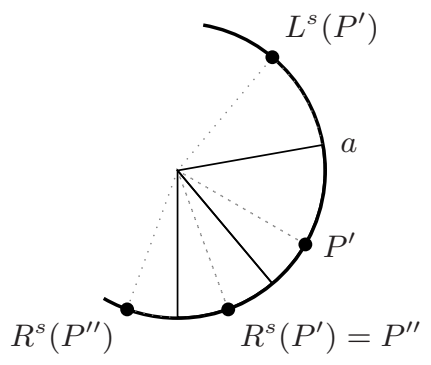

(1)

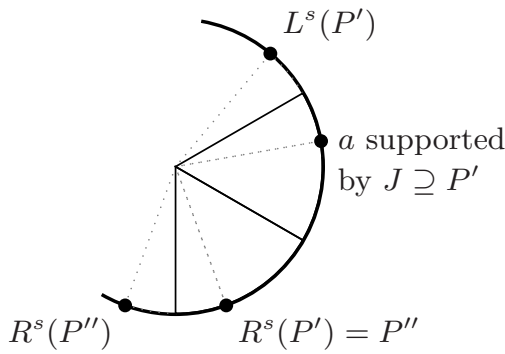

(3)

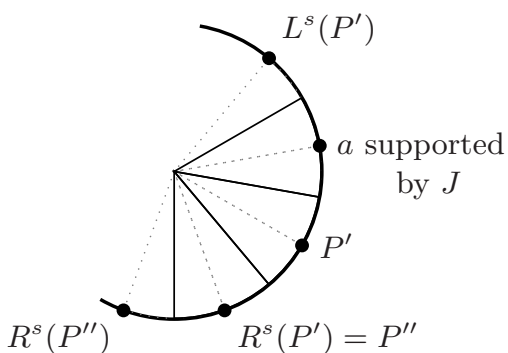

$(2)$

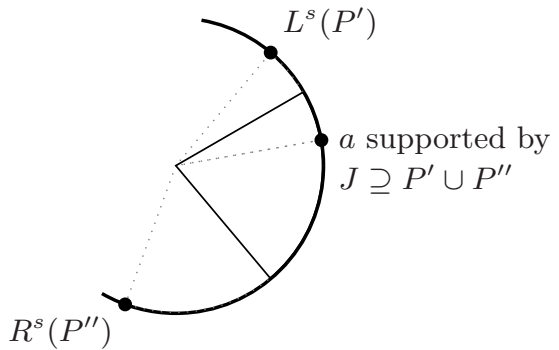

(4)

Figure 2.10: (1) Nash equilibrium $s$. There does not exist a defection by $J$ to agenda $a$ such that: (2) The agendas supported by $P^{\prime}$ and $L^{s}\left(P^{\prime}\right)$ in $s$ are also supported in $s^{\prime}$. (3) The agendas supported by $L^{s}\left(P^{\prime}\right)$ and $R^{s}\left(P^{\prime}\right)$ in $s$ are also supported in $s^{\prime}$ but the agenda supported by $P^{\prime}$ in $s$ is not supported in $s^{\prime}$. (4) The agenda supported by $L^{s}\left(P^{\prime}\right)$ in $s$ is also supported in $s^{\prime}$ but the agendas supported by $P^{\prime}$ and $R^{s}\left(P^{\prime}\right)$ in $s$ are not supported in $s^{\prime}$.

Thus, if there exists a credible defection from $s$, it must involve a coalition $J$ with exactly two politicians - a defection by a single politician does not exist since $s$ is a Nash equilibrium. Moreover, the credible defection must be to an agenda $a$ that is not supported by any party in $s$, i.e., $a$ must lie between the agendas supported by two adjacent parties in $s$, say $P^{\prime}$ and $L^{s}\left(P^{\prime}\right)$ (as shown in Figure 2.10(1)). We argue that there does not exist any such defection from $s$. To see this, first suppose that both the agendas supported by $P^{\prime}$ and $L^{s}\left(P^{\prime}\right)$ in $s$ are also supported in $s^{\prime}=\left(s_{J}^{\prime}, s_{-J}\right.$ ) (as shown in Figure 2.10(2)). Then in the strategy profile $s^{\prime}$, the utility of each politician in $J$ equals $\frac{l^{s}\left(P^{\prime}\right)}{4}$. If this were a defection from $s$, increasing the utility of both politicians in $J$ over their utilities in the strategy profile $s$, 
then $s$ could not have been a Nash equilibrium. This is because when the strategy profile is $s$, any single politician in $J$ could unilaterally deviate to $a$ and obtain the utility $\frac{l^{s}\left(P^{\prime}\right)}{2}$ as she now forms a singleton party supporting an agenda between the agendas supported by $P^{\prime}$ and $L^{s}\left(P^{\prime}\right)$ in $s$, which remain supported after her deviation. Next, suppose that only the agenda supported by $L^{s}\left(P^{\prime}\right)$ in $s$ is supported in $s^{\prime}$. Then all the politicians in $P^{\prime}$ must be part of the defecting coalition $J$. If the agenda supported by $R^{s}\left(P^{\prime}\right)$ in $s$ is also supported in $s^{\prime}$ (as shown in Figure 2.10(3)), then the utility of any politician in $P^{\prime}$ in $s^{\prime}$ cannot be greater than her utility in $s$ since the weight of her party is the same in both profiles. On the other hand, if the agenda supported by $R^{s}\left(P^{\prime}\right)$ in $s$ is not supported in $s^{\prime}$ (as shown in Figure 2.10(4)), then all the politicians in $R^{s}\left(P^{\prime}\right)$ must also be part of the defecting coalition. But if two different parties in $s$ are part of the defecting coalition and the size of the defecting coalition is equal to two, then each of the defecting parties must be singleton. Moreover, letting $P^{\prime \prime}=R^{s}\left(P^{\prime}\right)$, it must be that none of the politicians in $R^{s}\left(P^{\prime \prime}\right)$ are part of $J$. Therefore, each politician in $J$ obtains $\frac{l^{s}\left(P^{\prime}\right)+r^{s}\left(P^{\prime}\right)+r^{s}\left(P^{\prime \prime}\right)}{4}$ after the defection. This is no more than $\frac{l^{s}\left(P^{\prime}\right)+r^{s}\left(P^{\prime}\right)}{2}$, the utility of the politician in the singleton party $P^{\prime}$ in $s$, because $l^{s}\left(P^{\prime}\right)+r^{s}\left(P^{\prime}\right)$ is at least equal to the maximum distance between any two adjacent parties in $s$ (second condition in Theorem 5). The argument in the other two cases - when only the agenda supported by $P^{\prime}$ in $s$ is supported in $s^{\prime}$ and when neither the agenda supported by $P^{\prime}$ nor by $L^{s}\left(P^{\prime}\right)$ in $s$ is supported in $s^{\prime}$ - is similar.

Since there exists a pure-strategy Nash equilibrium under the proportional rule, we have the following corollary:

Corollary 8. For any $|I| \geq 3$, there exists a defection-proof Nash equilibrium under proportional rule.

\subsection{Summary}

Our aim in this paper was to study whether the predictions of Duverger (1954) have game theoretic foundations in a spatial model. Unfortunately, the standard model with a linear set of agendas does not provide satisfactory answers to this question; the set of pure-strategy Nash equilibria is 
empty under the proportional rule whereas it is singleton under the plurality rule for refinements that allow explicit coordination on party-level. This motivated us to instead use the set of agendas equal to the unit circle. As we have shown, this departure generates significantly different results; we now have multiple pure-strategy Nash equilibria under both rules. We used the notion of defection-proof Nash equilibrium to refine our predictions. Under the plurality rule, either two or three parties form in any defection-proof Nash equilibrium. This result is partially consistent with Duverger's law since there exists defection-proof Nash equilibria with three parties. On the other hand, under the proportional rule, multiple parties form in any defection-proof Nash equilibrium. Thus, Duverger's hypothesis and the Duvergian comparative prediction are supported by our results.

\subsection{Proofs}

\section{Plurality Rule}

Proof of Theorem 1: We prove the theorem through a series of lemmas.

Lemma 9. If $s$ is a Nash equilibrium with $|\mathcal{P}(s)| \geq 2$, then all parties in $\mathcal{P}(s)$ have equal weights.

Proof. Suppose $s$ is a Nash equilibrium with $|\mathcal{P}(s)| \geq 2$ but there exists a $P \in \mathcal{P}(s)$ such that $w_{P}(s)<\max _{P^{\prime} \in \mathcal{P}(s)} w_{P^{\prime}}(s)$. Hence, $P l_{P}(w(s))=0$ and $u_{i}(s)=0$ for all $i \in P$. Pick any politician $i \in P$ and party $\hat{P} \in$ $\arg \max _{P^{\prime} \in \mathcal{P}(s)} w_{P^{\prime}}(s)$. Consider the strategy profile $\left(s_{i}^{\prime}, s_{-i}\right)$ such that $s_{i}^{\prime}=$ $\hat{a}$, where $\hat{a}$ is the agenda supported by $\hat{P}$ in $s$. Note that $\hat{P} \cup\{i\} \in \mathcal{P}\left(s_{i}^{\prime}, s_{-i}\right)$. If $\hat{P} \cup\{i\}=\arg \max _{P^{\prime} \in \mathcal{P}\left(s_{i}^{\prime}, s_{-i}\right)} w_{P^{\prime}}\left(s_{i}^{\prime}, s_{-i}\right)$, then $u_{i}\left(s_{i}^{\prime}, s_{-i}\right)>0$, a contradiction. If not, then pick any $\hat{P}^{\prime} \in \arg \max _{P^{\prime} \in \mathcal{P}\left(s_{i}^{\prime}, s_{-i}\right)} w_{P^{\prime}}\left(s_{i}^{\prime}, s_{-i}\right)$. Let $\hat{a}^{\prime}$ be the agenda supported by $\hat{P}^{\prime}$ in $\left(s_{i}^{\prime}, s_{-i}\right)$. Consider the strategy $\left(s_{i}^{\prime \prime}, s_{-i}\right)$ such that $s_{i}^{\prime \prime}=\hat{a}^{\prime}$. The sets of agendas supported by the parties are the same in $\left(s_{i}^{\prime}, s_{-i}\right)$ and $\left(s_{i}^{\prime \prime}, s_{-i}\right)$. Hence, $\hat{P}^{\prime} \cup\{i\} \in \arg \max _{P^{\prime} \in \mathcal{P}\left(s_{i}^{\prime \prime}, s_{-i}\right)} w_{P^{\prime}}\left(s_{i}^{\prime \prime}, s_{-i}\right)$. Therefore, $u_{i}\left(s_{i}^{\prime \prime}, s_{-i}\right)>0$, a contradiction.

Lemma 10. If $s$ is a Nash equilibrium with $|\mathcal{P}(s)| \geq 2$, then for any two adjacent parties $P$ and $P^{\prime}$ in $\mathcal{P}(s)$, we have $l^{s}(P)=r^{s}\left(P^{\prime}\right)$ and $r^{s}(P)=$ 
$l^{s}\left(P^{\prime}\right)$. Furthermore, if $|\mathcal{P}(s)|$ is odd, then all parties are equidistant from each other.

Proof. Let $P$ and $P^{\prime}$ be two adjacent parties in $\mathcal{P}(s)$. Without loss of generality, let $P^{\prime}=L^{s}(P)$. Hence, $l^{s}(P)=r^{s}\left(P^{\prime}\right)$. By Lemma $9, P$ and $P^{\prime}$ have equal weights. So $r^{s}(P)=l^{s}\left(P^{\prime}\right)$.

Let $P^{1}=P$ and $P^{k+1}=R^{s}\left(P^{k}\right)$ for $k=1, \ldots,|\mathcal{P}(s)|-1$. Note that $P^{|\mathcal{P}(s)|}=P^{\prime}$. If $|\mathcal{P}(s)|$ is odd, then we have $r^{s}\left(P^{1}\right)=l^{s}\left(P^{2}\right)=r^{s}\left(P^{3}\right)=$ $\ldots=r^{s}\left(P^{|\mathcal{P}(s)|}\right), r^{s}\left(P^{|\mathcal{P}(s)|}\right)=l^{s}\left(P^{1}\right)$ and $l^{s}\left(P^{1}\right)=r^{s}\left(P^{2}\right)=l^{s}\left(P^{3}\right)=$ $\ldots=l^{s}\left(P^{|\mathcal{P}(s)|}\right)$. Therefore, all parties are equidistant from each other.

Lemma 11. If $s$ is a Nash equilibrium with $|\mathcal{P}(s)| \geq 2$, then $\max _{P, P^{\prime} \in \mathcal{P}(s)}|P|$ $-\left|P^{\prime}\right| \leq 1$.

Proof. Pick any $P, P^{\prime} \in \mathcal{P}(s)$. Without loss of generality, let $|P|>\left|P^{\prime}\right|+1$. Consider a politician $i \in P$. We have $u_{i}(s)=\frac{w_{P}(s)}{|P|}$. Let $s_{i}^{\prime}=a^{\prime}$, where $a^{\prime}$ is the agenda supported by party $P^{\prime}$ in $s$. Since the sets of agendas supported in $\left(s_{i}^{\prime}, s_{-i}\right)$ and $s$ are the same, all parties formed in $\left(s_{i}^{\prime}, s_{-i}\right)$ have equal weights ( $s$ is a Nash equilibrium and Lemma 9). Furthermore, the weight of party $P^{\prime} \cup\{i\}$ in the strategy profile $\left(s_{i}^{\prime}, s_{-i}\right)$ is equal to $w_{P^{\prime}}(s)$. Hence, $u_{i}\left(s_{i}^{\prime}, s_{-i}\right)=\frac{w_{P^{\prime}}(s)}{\left|P^{\prime}\right|+1}$. But $w_{P}(s)=w_{P^{\prime}}(s)$, by Lemma 9. Therefore, $u_{i}\left(s_{i}^{\prime}, s_{-i}\right)>u_{i}(s)$, a contradiction.

Lemma 12. A strategy profile $s$ such that $|\mathcal{P}(s)|=2$ is a Nash equilibrium if and only if $\min \left\{l^{s}(P), r^{s}(P)\right\}>\frac{1}{3}$ for any $P \in \mathcal{P}(s)$ and $\max _{P, P^{\prime} \in \mathcal{P}(s)}|P|-$ $\left|P^{\prime}\right| \leq 1$.

Proof. Let $s$ be a Nash equilibrium such that $|\mathcal{P}(s)|=2$. Then $\max _{P, P^{\prime} \in \mathcal{P}(s)}$ $|P|-\left|P^{\prime}\right| \leq 1$ follows from Lemma 11 .

Let $\mathcal{P}(s)=\left\{P, P^{\prime}\right\}$. Since $|I| \geq 3$, at least one of the parties is not singleton. Without loss of generality, let $|P|>1$. Pick an $i \in P$. Since $w_{P}(s)=w_{P^{\prime}}(s)=\frac{1}{2}$, we have $u_{i}(s) \leq \frac{1}{4}$.

Let $d=\min \left\{l^{s}(P), r^{s}(P)\right\}$. We call the arc between the agendas supported by parties $P$ and $P^{\prime}$ in $s$ with length $d$ as arc $d$, and the other arc as arc $1-d$ (in case $d=\frac{1}{2}$, then call any one of the two arcs defined by the agendas supported by $P$ and $P^{\prime}$ in $s$ as arc $d$ and the other as arc $1-d$ ).

Suppose $d \leq \frac{1}{3}$. Let politician $i$ deviate to $s_{i}^{\prime}$, which is the midpoint of arc $1-d$. In strategy profile $\left(s_{i}^{\prime}, s_{-i}\right)$, there are three parties $\{i\}, P \backslash\{i\}$ and 
$P^{\prime}$. Furthermore, $w_{\{i\}}\left(s_{i}^{\prime}, s_{-i}\right)=\frac{1-d}{2} \geq \frac{1}{3}, w_{P \backslash\{i\}}\left(s_{i}^{\prime}, s_{-i}\right)=w_{P^{\prime}}\left(s_{i}^{\prime}, s_{-i}\right)=$ $\frac{1+d}{4} \leq \frac{1}{3}$. Hence, $u_{i}\left(s_{i}^{\prime}, s_{-i}\right) \geq \frac{1}{3}$, a contradiction.

To prove the other implication, suppose $s$ is a strategy profile with $\mathcal{P}(s)=\left\{P, P^{\prime}\right\}, d>\frac{1}{3}$ and $\max _{P, P^{\prime} \in \mathcal{P}(s)}|P|-\left|P^{\prime}\right| \leq 1$. Pick any $i \in P$. We have $u_{i}(s)=\frac{1}{2|P|}$. Consider any deviation $s_{i}^{\prime}$ by politician $i$. Now, two cases are possible:

(i) $|P|>1$ : Suppose $s_{i}^{\prime}$ is an unsupported agenda on arc $d$. Then three parties $\{i\}, P \backslash\{i\}$ and $P^{\prime}$ form in $\left(s_{i}^{\prime}, s_{-i}\right)$. Moreover, $w_{\{i\}}\left(s_{i}^{\prime}, s_{-i}\right)=\frac{d}{2}$ but $w_{P \backslash\{i\}}\left(s_{i}^{\prime}, s_{-i}\right)>\frac{1}{2}-\frac{d}{2} \geq \frac{d}{2}$ since $d \leq \frac{1}{2}$. Hence, $u_{i}\left(s_{i}^{\prime}, s_{-i}\right)=0$. Hence, $i$ has no incentive to deviate from $s_{i}$ to $s_{i}^{\prime}$. Next, suppose $s_{i}^{\prime}$ is an unsupported agenda on $\operatorname{arc} 1-d$. Again, three parties $\{i\}$, $P \backslash\{i\}$ and $P^{\prime}$ form in $\left(s_{i}^{\prime}, s_{-i}\right)$. Moreover, $w_{\{i\}}\left(s_{i}^{\prime}, s_{-i}\right)=\frac{1-d}{2}$ but either $P^{\prime}$ or $P \backslash\{i\}$ has a weight of at least $\frac{1+d}{4}>\frac{1-d}{2}$ since $d>\frac{1}{3}$. Hence, $u_{i}\left(s_{i}^{\prime}, s_{-i}\right)=0$ and $i$ has no incentive to deviate from $s_{i}$ to $s_{i}^{\prime}$. Finally, if $s_{i}^{\prime}$ is the agenda supported by party $P^{\prime}$ in $s$, then $u_{i}\left(s_{i}^{\prime}, s_{-i}\right)=\frac{1}{2\left(\left|P^{\prime}\right|+1\right)} \leq \frac{1}{2|P|}$ since $|P|-\left|P^{\prime}\right| \leq 1$. So $i$ has no incentive to make this deviation.

(ii) $|P|=1$ : As long as $s_{i}^{\prime}$ is not the agenda supported by $P^{\prime}, u_{i}\left(s_{i}^{\prime}, s_{-i}\right)=$ $\frac{1}{2}$. If $s_{i}^{\prime}$ is the agenda supported by $P^{\prime}$, then $u_{i}\left(s_{i}^{\prime}, s_{-i}\right)=\frac{1}{\left|P^{\prime}\right|+1} \leq \frac{1}{3}$. So $i$ has no incentive to deviate.

A similar argument can be made for any politician in party $P^{\prime}$. Hence, $s$ is a Nash equilibrium.

Lemma 13. A strategy profile $s$ such that $|\mathcal{P}(s)| \geq 3$ and $|I| \geq 2|\mathcal{P}(s)|$ is a Nash equilibrium if and only if all parties in $\mathcal{P}(s)$ have equal weights and $\max _{P, P^{\prime} \in \mathcal{P}(s)}|P|-\left|P^{\prime}\right| \leq 1$.

Proof. Suppose strategy profile $s$ is such that all parties have equal weights and $\max _{P, P^{\prime} \in \mathcal{P}(s)}|P|-\left|P^{\prime}\right| \leq 1$. Pick any $P \in \mathcal{P}(s)$ and $i \in P$. Since $w_{P}(s)=\frac{1}{|\mathcal{P}(s)|}$, we have $u_{i}(s)=\frac{1}{|\mathcal{P}(s)||P|}$. Furthermore, since $|I| \geq 2|\mathcal{P}(s)|$, we must have $\left|P^{\prime}\right| \geq 2$ for all $P^{\prime} \in \mathcal{P}(s)$. Consider any deviation $s_{i}^{\prime}$ by politician $i$. If $s_{i}^{\prime}$ is an agenda supported by some $P^{\prime} \in \mathcal{P}(s)$, then the sets of agendas supported by the parties are the same in $s$ and $\left(s_{i}^{\prime}, s_{-i}\right)$. Hence, all parties formed in $\left(s_{i}^{\prime}, s_{-i}\right)$ have equal weights and $w_{P^{\prime} \cup\{i\}}\left(s_{i}^{\prime}, s_{-i}\right)=w_{P^{\prime}}(s)$. 
Therefore, $u_{i}\left(s_{i}^{\prime}, s_{-i}\right)=\frac{1}{|\mathcal{P}(s)|\left(\left|P^{\prime}\right|+1\right)} \leq \frac{1}{|\mathcal{P}(s)||P|}$ since $|P| \leq\left|P^{\prime}\right|+1$. If $s_{i}^{\prime}$ is an agenda that is not supported in strategy $s$, then there exists a $P^{\prime} \in \mathcal{P}(s)$ such that $s_{i}^{\prime}$ is between the agendas supported by $P^{\prime}$ and $L^{s}\left(P^{\prime}\right)$ in $s$. Hence, $w_{\{i\}}\left(s_{i}^{\prime}, s_{-i}\right)=\frac{l^{s}\left(P^{\prime}\right)}{2}$. But the weight of party $R^{\left(s_{i}^{\prime}, s_{i}\right)}\left(P^{\prime}\right)$ in $\left(s_{i}^{\prime}, s_{-i}\right)$ equals $\frac{l^{s}\left(P^{\prime}\right)+r^{s}\left(P^{\prime}\right)}{2}$ (using the fact that there are at least three parties in $s$ and all these parties have equal weights). Hence, $u_{i}\left(s_{i}^{\prime}, s_{-i}\right)=0$ and therefore, there is no incentive for her to deviate. Lemmas 9 and 11 prove the other implication.

Lemma 14. There does not exist a Nash equilibrium s such that either (i) $|\mathcal{P}(s)|=1$ or $($ ii) $|\mathcal{P}(s)|>6$ and $|I|<2|\mathcal{P}(s)|$.

Proof. Suppose $s$ is such a Nash equilibrium. If $|\mathcal{P}(s)|=1$, then any politician $i$ can deviate to any $s_{i}^{\prime}$ and obtain $u_{i}\left(s_{i}^{\prime}, s_{-i}\right)=\frac{1}{2}>\frac{1}{I T}=u_{i}(s)$. Next, if $|\mathcal{P}(s)|>6$ and $|I|<2|\mathcal{P}(s)|$, then there exists at least one party $P \in \mathcal{P}(s)$ such that $P=\{i\}$. It follows from Lemma 9 that $u_{i}(s)=\frac{1}{\mathcal{P}(s) \mid}$. Let $P^{\prime}$ be the closest party adjacent to $P$ in $s$. We know that $\left|P^{\prime}\right| \in\{1,2\}$ (Lemma 11). If politician $i$ deviates to $s_{i}^{\prime}$, which is the agenda supported by $P^{\prime}$ in $s$, then there are at most two parties with the highest weight in $\left(s_{i}^{\prime}, s_{-i}\right)$ and $P^{\prime} \cup\{i\}$ is one of these two parties. Hence, $u_{i}\left(s_{i}^{\prime}, s_{-i}\right) \geq$ $\frac{1}{2\left(\left|P^{\prime}\right|+1\right)} \geq \frac{1}{6}>\frac{1}{|\mathcal{P}(s)|}$, a contradiction.

Lemma 15. A strategy profile $s$ such that $5 \leq|\mathcal{P}(s)| \leq 6$ and $|I|<2|\mathcal{P}(s)|$ is a Nash equilibrium if and only if all parties are equidistant from each other, $\max _{P, P^{\prime} \in \mathcal{P}(s)}|P|-\left|P^{\prime}\right| \leq 1$, and there do not exist $P, P^{\prime} \in \mathcal{P}(s)$ such that $P$ and $P^{\prime}$ are adjacent, and $|P|=\left|P^{\prime}\right|=1$.

Proof. Let $s$ be such a Nash equilibrium. First, suppose that the parties are not equidistant. It follows from Lemma 10 that $|\mathcal{P}(s)|=6$ and $l^{s}\left(P^{\prime \prime}\right) \neq$ $r^{s}\left(P^{\prime \prime}\right)$ for all $P^{\prime \prime} \in \mathcal{P}(s)$. Since $|I|<2|\mathcal{P}(s)|$ there exists a party $P \in \mathcal{P}(s)$ such that $P=\{i\}$. Hence, $u_{i}(s)=\frac{1}{|\mathcal{P}(s)|}$ (Lemma 9$)$. Let $P^{\prime}$ be the closest party adjacent to $P$ in $s$. We know that $\left|P^{\prime}\right| \in\{1,2\}$ (Lemma 11). If politician $i$ deviates to $s_{i}^{\prime}$, which is the agenda supported by $P^{\prime}$ in $s$, then the weight of party $P^{\prime} \cup\{i\}$ in $\left(s_{i}^{\prime}, s_{-i}\right)$ is strictly greater than any other party's weight and hence, $u_{i}\left(s_{i}^{\prime}, s_{-i}\right) \geq \frac{1}{3}>\frac{1}{6}$, a contradiction. Therefore, all parties in $s$ are equidistant from each other. 
Next, suppose that there are two adjacent parties $P, P^{\prime} \in \mathcal{P}(s)$ such that $|P|=\left|P^{\prime}\right|=1$. Let $P=\{i\}$. Then $u_{i}(s)=\frac{1}{|\mathcal{P}(s)|}$ (Lemma 9). If politician $i$ deviates to $s_{i}^{\prime}$, which is the agenda supported by $P^{\prime}$ in $s$, then there are exactly two parties in $\left(s_{i}^{\prime}, s_{-i}\right)$ with the highest weight and party $P^{\prime} \cup\{i\}$ in $\left(s_{i}^{\prime}, s_{-i}\right)$ is one of them. Hence, $u_{i}\left(s_{i}^{\prime}, s_{-i}\right)=\frac{1}{4}>\frac{1}{|\mathcal{P}(s)|}$, a contradiction.

Finally, we show the other implication. Let $s$ satisfy the conditions listed in the lemma. Pick any $P \in \mathcal{P}(s)$ and $i \in P$. Then $|P| \leq 2$ and $u_{i}(s)=\frac{1}{|\mathcal{P}(s)||P|}$. Consider any deviation $s_{i}^{\prime}$ by politician $i$.

(i) Suppose $|P|=2$ : If $s_{i}^{\prime}$ is an agenda supported by some $P^{\prime} \in \mathcal{P}(s)$, then the sets of agendas supported by the parties are the same in $s$ and $\left(s_{i}^{\prime}, s_{-i}\right)$. Hence, $w_{P^{\prime} \cup\{i\}}\left(s_{i}^{\prime}, s_{-i}\right)=w_{P^{\prime}}(s)$ and therefore, $u_{i}\left(s_{i}^{\prime}, s_{-i}\right)=$ $\frac{1}{|\mathcal{P}(s)|\left(\left|P^{\prime}\right|+1\right)} \leq \frac{1}{|\mathcal{P}(s)||P|}$ since $|P| \leq\left|P^{\prime}\right|+1$. If $s_{i}^{\prime}$ is an agenda that is not supported by any party in strategy $s$, then there exists a $P^{\prime} \in \mathcal{P}(s)$ such that $s_{i}^{\prime}$ is between the agendas supported by $P^{\prime}$ and $L^{s}\left(P^{\prime}\right)$ in $s$. Hence, $w_{\{i\}}\left(s_{i}^{\prime}, s_{-i}\right)=\frac{l^{s}\left(P^{\prime}\right)}{2}$. But the weight of party $R^{\left(s_{i}^{\prime}, s_{i}\right)}\left(P^{\prime}\right)$ in $\left(s_{i}^{\prime}, s_{-i}\right)$ equals $\frac{l^{s}\left(P^{\prime}\right)+r^{s}\left(P^{\prime}\right)}{2}$ (using the fact that there are at least three parties in $s$ and all these parties have equal weights). Hence, $u_{i}\left(s_{i}^{\prime}, s_{-i}\right)=0$ and therefore, there is no incentive for her to deviate.

(ii) Suppose $|P|=1$ : Let $\operatorname{arc} d^{\prime}$ be the arc between the agendas supported by $L^{s}(P)$ and $R^{s}(P)$ in $s$ that does not contain $s_{i}$. If $s_{i}^{\prime}$ is in $\operatorname{arc} d^{\prime}$ but $s_{i}^{\prime}$ is neither the agenda supported by $L^{s}(P)$ nor $R^{s}(P)$ in $s$, then parties $L^{s}(P)$ and $R^{s}(P)$ are also formed in strategy $\left(s_{i}^{\prime}, s_{-i}\right)$ and at least one of them obtains a higher weight than the party of politician $i$ in $\left(s_{i}^{\prime}, s_{-i}\right)$. Hence, $u_{i}\left(s_{i}^{\prime}, s_{-i}\right)=0$ and therefore, there is no incentive to deviate. If $s_{i}^{\prime}$ is the agenda supported by $L^{s}(P)$ in $s$, then $L^{s}(P) \cup\{i\}$ and $R^{s}(P)$ form in strategy $\left(s_{i}^{\prime}, s_{-i}\right)$ and obtain the highest weight. Since $\left|L^{s}(P)\right|=2$, we have $u_{i}\left(s_{i}^{\prime}, s_{-i}\right)=\frac{1}{6}$. Therefore, there is no incentive to deviate. A similar argument works if $s_{i}^{\prime}$ is the agenda supported by $R^{s}(P)$ in $s$. In the remaining case, $u_{i}\left(s_{i}^{\prime}, s_{-i}\right)=0$ since both $L^{s}(P)$ and $R^{s}(P)$ are also formed in strategy $\left(s_{i}^{\prime}, s_{-i}\right)$ and at least one of them obtains a higher weight than the party of politician $i$ in $\left(s_{i}^{\prime}, s_{-i}\right)$. Hence, there is no incentive to deviate.

Therefore, $s$ is a Nash equilibrium. 
Lemma 16. A strategy profile $s$ such that $3 \leq|\mathcal{P}(s)| \leq 4$ and $|I|<2|\mathcal{P}(s)|$ is a Nash equilibrium if and only if all parties are equidistant from each other and $\max _{P, P^{\prime} \in \mathcal{P}(s)}|P|-\left|P^{\prime}\right| \leq 1$.

Proof. The proof of this lemma is similar to the proof of Lemma 15.

The above lemmas together imply the characterization in the theorem.

Proof of Theorem 3: We prove the theorem through a series of lemmas.

Lemma 17. Let $s$ be such that $|\mathcal{P}(s)| \geq 4$. Then $s$ is not a defection-proof Nash equilibrium.

Proof. Assume that $s$ is a defection-proof Nash equilibrium. Let $\mathcal{P}(s)=$ $\left\{P^{1}, \ldots, P^{n}\right\}$ such that $n \geq 4$. Without loss of generality, let $P^{k+1}=$ $R^{s}\left(P^{k}\right)$ for all $k=1, \ldots, n-1$ and $l^{s}\left(P^{3}\right) \leq r^{s}\left(P^{3}\right)$. Since $s$ is a Nash equilibrium, all parties in $\mathcal{P}(s)$ have equal weights. Therefore, $u_{i}(s)=$ $\frac{1}{|\mathcal{P}(s)|\left|P^{k}\right|}$ for all $i \in P^{k}$. Moreover, $\left|P^{2}\right|+\left|P^{3}\right| \leq 2\left|P^{k}\right|+1$ for $k=2,3$ (using Lemma 11).

Consider the arc between the agendas supported by $P^{2}$ and $P^{3}$ in $s$ corresponding to $l^{s}\left(P^{3}\right)$. Let $a$ be the midpoint of this arc. Consider the coalition $J=P^{2} \cup P^{3}$ and $s_{J}^{\prime}$ such that $s_{j}^{\prime}=a$ for all $j \in J$. Let $s^{\prime}=\left(s_{J}^{\prime}, s_{-J}\right)$. Now, $\mathcal{P}\left(s^{\prime}\right)=\left\{P^{1}, P^{2} \cup P^{3}, P^{4}, \ldots, P^{n}\right\}$ and

$$
l^{s^{\prime}}\left(P^{2} \cup P^{3}\right)=l^{s}\left(P^{2}\right)+\frac{l^{s}\left(P^{3}\right)}{2}=r^{s}\left(P^{3}\right)+\frac{r^{s}\left(P^{2}\right)}{2}=r^{s^{\prime}}\left(P^{2} \cup P^{3}\right) .
$$

Thus, the weight of $P^{2} \cup P^{3}$ in $s^{\prime}$ equals $l^{s}\left(P^{2}\right)+\frac{l^{s}\left(P^{3}\right)}{2}$. Now, $r^{s^{\prime}}\left(P^{1}\right)=$ $l^{s^{\prime}}\left(P^{2} \cup P^{3}\right)$ and $l^{s^{\prime}}\left(P^{1}\right)=l^{s}\left(P^{1}\right)=l^{s}\left(P^{3}\right) \leq r^{s}\left(P^{3}\right)=l^{s}\left(P^{2}\right)$. Similarly, $l^{s^{\prime}}\left(P^{4}\right)=r^{s^{\prime}}\left(P^{2} \cup P^{3}\right)$ and $r^{s^{\prime}}\left(P^{4}\right) \leq r^{s}\left(P^{3}\right)$. Therefore, in $s^{\prime}, P^{2} \cup P^{3}$ has a greater weight than both $P^{1}$ and $P^{4}$. Clearly, $w_{P^{k}}\left(s^{\prime}\right)=w_{P^{k}}(s)$ for all $k>4$. Therefore, in $s^{\prime}, P^{2} \cup P^{3}$ is the unique party with the maximum weight. Hence, $u_{j}\left(s^{\prime}\right)=\frac{1}{\left|P^{2}\right|+\left|P^{3}\right|}$ for all $j \in J$.

Since $|\mathcal{P}(s)|\left|P^{k}\right| \geq 4\left|P^{k}\right|>2\left|P^{k}\right|+1 \geq\left|P^{2}\right|+\left|P^{3}\right|$ for $k=2,3, s_{J}^{\prime}$ is a defection from $s$ by $J$.

Consider any subcoalition $J^{\prime} \subset J$ and let $s_{J^{\prime}}^{\prime \prime}$ be such that $s_{j}^{\prime \prime}=a^{\prime} \neq a$ for all $j \in J^{\prime \prime}$. Let $s^{\prime \prime}=\left(s_{J^{\prime}}^{\prime \prime}, s_{-J^{\prime}}^{\prime}\right)$. If $a^{\prime}$ lies on the arc between the agendas supported by $P^{1}$ and $P^{4}$ in $s^{\prime}$ that does not contain $a$, then party $J \backslash J^{\prime}$ will be the unique party with the maximum weight in $s^{\prime \prime}$. Hence, the utility 
of each $j \in J^{\prime \prime}$ will be zero in $s^{\prime \prime}$. In all other cases, the new party $J^{\prime}$ will obtain a weight of $\frac{l^{s^{\prime}}\left(P^{2} \cup P^{3}\right)}{2}$, which is less than the weight obtained by at least either $P^{1}$ or $P^{4}$ in $s^{\prime \prime}$. Thus, the utility of each $j \in J^{\prime \prime}$ will again be zero in $s^{\prime \prime}$. So there does not exist any subcoalition $J^{\prime} \subset J$ with a defection from $s^{\prime}$. Therefore, $s_{J}^{\prime}$ is a credible defection from $s$ by $J$, a contradiction.

Lemma 18. Let $s$ be a Nash equilibrium such that $|\mathcal{P}(s)|=3$. Then, $s$ is a defection-proof Nash equilibrium.

Proof. Let $\mathcal{P}(s)=\left\{P^{1}, P^{2}, P^{3}\right\}, J$ a coalition of politicians, and $s_{J}^{\prime}$ a profile for this coalition such that $s_{j} \neq s_{j}^{\prime}=a$ for all $j \in J$. Suppose $s_{J}^{\prime}$ is a credible defection from $s$ by $J$. Consider the following cases:

(i) $P^{k} \backslash J \neq \emptyset$ for all $k \in\{1,2,3\}$. Pick any $j \in J$ and consider the strategy profile $\left(s_{j}^{\prime}, s_{-j}\right)$. Clearly the set of agendas supported in $\left(s_{J}^{\prime}, s_{-J}\right)$ is equal to the set of agendas supported in $\left(s_{j}^{\prime}, s_{-j}\right)$. Therefore, the weight of party supporting $a$ in $\left(s_{J}^{\prime}, s_{-J}\right)$ is equal to the weight of the party supporting $a$ in $\left(s_{j}^{\prime}, s_{-j}\right)$. But the latter party is singleton. Thus, $u_{j}\left(s_{j}^{\prime}, s_{-j}\right) \geq u_{j}\left(s_{J}^{\prime}, s_{-J}\right)>u_{j}(s)$, a contradiction to the fact that $s$ is a Nash equilibrium.

(ii) $P^{1} \subseteq J$ and $P^{k} \backslash J \neq \emptyset$ for $k=2,3$. Then $a$ is not supported by $P^{1}$ in $s$. If $a$ is also not supported by $P^{2}$ or $P^{3}$ in $s$, then three parties form in $\left(s_{J}^{\prime}, s_{-J}\right)$ but the weight of the party supporting $a$ is less than the weight of at least one other party. Thus, $u_{j}\left(s_{J}^{\prime}, s_{-J}\right)=0$ for all $j \in J$, a contradiction. If $a$ is supported by, without loss of generality, $P^{2}$, then $P^{2} \cap J=\emptyset$. Now, two parties form in $\left(s_{J}^{\prime}, s_{-J}\right)$. Pick any $j \in P^{1}$. Then $u_{j}\left(s_{J}^{\prime}, s_{-J}\right) \leq \frac{1}{2\left|P^{1}\right|+2\left|P^{2}\right|}$. On the other hand, $u_{j}(s)=\frac{1}{3\left|P^{1}\right|}$. However, $3\left|P^{1}\right| \leq 2\left|P^{1}\right|+2\left|P^{2}\right|$ because $\left|P^{1}\right| \leq\left|P^{2}\right|+1 \leq 2\left|P^{2}\right|$. So $s_{J}^{\prime}$ cannot be a defection. Similarly, we can obtain contradictions when either:

(iii) $P^{2} \subseteq J$ and $P^{k} \backslash J \neq \emptyset$ for $k=1,3$, or

(iv) $P^{3} \subseteq J$ and $P^{k} \backslash J \neq \emptyset$ for $k=1,2$.

(v) $P^{1} \cup P^{2} \subseteq J$ and $P^{3} \backslash J \neq \emptyset$. Then $a$ is not supported by both $P^{1}$ and $P^{2}$ in $s$. If $a$ is also not supported by $P^{3}$ in $s$, then two parties form in $\left(s_{J}^{\prime}, s_{-J}\right)$. Pick any $j \in P^{1}$. Then $u_{j}\left(s_{J}^{\prime}, s_{-J}\right) \leq \frac{1}{2\left|P^{1}\right|+2\left|P^{2}\right|}$. On the other hand, $u_{j}(s)=\frac{1}{3\left|P^{1}\right|}$. However, as above, $3\left|P^{1}\right| \leq 2\left|P^{1}\right|+2\left|P^{2}\right|$. 
So $s_{J}^{\prime}$ cannot be a defection, a contradiction. If $a$ is supported by $P^{3}$, then $P^{3} \cap J=\emptyset$. Now, a single party is formed in $\left(s_{J}^{\prime}, s_{-J}\right)$. However, since $\left(s_{J}^{\prime}, s_{-J}\right)$ is not a Nash equilibrium, there exists a credible defection by a single politician, without loss of generality by $j \in J$, from $\left(s_{J}^{\prime}, s_{-J}\right)$. Thus, $\left(s_{J}^{\prime}, s_{-J}\right)$ is not a credible defection from $s$ by $J$, a contradiction. We can similarly obtain contradictions when either:

(vi) $P^{1} \cup P^{3} \subseteq J$ and $P^{2} \backslash J \neq \emptyset$, or

(vii) $P^{2} \cup P^{3} \subseteq J$ and $P^{1} \backslash J \neq \emptyset$.

(viii) $P^{1} \cup P^{2} \cup P^{3}=J$. A single party is formed after the defection and hence, the resulting profile is not a Nash equilibrium. Thus, the initial defection is not credible, a contradiction.

Lemma 19. Let $s$ be a Nash equilibrium such that $|\mathcal{P}(s)|=2$. Then $s$ is a defection-proof Nash equilibrium.

Proof. Let $\mathcal{P}(s)=\left\{P^{1}, P^{2}\right\}, J$ a coalition of politicians, and $s_{J}^{\prime}$ a profile for this coalition such that $s_{j} \neq s_{j}^{\prime}=a$ for all $j \in J$. Suppose $s_{J}^{\prime}$ is a credible defection from $s$ by $J$. Consider the following cases:

(i) $P^{k} \backslash J \neq \emptyset$ for all $k \in\{1,2\}$. Pick any $j \in J$ and consider the strategy profile $\left(s_{j}^{\prime}, s_{-j}\right)$. Clearly the set of agendas supported in $\left(s_{J}^{\prime}, s_{-J}\right)$ is equal to the set of agendas supported in $\left(s_{j}^{\prime}, s_{-j}\right)$. Therefore, the weight of party supporting $a$ in $\left(s_{J}^{\prime}, s_{-J}\right)$ is equal to the weight of the party supporting $a$ in $\left(s_{j}^{\prime}, s_{-j}\right)$. But the latter party is singleton. Thus, $u_{j}\left(s_{j}^{\prime}, s_{-j}\right) \geq u_{j}\left(s_{J}^{\prime}, s_{-J}\right)>u_{j}(s)$, a contradiction to the fact that $s$ is a Nash equilibrium.

(ii) $P^{1} \subseteq J$ and $P^{2} \backslash J \neq \emptyset$. Then $a$ is not supported by $P^{1}$ in $s$. If $a$ is also not supported by $P^{2}$ in $s$, then two parties form in $\left(s_{J}^{\prime}, s_{-J}\right)$. The weight of the party supporting $a$ is equal to $\frac{1}{2}$. Thus, for any $j \in P^{1}$, we have $u_{j}\left(s_{J}^{\prime}, s_{-J}\right) \leq \frac{1}{2\left|P^{1}\right|}=u_{j}(s)$, a contradiction. If $a$ is supported by $P^{2}$, then $P^{2} \cap J=\emptyset$. Now, a single party is formed in $\left(s_{J}^{\prime}, s_{-J}\right)$. However, since $\left(s_{J}^{\prime}, s_{-J}\right)$ is not a Nash equilibrium, $\left(s_{J}^{\prime}, s_{-J}\right)$ is not a credible defection from $s$ by $J$, a contradiction. We can similarly obtain a contradiction when:

(iii) $P^{2} \subseteq J$ and $P^{1} \backslash J \neq \emptyset$.

(iv) $P^{1} \cup P^{2}=J$. A single party is formed after the defection and hence, the resulting profile is not a Nash equilibrium. Thus, the initial defection 
is not credible, a contradiction.

These lemmas together imply the characterization in the theorem.

\section{Proportional Rule}

Proof of Theorem 5: We prove the theorem through a series of lemmas.

Lemma 20. Let $s$ be such that there exists a party $P$ in $\mathcal{P}(s)$ with $|P| \geq 3$. Then $s$ is not a Nash equilibrium.

Proof. Let $P \in \mathcal{P}(s)$ such that $|P| \geq 3$. Without loss of generality, suppose $l^{s}(P) \geq r^{s}(P)$. Pick any politician $i \in P$ and consider the strategy profile $\left(s_{i}^{\prime}, s_{-i}\right)$ such that $s_{i}^{\prime}$ is any agenda on the arc corresponding to $l^{s}(P)$ except the agendas supported by $P$ and $L^{s}(P)$ in $s$. Then $u_{i}\left(s_{i}^{\prime}, s_{-i}\right)=\frac{l^{s}(P)}{2}>$ $\frac{l^{s}(P)}{|P|} \geq \frac{l^{s}(P)+r^{s}(P)}{2|P|}=u_{i}(s)$. Therefore, $s$ is not a Nash equilibrium.

Lemma 21. Let $s$ be a Nash equilibrium. Then for any $P \in \mathcal{P}(s)$ such that $|P|=2$, we must have $l^{s}(P)=r^{s}(P)=\max _{P^{\prime} \in \mathcal{P}(s)}\left\{l^{s}\left(P^{\prime}\right), r^{s}\left(P^{\prime}\right)\right\}$.

Proof. Let $P \in \mathcal{P}(s)$ such that $|P|=2$. Let $d^{*}=\max _{P^{\prime} \in \mathcal{P}(s)}\left\{l^{s}\left(P^{\prime}\right), r^{s}\left(P^{\prime}\right)\right\}$. Suppose $d^{*}>\min \left\{l^{s}(P), r^{s}(P)\right\}$. Note that $d^{*} \geq \max \left\{l^{s}(P), r^{s}(P)\right\}$. Therefore, $\frac{l^{s}(P)+r^{s}(P)}{2}<d^{*}$. Let $P^{\prime \prime}=\arg \max _{P^{\prime} \in \mathcal{P}(s)}\left\{l^{s}\left(P^{\prime}\right), r^{s}\left(P^{\prime}\right)\right\}$ and without loss of generality, suppose $l^{s}\left(P^{\prime \prime}\right) \geq r^{s}\left(P^{\prime \prime}\right)$. Pick any politician $i \in P$ and consider the strategy profile $\left(s_{i}^{\prime \prime}, s_{-i}\right)$ such that $s_{i}^{\prime \prime}$ is any agenda on the arc corresponding to $l^{s}\left(P^{\prime \prime}\right)$ except the agendas supported by $P^{\prime \prime}$ and $L^{s}\left(P^{\prime \prime}\right)$ in $s$. Then $u_{i}\left(s_{i}^{\prime \prime}, s_{-i}\right)=\frac{l^{s}\left(P^{\prime \prime}\right)}{2}=\frac{d^{*}}{2}>\frac{l^{s}(P)+r^{s}(P)}{4}=u_{i}(s)$. Therefore, $s$ is not a Nash equilibrium.

Lemma 22. Let $s$ be a Nash equilibrium. Then for any $P \in \mathcal{P}(s)$ such that $|P|=1$, we must have $l^{s}(P)+r^{s}(P) \geq \max _{P^{\prime} \in \mathcal{P}(s)}\left\{l^{s}\left(P^{\prime}\right), r^{s}\left(P^{\prime}\right)\right\}$.

Proof. Let $P \in \mathcal{P}(s)$ such that $|P|=1$. Suppose $l^{s}(P)+r^{s}(P)<\max _{P^{\prime} \in \mathcal{P}(s)}$ $\left\{l^{s}\left(P^{\prime}\right), r^{s}\left(P^{\prime}\right)\right\}$. Let $P^{\prime \prime}=\arg \max _{P^{\prime} \in \mathcal{P}(s)}\left\{l^{s}\left(P^{\prime}\right), r^{s}\left(P^{\prime}\right)\right\}$ and without loss of generality, suppose $l^{s}\left(P^{\prime \prime}\right) \geq r^{s}\left(P^{\prime \prime}\right)$. Pick any politician $i \in P$ and consider the strategy profile $\left(s_{i}^{\prime \prime}, s_{-i}\right)$ such that $s_{i}^{\prime \prime}$ is any agenda on the arc corresponding to $l^{s}\left(P^{\prime \prime}\right)$ except the agendas supported by $P^{\prime \prime}$ and $L^{s}\left(P^{\prime \prime}\right)$ in $s$. Then $u_{i}\left(s_{i}^{\prime \prime}, s_{-i}\right)=\frac{l^{s}\left(P^{\prime \prime}\right)}{2}>\frac{l^{s}(P)+r^{s}(P)}{2}=u_{i}(s)$. Therefore, $s$ is not a Nash equilibrium. 
Lemma 23. Let $s$ be such that for any party $P \in \mathcal{P}(s)$ either

(i) $|P|=2$ and $l^{s}(P)=r^{s}(P)=\max _{P^{\prime} \in \mathcal{P}(s)}\left\{l^{s}\left(P^{\prime}\right), r^{s}\left(P^{\prime}\right)\right\}$ or

(ii) $|P|=1$ and $l^{s}(P)+r^{s}(P) \geq \max _{P^{\prime} \in \mathcal{P}(s)}\left\{l^{s}\left(P^{\prime}\right), r^{s}\left(P^{\prime}\right)\right\}$.

Then $s$ is a Nash equilibrium.

Proof. Let $s$ be such a strategy profile and $d^{*}=\max _{P^{\prime} \in \mathcal{P}(s)}\left\{l^{s}\left(P^{\prime}\right), r^{s}\left(P^{\prime}\right)\right\}$. Pick a $P \in \mathcal{P}(s)$ such that $|P|=2$. A politician $i$ in party $P$ gets $\frac{d^{*}}{2}$. Consider a deviation $s_{i}^{\prime}$. First, suppose $s_{i}^{\prime}$ is not an agenda supported in $s$. Clearly, $s_{i}^{\prime}$ lies between two agendas supported in $s$. Furthermore, since $|P|=2$, all the agendas that are supported in $s$ are also supported in $\left(s_{i}^{\prime}, s_{-i}\right)$. Hence, there exists a $P^{\prime \prime} \in \mathcal{P}(s)$ such that $u_{i}\left(s_{i}^{\prime}, s_{-i}\right)=\frac{l^{s}\left(P^{\prime \prime}\right)}{2} \leq$ $\frac{d^{*}}{2}=u_{i}(s)$. Second, suppose $s_{i}^{\prime}$ is an agenda supported in $s$ by $P^{\prime \prime}$ such that $\left|P^{\prime \prime}\right|=2$. Now, the set of agendas supported in $\left(s_{i}^{\prime}, s_{-i}\right)$ equals the set of agendas supported in $s$. Clearly, $u_{i}\left(s_{i}^{\prime}, s_{-i}\right)=\frac{d^{*}}{3}<u_{i}(s)$. Finally, suppose $s_{i}^{\prime}$ is an agenda supported in $s$ by $P^{\prime \prime}$ such that $\left|P^{\prime \prime}\right|=1$. Again, the set of agendas supported in $\left(s_{i}^{\prime}, s_{-i}\right)$ equals the set of agendas supported in $s$. Moreover, $u_{i}\left(s_{i}^{\prime}, s_{-i}\right)=\frac{l^{s}\left(P^{\prime \prime}\right)+r^{s}\left(P^{\prime \prime}\right)}{4} \leq \frac{d^{*}}{2}=u_{i}(s)$.

Next, pick a $P \in \mathcal{P}(s)$ such that $|P|=1$. Since $l^{s}(P)+r^{s}(P) \geq d^{*}$, the politician $i$ in party $P$ gets utility of at least $\frac{d^{*}}{2}$. Consider a deviation $s_{i}^{\prime}$. First, suppose $s_{i}^{\prime}$ is not an agenda supported in $s$. If $s_{i}^{\prime}$ does not lie on the arc between the agendas supported by $L^{s}(P)$ and $R^{s}(P)$ that contains $s_{i}$, then there exists a $P^{\prime \prime} \in \mathcal{P}(s)$ such that $u_{i}\left(s_{i}^{\prime}, s_{-i}\right)=\frac{l^{s}\left(P^{\prime \prime}\right)}{2} \leq \frac{d^{*}}{2} \leq u_{i}(s)$. On the other hand, if $s_{i}^{\prime}$ lies on the arc between the agendas supported by $L^{s}(P)$ and $R^{s}(P)$ that contains $s_{i}$, then $u_{i}\left(s_{i}^{\prime}, s_{-i}\right)=u_{i}(s)$. Second, suppose $s_{i}^{\prime}$ is an agenda supported in $s$ by $P^{\prime \prime}$ such that $\left|P^{\prime \prime}\right|=2$. If $P^{\prime \prime} \notin\left\{L^{s}(P), R^{s}(P)\right\}$, then $u_{i}\left(s_{i}^{\prime}, s_{-i}\right)=\frac{d^{*}}{3}<\frac{d^{*}}{2} \leq u_{i}(s)$. On the other hand, if $P^{\prime \prime}=L^{s}(P)$ (a similar argument works when $P^{\prime \prime}=R^{s}(P)$ ), then $u_{i}\left(s_{i}^{\prime}, s_{-i}\right)=\frac{l^{s}\left(P^{\prime \prime}\right)+l^{s}(P)+r^{s}(P)}{6} \leq \frac{d^{*}}{2} \leq u_{i}(s)$. Finally, suppose $s_{i}^{\prime}$ is an agenda supported in $s$ by $P^{\prime \prime}$ such that $\left|P^{\prime \prime}\right|=1$. If $P^{\prime \prime} \notin\left\{L^{s}(P), R^{s}(P)\right\}$, then $u_{i}\left(s_{i}^{\prime}, s_{-i}\right) \leq \frac{d^{*}}{2} \leq u_{i}(s)$. On the other hand, if $P^{\prime \prime}=L^{s}(P)$ (a similar argument works when $\left.P^{\prime \prime}=R^{s}(P)\right)$, then $u_{i}\left(s_{i}^{\prime}, s_{-i}\right)=\frac{l^{s}\left(P^{\prime \prime}\right)+l^{s}(P)+r^{s}(P)}{4} \leq$ $\frac{d^{*}+l^{s}(P)+r^{s}(P)}{4} \leq \frac{l^{s}(P)+r^{s}(P)}{2}=u_{i}(s)$.

Therefore, $s$ is a Nash equilibrium.

These lemmas together imply the characterization in the theorem. 
Proof of Theorem 7: Every defection-proof Nash equilibrium is by definition a Nash equilibrium.

It remains to show that every Nash equilibrium is also a CPNE. Suppose $s$ is a Nash equilibrium. Let $J$ be a coalition of politicians, and $s_{J}^{\prime}$ a profile for this coalition such that $s_{j} \neq s_{j}^{\prime}=a$ for all $j \in J$. Suppose $s_{J}^{\prime}$ is a credible defection

Since $s$ is a Nash equilibrium, we must have $|J| \geq 2$. Consider the profile $s^{\prime}=\left(s_{J}^{\prime}, s_{-J}\right)$ and let $P \in \mathcal{P}\left(s^{\prime}\right)$ be such that $J \subseteq P$.

First, suppose $|P| \geq 3$. If $J$ consists of all politicians forming a grand coalition then any deviation by any single player will give her a higher utility. This contradicts $s^{\prime}$ being a credible defection from $s$ by $J$, hence $|J|<|I|$ and there will be more than 1 party formed under $s^{\prime}$. Without loss of generality, let $l^{s^{\prime}}(P) \geq r^{s^{\prime}}(P)$. Pick any politician $j \in J$ and consider the strategy profile $\left(s_{j}^{\prime \prime}, s_{-j}^{\prime}\right)$ such that $s_{j}^{\prime \prime}$ is any agenda on the arc corresponding to $l^{s^{\prime}}(P)$ except the agendas supported by $P$ and $L^{s^{\prime}}(P)$ in $s^{\prime}$. Then $u_{j}\left(s_{j}^{\prime \prime}, s_{-j}^{\prime}\right)=\frac{l^{s^{\prime}}(P)}{2}>\frac{l^{s^{\prime}}(P)}{|P|} \geq \frac{l^{s^{\prime}}(P)+r^{s^{\prime}}(P)}{2|P|}=u_{j}\left(s^{\prime}\right)$. Therefore, $s_{j}^{\prime \prime}$ is a credible defection from $s^{\prime}$ by $j \in J$; a contradiction. Thus, it must be that $|P|=|J|=2$. Therefore, $a$ is not supported by any party in $s$ and hence, $a$ lies between the agendas supported by some $P^{\prime}$ and $L^{s}\left(P^{\prime}\right)$ in $s$. Consider the following cases:

(i) Suppose $P^{\prime} \backslash J \neq \emptyset$ and $L^{s}\left(P^{\prime}\right) \backslash J \neq \emptyset$. Pick any $j \in J$. Then $u_{j}\left(s^{\prime}\right)=$ $\frac{l^{s}\left(P^{\prime}\right)}{2}$. Since $s_{J}^{\prime}$ is a defection from $s$ by $J$, it must be that $u_{j}\left(s^{\prime}\right)>u_{j}(s)$. Consider the strategy profile $\left(s_{j}^{\prime}, s_{-j}\right)$. Clearly, $u_{j}\left(s_{j}^{\prime}, s_{-j}\right)=\frac{l^{s}\left(P^{\prime}\right)}{2}>u_{j}(s)$, a contradiction to the fact that $s$ is a Nash equilibrium.

(ii) Suppose $P^{\prime} \subseteq J$ and $L^{s}\left(P^{\prime}\right) \backslash J \neq \emptyset$. If $R^{s}\left(P^{\prime}\right) \backslash J \neq \emptyset$, then for any $j \in J \cap P^{\prime}$ we have $u_{j}\left(s^{\prime}\right)=\frac{l^{s}\left(P^{\prime}\right)+r^{s}\left(P^{\prime}\right)}{4} \leq u_{j}(s)$ (the equality uses the fact that $|J|=2)$. On the other hand, if $R^{s}\left(P^{\prime}\right) \subseteq J$, then $P^{\prime} \cup R^{s}\left(P^{\prime}\right) \subseteq J$ and $|J|=2$ implies that $P^{\prime} \cup R^{s}\left(P^{\prime}\right)=J$. Let $P^{\prime \prime}=R^{s}\left(P^{\prime}\right)$. Since $P^{\prime} \cup R^{s}\left(P^{\prime}\right)=J$, both parties $L^{s}\left(P^{\prime}\right)$ and $R^{s}\left(P^{\prime \prime}\right)$ form in $s^{\prime}$. Moreover, since $s$ is a Nash equilibrium and $\left|P^{\prime}\right|=1$, we have $r^{s}\left(P^{\prime \prime}\right) \leq l^{s}\left(P^{\prime}\right)+r^{s}\left(P^{\prime}\right)$. Thus, for $j \in P^{\prime}, u_{j}\left(s^{\prime}\right)=\frac{l^{s}\left(P^{\prime}\right)+r^{s}\left(P^{\prime}\right)+r^{s}\left(P^{\prime \prime}\right)}{4} \leq \frac{l^{s}\left(P^{\prime}\right)+r^{s}\left(P^{\prime}\right)}{2}=u_{j}(s)$, a contradiction. We can similarly obtain a contradiction when:

(iii) $P^{\prime} \backslash J \neq \emptyset$ and $L^{s}\left(P^{\prime}\right) \subseteq J$.

(iv) Suppose $P^{\prime} \subseteq J$ and $L^{s}\left(P^{\prime}\right) \subseteq J$. Let $P^{\prime \prime}=L^{s}\left(P^{\prime}\right)$. Then $P^{\prime} \cup P^{\prime \prime}=$ $J$ since $|J|=2$. Moreover both parties $L^{s}\left(P^{\prime \prime}\right)$ and $R^{s}\left(P^{\prime}\right)$ form in $s^{\prime}$ 
(these parties exist since $|I| \geq 3>|J|$ ). Since $s$ is a Nash equilibrium and $\left|P^{\prime}\right|=1$, we have $l^{s}\left(P^{\prime \prime}\right) \leq l^{s}\left(P^{\prime}\right)+r^{s}\left(P^{\prime}\right)$. Thus, for $j \in P^{\prime}, u_{j}\left(s^{\prime}\right)=$ $\frac{l^{s}\left(P^{\prime \prime}\right)+l^{s}\left(P^{\prime}\right)+r^{s}\left(P^{\prime}\right)}{4} \leq \frac{l^{s}\left(P^{\prime}\right)+r^{s}\left(P^{\prime}\right)}{2}=u_{j}(s)$, a contradiction. 


\section{Chapter 3}

\section{Equilibrium Concepts for a Party Formation Setting}

\subsection{Introduction}

In our first chapter we studied a spatial model of strategic party formation where the set of available agendas is the unit circle. We investigated how electoral systems affect the number of parties that form and their perspective positions with a focus on pluralistic and proportional electoral rules. The set of pure-strategy Nash equilibria for this model was very large and the specific context needed some refinements. We introduced the definition of Defection-proof Nash equilibria. Using this refinement we found theoretical support for famous predictions of electoral outcomes by the French political scientist Duverger. In this chapter we deal with other selection criteria that are more commonly used in the literature. Our aim is to present alternative equilibrium notions, characterize the set of equilibria they select and provide insights into those refinements. We hope this paper will serve as a useful tool for further research in political party formation. For the sake of completeness, we start by repeating the model and main findings of Chapter 2. 


\section{$3.2 \quad$ Model}

Our model resembles the Downsian model of electoral competition (Downs (1957)). However the set of available agendas to politicians is no longer the unit interval but rather the circumference of a circle of unit length, denoted by $A$. Politicians, denoted by $I$, are purely office-oriented as they select agendas independently and simultaneously. The set of politicians who support the same agenda is called a party. A party can also consist of only one politician. $\mathcal{P}(s)$ denotes the set of all parties formed under the strategy profile $s$, where $s$ is a vector that consists of an agenda for each politician in the elections.

Voters are sincere and non-strategic, each votes for the party located closest to her most preferred agenda. Their most preferred agendas are distributed uniformly on the circle.

An electoral system $\rho$ determines the power of a party. Under pluralistic rule, the winner takes all. Under proportional rule, each party has power proportional to the number of votes it receives. The utility of an individual politician is equal to the power of the party she joins divided by the number of all politicians in that party.

Adding some more definitions will help us with the proofs below. When a party $P$ is located on the circle, the first party on its left and the first party on its right are the adjacent parties to $P$. The distance on the circle between party $P$ and its adjacent party on the right is called the left distance of party $P$ and denoted by $l^{s}(P)$, where $s$ is the strategy profile under which those parties are formed. The right distance of party $P, r^{s}(P)$, is defined similarly. The weight of a party is the proportion of voters who vote for party $P$. Please note that the weight of a party is the average of its right and left distances. The distribution of weights under a strategy profile $s$ determines the power of a party under each electoral rule.

Policy and welfare implications and post-election politics are ignored in this model. For a detailed discussion of the model and its assumptions see Chapter 2.

We begin with the characterization of the set of Nash equilibria under plurality rule, for the proof see Chapter 2 . 
Theorem 24. Under plurality rule, a strategy profile $s$ is a Nash equilibrium if and only if the numbers of politicians in any two parties in $\mathcal{P}(s)$ differ by at most 1, and exactly one of the following holds:

(i) $|\mathcal{P}(s)|=2$ and $\min \left\{l^{s}(P), r^{s}(P)\right\}>\frac{1}{3}$ for some $P \in \mathcal{P}(s)$.

(ii) $3 \leq|\mathcal{P}(s)| \leq \frac{|I|}{2}$ and all parties have equal weights.

(iii) $3 \leq|\mathcal{P}(s)| \leq 4,|\mathcal{P}(s)|>\frac{|I|}{2}$ and all parties are equidistant from each other.

(iv) $5 \leq|\mathcal{P}(s)| \leq 6,|\mathcal{P}(s)|>\frac{|I|}{2}$, all parties are equidistant from each other, and there does not exist any pair of singleton parties that are adjacent.

Secondly, we present the characterization of the set of Nash equilibria under the proportional rule, see Chapter 2 for the proof.

Theorem 25. Under proportional rule, $s$ is a Nash equilibrium if and only if for any party $P \in \mathcal{P}(s)$ either

(i) $|P|=2$ and $l^{s}(P)=r^{s}(P)=\max _{P^{\prime} \in \mathcal{P}(s)}\left\{l^{s}\left(P^{\prime}\right), r^{s}\left(P^{\prime}\right)\right\}$ or

(ii) $|P|=1$ and $l^{s}(P)+r^{s}(P) \geq \max _{P^{\prime} \in \mathcal{P}(s)}\left\{l^{s}\left(P^{\prime}\right), r^{s}\left(P^{\prime}\right)\right\}$.

Duverger says that under plurality voting two parties are generated, under proportional voting there is a tendency to multipartyism and more parties are generated under proportional system compared to majoritarian systems (Riker (1982), Morelli (2004)). In both rules, multiple configurations of parties are possible in Nash equilibrium, some are consistent with the predictions of Duverger. We find these sets of equilibria too broad and want to make a further selection.

\subsection{Equilibrium Refinements}

\section{Strong Nash Equilibrium}

A natural alternative to the concept of Nash equilibrium is strong Nash equilibrium, being widely used in the literature. Nash equilibrium strategies 
are stable against unilateral deviations by a single politician, however it disregards coordinated deviations by a coalition of politicians. Strong Nash requires that there is no beneficial deviation by any coalition of politicians from the equilibrium.

Definition 4 (Strong Nash Equilibrium). A strategy profile $s$ is a strong Nash equilibrium if and only if there exists no coalition $J \subseteq I$ such that for some $s_{J}^{\prime} \in A^{|J|}$ and $i \in J$ we have $u_{i}\left(s_{J}^{\prime}, s_{-J}\right)>u_{i}(s)$ and for all $j \in J$ we have $u_{j}\left(s_{J}^{\prime}, s_{-J}\right) \geq u_{j}(s)$.

The following two theorems show that selection on basis of strong Nash leads to the empty set and as such strong Nash appears to be too strong in the present setting.

Theorem 26. Let $|I| \geq 3$ and $\rho$ and be plurality rule. Then the set of strong Nash equilibria is empty.

Proof. Consider an electoral competition with at least 3 politicians under plurality rule. To prove the point that a strong Nash equilibrium does not exist, let's start by assuming on the contrary that $s$ is a strong Nash equilibrium of this strategic party formation game. If $s$ is a strong Nash equilibrium, then clearly it is also a Nash equilibrium and Theorem 24 tells us that all parties must have equal weight. Consider the following cases:

Assume $s$ to be a strong Nash-equilibrium with 3 or more parties. Take any two adjacent parties. If they move away from each other in a symmetric fashion, then they increase their vote share symmetrically and they become the only two winning parties. Numbers of politicians in both parties remain unchanged, hence each of the politicians in those parties is better off. Therefore $s$ cannot be a strong Nash equilibrium.

Let $s$ be a strategy profile which forms 2 parties. There is at least one party with 2 or more politicians, say party $P$. Each politician in party $P$ receives a utility equal to $\frac{1}{2|P|}$. If party $P$ splits into two and those two new parties move in opposite directions, come close to the other existing party until it loses all its power. These two new parties share the total power. All politicians who deviate from $s$ receive strictly more than before, a contradiction.

Therefore $s$ is not a strong Nash equilibrium. The set of strong Nash equilibria under plurality rule is empty. 
Theorem 27. Let $|I| \geq 3$ and $\rho$ and be proportional rule. Then the set of strong Nash equilibria is empty.

Proof. Consider an electoral competition with at least 3 politicians under proportional rule. To prove the point that a strong Nash equilibrium does not exist, let's start by assuming on the contrary that $s$ is a strong Nash equilibrium of this strategic party formation game.

If there are at least 3 parties formed, then take two arbitrary consecutive parties $P$ and $P^{\prime}$ in $\mathcal{P}(s)$. Consider a coalitional deviation from $s$ by parties $P$ and $P^{\prime}$ moving further away from each other. Now both parties have a higher vote share than before, hence more power due to proportional rule. The number of politicians haven't changed, therefore all politicians who deviate from $s$ receive strictly more than before, a contradiction.

If $s$ is a strategy profile which forms only two parties, then at least one of them consists of more than one politician. If this party splits into two and each half moves further away from each other, all deviating politicians receive strictly more than before as we explained above.

Therefore $s$ is not a strong Nash equilibrium. The set of strong Nash equilibria under plurality rule is empty.

No strong Nash equilibrium exists under plurality or proportional rules, hence strong Nash is clearly not the refinement we are looking for. We consider other alternatives.

\section{Party-formation restricted Strong Nash Equilibrium}

Some coalitional deviations are quite common in politics and some are not. We do not observe, for example, a group of politicians deciding together to form two new parties on very far agendas from each other. On the other hand, we frequently observe a shift in a party's agenda, a split in a party where a subset of politicians form a new party supporting a new agenda or merger of parties. Those coalitional deviations have one thing in common, that is each politician in the deviating coalition picks the same agenda. We restrict the possible deviations in strong Nash equilibrium accordingly and define Party formation restricted strong Nash equilibrium as follows:

Definition 5 (Party formation restricted strong Nash Equilibrium). A 
strategy profile $s$ is called pf-restricted strong Nash equilibrium if and only if there exists no coalition $J \subseteq I$ such that for some $a \in A$ and $i \in J$ we have $u_{i}\left(a, \ldots, a, s_{-J}\right)>u_{i}(s)$ and for all $j \in J$ we have $u_{j}\left(a, \ldots, a, s_{-J}\right) \geq u_{j}(s)$.

The following theorems characterize the set of pf-restricted strong Nash equilibria under plurality and proportional rules.

Theorem 28. Let $|I| \geq 3$ and $\rho$ be plurality rule. A strategy profile $s$ is a pf-restricted strong Nash equilibrium if and only if the number of politicians in every party differ from each other by at most 1 and precisely one of the following holds:

(i) $|\mathcal{P}(s)|=2, \min \left\{l^{s}(P), r^{s}(P)\right\}>\frac{1}{3}$ for some $P$ in $\mathcal{P}(s)$ and $|I|=2 k$ for some $k \in \mathbb{N}$

(ii) $|\mathcal{P}(s)|=3$, all parties are equidistant from each other and there is no $k \in \mathbb{N}$ such that $|I|=3 k+2$.

Proof. We prove the theorem through a series of lemmas.

Lemma 29. Let $|I| \geq 3$ and $\rho$ be plurality rule. Let $s$ be a strategy profile such that $|\mathcal{P}(s)| \geq 4$. Then $s$ is not pf-restricted strong Nash.

Proof. The same arguments we used in parts $i$ and $i i$ in the proof of Theorem 26 for strong Nash also applies to pf-restricted strong Nash since all the politicians in the coalitions are deviating to the same agenda.

Lemma 30. Let $|I| \geq 3$ and $\rho$ be plurality rule. Let $s$ be a strategy profile which forms three parties. Then $s$ is a pf-restricted strong Nash equilibrium if and only if it is a Nash equilibrium and there is no $k \in \mathbb{N}$ such that $|I|=3 k+2$.

Proof. Let $s$ be a Nash equilibrium. By Theorem 24, we know that all three parties formed are equidistant from one another and the number of politicians in every party differ from each other by at most 1 . Now there is no beneficial correlated group deviation such that those three parties remain but some politicians move to another party. If a group of politicians set up a new party while those three parties remain, each of those politicians 
receives no utility. If all politicians in a party moves that party to a nonoccupied agenda, they receive no utility at all. Hence, there is no incentive for such deviations.

It is left to check if any of those parties have an incentive to merge with another. Let $P$ and $P^{\prime}$ be two arbitrary parties in $\mathcal{P}(s)$. A politician $i$ in party $P$ gets a utility of $\frac{1}{3|P|}$. There are three possible cases:

(i) Let $|P|=\left|P^{\prime}\right|+1$. Then $|P| \geq 2$. If parties $P$ and $P^{\prime}$ merge, politician $i$ gets a utility of $\frac{1}{4|P|-2}$.

(ii) Let $|P|=\left|P^{\prime}\right|-1$. If parties $P$ and $P^{\prime}$ merge, politician $i$ gets a utility of $\frac{1}{4|P|+2}$.

(iii) Let $|P|=\left|P^{\prime}\right|$. If parties $P$ and $P^{\prime}$ merge, politician $i$ gets a utility of $\frac{1}{4|P|}$.

In any of the cases above, there is no incentive for merger.

We checked all possible deviations except the merger of three parties. If parties consist of different number of politicians, then a party more crowded than at least one other, has an incentive to merge with others. If there is only one party more crowded than the other two, the collusion will not take place, because one of the small parties will not agree with it. If there are two crowded parties, they will agree on merging with the third on its agenda and all deviating politicians will get better off. Two parties can have at most 1 difference between the number of politicians, so this situation with two crowded, one smaller party only exists when $|I| \equiv 2(\bmod 3)$. Hence we conclude that $s$ is a pf-restricted strong Nash equilibrium if and only if $s$ is a Nash equilibrium and $|I| \not \equiv 2(\bmod 3)$.

Lemma 31. Let $|I| \geq 3$ and $\rho$ be plurality rule. Let $s$ be a strategy profile which forms two parties. Then, $s$ is a pf-restricted strong Nash equilibrium if and only if $s$ is a Nash equilibrium and $|I|$ is even.

Proof. Let $s$ be a Nash equilibrium of only parties $P$ and $P^{\prime}$. Shifting a party does not alter the utilities. Since $s$ is a Nash equilibrium, if a single politician forms a new party when the other two parties still exist, that will not be beneficial for her. Therefore it is not beneficial for a group of 
politicians to do it either. Similarly, a group from one party cannot gain by switching to the other party. When two parties merge if $|I|$ is even nobody's utility is affected. If $|I|$ is odd the larger party gains from merger. So the larger party moves on the smaller party and all politicians of the larger party strictly gain from it.

The above lemmas together imply the characterization in the theorem.

Corollary 32. Let $|I| \geq 3$ and $\rho$ be plurality rule. There is a pf-restricted strong Nash equilibrium if and only if $|I| \not \equiv 5(\bmod 6)$.

Proof. Theorem 26 tells us that we can construct a Nash equilibrium by distributing the politicians to 2 or 3 equidistant agendas in as equal numbers as possible. Now if $|I| \equiv 0(\bmod 6),|I| \equiv 2(\bmod 6)$ or $|I| \equiv 4(\bmod 6)$ then $|I|$ is even, we can construct a Nash equilibrium with two parties and it will be pf-restricted strong Nash according to Lemma 31. If $|I| \equiv 1(\bmod$ 6) then $|I| \equiv 1(\bmod 3)$ or if $|I| \equiv 3(\bmod 6)$ then $|I| \equiv 0(\bmod 3)$ and in these cases we can construct a Nash equilibrium with three parties which will be pf-restricted strong Nash according to Lemma 30. If $|I| \equiv 5(\bmod$ 6) then $|I| \equiv 2(\bmod 3)$, we cannot construct any pf-restricted strong Nash equilibria.

Theorem 33. Let $|I| \geq 3$, $\rho$ be proportional rule and $s$ be a strategy profile. Then $s$ is a pf-restricted strong Nash equilibrium if and only if $s$ is a Nash equilibrium and there exists politicians $i$ and $j$ such that $i \neq j, u_{i}(s)>\frac{1}{|T|}$ and $u_{j}(s)>\frac{1}{|T|}$.

Proof. Consider an electoral competition with at least 3 politicians under proportional rule. Let $s$ be a Nash equilibrium strategy profile. We will try to construct a beneficial coalitional deviation to the same agenda $a$.

If agenda $a$ lies between parties $P$ and $P^{\prime}$ under $s$, then at least one of those parties, say $P$, must have moved to $a$ with the deviation. Otherwise the politician who gets strictly better off by this deviation could have deviated by herself to $a$ and got a better payoff, which is not possible because $s$ is Nash.

Now we know in this deviation all politicians in $P$ must have moved to $a$. If $a$ was not occupied by a party under $s$, then party $P$ simply 
moved to the side. If the neighboring parties still exist, then politicians in party $P$ do not improve their payoffs. And if any more politicians join the deviation their payoffs go down. Therefore in a beneficial coalitional deviation to agenda $a$, at least one of the neighbors of party $P$ under $s$ also joins the deviation. If $a$ was occupied by a party $P^{\prime \prime}$ before and only politicians in party $P$ joins this party, then politicians in party $P$ do not get better off. Before the deviation, each politician in party $P$ receives $\frac{l^{s}(P)+r^{s}(P)}{2}$ and afterwards they receive $\frac{l^{s}\left(P^{\prime \prime}\right)+l^{s}(P)+r^{s}(P)}{2+\left|P^{\prime \prime}\right|} .\left|P^{\prime \prime}\right|$ is at least 1. $l^{s}\left(P^{\prime \prime}\right)>l^{s}(P)+r^{s}(P)$ cannot be the case, by Theorem 25 since $s$ is a Nash equilibrium. So politicians in party $P$ do not get better off by this deviation if at least one of its neighbors does not join. If politicians from parties that are not neighbors join, the politicians in party $P$ that deviated get worse off. Therefore in a beneficial coalitional deviation to agenda $a$, at least one of the neighbors of party $P$ under $s$ also joins the deviation.

A beneficial coalitional deviation to agenda $a$, therefore always includes a chain of consecutive parties merging on $a$. Then we can always find a subcoalition of this coalition which consists of only consecutive parties that can improve upon $s$ by themselves. We do that simply by starting from where the new party is formed and considering the parties who would have been neighbors of this new party now if they did not join the deviation. Afterwards we continue with consecutive parties in $s$ who joined the deviation. This chain improves upon $s$ by itself. So we can restrict our attention to the deviations in form of a chain or grand coalition, which is the case where all parties merge together.

Assume that a chain with $k$ parties accumulates at a point on the chain. Without loss of generality we name those $k$ parties from 1 to $k$. We denote $l^{s}(P)$ by $\Delta_{P}$ and $r^{s}(P)$ by $\Delta_{P+1}$ for any party $P$ in $\{1,2, \ldots, k\}$. Total number of politicians in those $k$ parties are denoted by $n$.

Now assume that those $k$ parties are all singletons. Fix an arbitrary politician $i$ from 1 to $k$. In $s$ she receives a utility equal to $\frac{\Delta_{i}+\Delta_{i+1}}{2}$. After collusion she gets a utility equal to $\frac{\sum_{j=1}^{k+1} \Delta_{j}}{2 k}$.

For any politician $j$ from 1 to $k$, we have $\Delta_{j} \leq \Delta_{\max }$ and $\Delta_{k+1} \leq \Delta_{\max }$ by definition of a maximum and $\Delta_{\max } \leq \Delta_{i}+\Delta_{i+1}$ by characterization of Nash equilibria. This gives us $\Delta_{k+1} \leq \Delta_{i}+\Delta_{i+1}$ and $\Delta_{j} \leq \Delta_{i}+\Delta_{i+1}$ 
for all $j$. If we add these inequalities for all politicians in $\{1,2, \ldots, i-$ $1, i+2, i+3, \ldots, k\}$ and we add $\Delta_{i}+\Delta_{i+1}$ to both sides then we obtain $\sum_{j=1}^{k+1} \Delta_{j} \leq k\left(\Delta_{i}+\Delta_{i+1}\right)$. Then we get $\frac{\sum_{j=1}^{k+1} \Delta_{j}}{2 k} \leq \frac{\Delta_{i}+\Delta_{i+1}}{2}$. Therefore politician $i$ cannot be strictly better after this deviation. Since the choice of politician $i$ was arbitrary, no politician can get strictly better by this deviation.

If there exists an independent agent, say $i$ which constitutes a party $P$, in the chain she receives $\frac{\Delta_{P}+\Delta_{P+1}}{2}$ before merger, and she receives $\frac{\sum_{\tilde{P}=1}^{k+1} \Delta_{\tilde{P}}}{2 n}$ after merger. Using the same argumentation as above we obtain $\frac{\sum_{\tilde{P}=1}^{k+1} \Delta_{\tilde{P}}}{2 k} \leq$ $\frac{\Delta_{P}+\Delta_{P+1}}{2}$. If $n>k$, then $\frac{\sum_{\tilde{P}=1}^{k+1} \Delta_{\tilde{P}}}{2 n}<\frac{\Delta_{P}+\Delta_{P+1}}{2}$ holds strictly. Therefore any politician in a singleton party is strictly worse off by merger as a chain. If there are at least two singleton parties in the chain, then this merger does not take place.

If there is exactly one independent candidate in the chain, say politician $i$ who constitutes party $P$, a politician in a party with two politicians in it receives a utility equal to $\frac{\Delta_{\max }}{2}$ before the merger and $\frac{\sum_{\tilde{P}=1}^{k+1} \Delta_{\tilde{P}}}{2(2 k-1)}$ after the merger. We have $\sum_{\tilde{P}=1}^{k+1} \Delta_{\tilde{P}} \leq(k+1) \Delta_{\max }$. And since $2 \leq k$, we know that $k+1 \leq 2 k-1$. Therefore $\sum_{\tilde{P}=1}^{k+1} \Delta_{\tilde{P}} \leq(2 k-1) \Delta_{\max }$. As a result $\frac{\sum_{\tilde{P}=1}^{k+1} \Delta_{\tilde{P}}}{2(2 k-1)} \leq \frac{\Delta_{\max }}{2}$. No politician from a party with two politicians can gain from this merger, so it does not take place.

If all parties have two politicians then each politician gets a utility equal to $\frac{\Delta_{\max }}{2}$ before the merger and $\frac{(k+1) \Delta_{\max }}{4 k}$ after the merger. The former is strictly larger since $k>1$. This merger does not take place.

After presenting why a chain merger will not be a beneficial deviation, we examine the grand coalition. If politicians of only one party, say $P$ gets worse off but the rest of the politicians Pareto improves, then this is a beneficial deviation. All parties except $P$ can switch their strategy to the position of that party. So $s$ is not a pf-restricted strong Nash equilibrium. If politicians from more than one party get worse off this deviation cannot take place. Then there is no room for improvement, hence $s$ is a pf-restricted strong Nash equilibrium.

Please note that the set of pf-restricted strong Nash equilibria under pro- 
portional rule is not empty. $k$ equidistant parties with 2 politicians in each except for one singleton party is pf-restricted strong Nash.

This refinement already improves upon strong Nash by making a nonempty selection. For plurality, it selects the party configurations with two or three parties which is supported by empirical observations, however the exact number of parties and the existence of an equilibrium depend on the exact number of politicians and is very responsive to small changes in the number which is not very realistic.

\section{Coalition-proof Nash Equilibrium}

The next alternative is another established notion in the literature, coalitionproof Nash equilibrium. It allows for multilateral deviations like strong Nash but also employs self-enforceability. Once a coalition makes a deviation, a subcoalition can make a further deviation. We start by defining a strictly beneficial deviation and credibility or self-enforceability.

Definition 6 (Strictly beneficial deviation). A strictly beneficial deviation from a strategy profile $s$ by a coalition $J \subseteq I$ is a strategy profile for coalition $J, s_{J}^{\prime} \in A^{|J|}$, such that $s_{j} \neq s_{j}^{\prime}$ for all $j \in J$, and $u_{j}\left(s_{J}^{\prime}, s_{-J}\right)>$ $u_{j}\left(s_{J}, s_{-J}\right)$ for all $j \in J$.

Definition 7 (Credible strictly beneficial deviation).

(i) A credible strictly beneficial deviation from a strategy profile $s$ by a politician $j \in I$ is a $s_{j}^{\prime} \in A$ such that $s_{j}^{\prime}$ is a strictly beneficial deviation from $s$ by politician $j$.

(ii) A credible strictly beneficial deviation from a strategy profile $s$ by a coalition $J \subseteq I$ such that $|J|>1$ is a strategy profile for coalition $J, s_{J}^{\prime} \in A^{|J|}$, such that $s_{J}^{\prime}$ is a defection from $s$ by coalition $J$ and there does not exist any subcoalition $J^{\prime} \subset J$ with a credible strictly beneficial deviation from $\left(s_{J}^{\prime}, s_{-J}\right)$.

Thus, a credible strictly beneficial deviation by a coalition is such that no further credible strictly beneficial deviation is possible by any proper subcoalition. 
Definition 8 (Coalition-Proof Nash Equilibrium). A coalition-proof Nash equilibrium is a strategy profile $s$ such that there is no credible strictly beneficial deviation from $s$ by any coalition $J \subseteq I$.

We kept the standard definition, therefore used a strictly beneficial deviation where all deviating agents must be strictly better off. It is also possible to define a stronger version of CPNE where one politician in the coalition needs to be strictly better off and the rest needs to be at least as good as before.

The next theorem shows that selection on basis of CPNE leads to the empty set under proportional rule.

Theorem 34. Let $|I| \geq 3$ and $\rho$ and be proportional rule. Then the set of CPNE is empty.

Proof. Consider an electoral competition with at least 3 politicians under proportional rule. Let us denote the maximum distance on the circle between any two adjacent parties by $\Delta_{\max }$.

Consider a coalition-proof Nash equilibrium strategy profile $s$, then clearly it is also a Nash equilibrium. Assume that there exists a party $P$ in $\mathcal{P}(s)$ with $|P|>1$. Theorem 25 tells us that $P$ is then a party with two politicians with a distance of $\Delta_{\max }$ to its both neighbors. If these politicians split and move in opposite directions until they come close enough to the adjacent parties, they can improve their payoffs. Now each of them receives a utility of $\frac{\Delta_{\max }}{2}$, if they deviate and have a distance of , for example, $\frac{\Delta_{\max }}{4}$ to their adjacent parties, each of them receives $\frac{7 \Delta_{\max }}{8}$. This is larger than $\frac{\Delta_{\max }}{2}$ and each of those politicians has an incentive to deviate further individually, hence this is a credible strictly beneficial deviation, a contradiction. Therefore $s$ only forms singleton parties.

Now let $s$ be a Nash equilibrium which only forms singleton parties. Since there are at least 3 politicians, there are at least 3 parties formed. Consider two adjacent parties moving in opposite directions. They both strictly improve their payoffs, hence a strictly beneficial deviation. Once this deviation takes place, any of those deviating politicians do not have an incentive to further deviate unilaterally, hence it is credible. 
For any Nash equilibrium we can construct a credible strictly beneficial deviation, therefore the set of CPNE under plurality rule is empty.

This equilibrium is very complex and we were not able to characterize the set of CPNE for pluralistic rule. The refinement for proportional rule is also too strong.

It is also possible to use a stronger definition of CPNE where a weakly beneficial deviation, which is a Pareto improvement of payoffs for the deviating politicians, replaces strictly beneficial deviation. Notice that the theorem and the proof stay the same even if we use the strong definition of a CPNE.

\section{Defection-proof Nash equilibrium}

As we discussed earlier, not all coalitional deviations are equally likely. Some politicians forming a coalition and switching all together to a new common agenda is the most commonly observed coalitional deviation in politics. Therefore, this time we alter the definition of a coalition-proof Nash equilibrium in the same way altered strong Nash before, when we defined pf-restricted strong Nash.

Definition 9 (Defection). A defection from a strategy profile $s$ by a coalition $J \subseteq I$ is a strategy profile for coalition $J, s_{J}^{\prime} \in A^{|J|}$, such that $s_{j} \neq s_{j}^{\prime}=a$ for all $j \in J$, and $u_{j}\left(s_{J}^{\prime}, s_{-J}\right)>u_{j}\left(s_{J}, s_{-J}\right)$ for all $j \in J$.

Clearly, a defection is a strictly beneficial deviation to the same agenda by a coalition of politicians.

Definition 10 (Credible Defection).

(i) A credible defection from a strategy profile $s$ by a politician $j \in I$ is a $s_{j}^{\prime} \in A$ such that $s_{j}^{\prime}$ is a defection from $s$ by politician $j$.

(ii) A credible defection from a strategy profile $s$ by a coalition $J \subseteq I$ such that $|J|>1$ is a strategy profile for coalition $J, s_{J}^{\prime} \in A^{|J|}$, such that $s_{J}^{\prime}$ is a defection from $s$ by coalition $J$ and there does not exist any subcoalition $J^{\prime} \subset J$ with a credible defection from $\left(s_{J}^{\prime}, s_{-J}\right)$. 
Thus, a credible defection by a coalition is such that no further credible defection is possible by any proper subcoalition.

Definition 11 (Defection-Proof Nash Equilibrium). A defection-proof Nash equilibrium is a strategy profile $s$ such that there is no credible defection from $s$ by any coalition $J \subseteq I$.

The following theorems characterize the set of DPNE under plurality and proportional rule.

Theorem 35. Under plurality rule, a strategy profile $s$ is a defection-proof Nash equilibrium if and only if the numbers of politicians in any two parties in $\mathcal{P}(s)$ differ by at most 1 and exactly one of the following holds:

(i) $|\mathcal{P}(s)|=2$ and $\min \left\{l^{s}(P), r^{s}(P)\right\}>\frac{1}{3}$ for some $P \in \mathcal{P}(s)$.

(ii) $|\mathcal{P}(s)|=3$ and all parties are equidistant from each other.

Theorem 36. Under proportional rule, $s$ is a defection-proof Nash equilibrium if and only if it is a Nash equilibrium.

Defection-proof Nash equilibrium prediction supports Duverger's observations by showing the tendencies for multipartyism under proportional rule, implying larger number of parties under plurality rule and that no more than three parties are generated under plurality rule.

\subsection{Summary}

In Chapter 2 we created a framework to operate on a circular political setting to observe the forces evident in strategic party formation. In this chapter we discuss what kind of equilibrium concept would fit this framework best, produce meaningful and explicit predictions.

Nash equilibrium, our first natural candidate equilibrium concept, for which only individual deviations are considered, gives us a too broad selection of outcomes hence lacks the predictive power. Strong Nash equilibrium, where any group deviation is taken into account, leads us to an empty set therefore it is not of much use here. 
On the other hand, not all moves are meaningful in a party-formation setting, thus we leave some out. Coordinated moves of politicians are expected to be made to the same political agenda. ${ }^{1}$ Strong Nash equilibrium is modified taking into account only this type of coalitional deviations and we came up with party formation-restricted Nash equilibrium. This promising candidate provided predictions that were overly sensitive to existence of one more politician or less running for the election, thus we deemed those predictions not robust.

Coalition-proof Nash equilibrium was another strong candidate controlling for further deviations from deviations and recently being influential in the literature. CPNE under plurality rule predicted no equilibrium and under proportional rule it was complicated to calculate the set of equilibria.

Finally, we combined the advantages of pf-restricted NE and CPNE to formulate defection -proof Nash equilibrium. This concept deals with deviations where deviators switch to the same political agenda and further deviations from deviations considered. It never predicts nonexistence of equilibrium, it makes more explicit and robust predictions. We conclude that in our strategic party formation setting defection-proof Nash equilibrium concept is a convenient tool and hopefully will help more researchers working in this field.

\footnotetext{
${ }^{1}$ This assumption was discussed further in Chapter 2.
} 



\section{Chapter 4}

\section{Overcoming Moral Hazard with Social Networks}

\subsection{Introduction}

Much recent literature regarding labor markets (e.g. Granovetter (1995), Bandeira et al. (2009), Beaman and Magruder (2012), Dustman et al. (2011), Munshi and Rosenzweig (2006)) has focused on the use of social networks in the workplace and how it affects various employer decisions such as recruitment and discipline within the firm. ${ }^{1}$ Recruitment decisions, in particular, have attracted a lot of interest. Starting with Montgomery (1991), a theoretical and empirical literature has developed trying to understand why referrals are used for recruitment rather than anonymous hiring. ${ }^{2}$ Empirically, there is increasing evidence that social networks matter much

\footnotetext{
${ }^{1}$ This chapter is based on a paper jointly written by Amrita Dhillon, Ronald Peeters and Ayşe Müge Yüksel, which has been released in CAGE Online Working Paper Series (number 2014/183).

${ }^{2}$ Kugler (2003), studying high skill industries in the United States, suggests that employers, through peer pressure from referrer to the new recruit, gain from a reduction in monitoring costs. Heath's (2011) research on garment factories in Bangladesh, finds that referrals serve as a disciplining device by employers. Dhillon et al. (2013) assume that social proximity encourages altruistic behavior between workers and referrers and provide evidence suggestive of using a referral system to avoid moral hazard as well.
} 
more than previously assumed. ${ }^{3}$

Social networks and connections thus appear to be vital for recruitment and the use of strong ties. Leveraging close ties with friends and family also seems to be a recurring pattern in blue collar jobs (Dhillon et al. (2013)). Yet empirical literature on the underlying reasons for the use of social networks in this regard is handicapped by the difficulties in separating the different possible reasons for their use. Disentangling various possible mechanisms for why referrals take place is important because the use of social networks might create more efficient outcomes or more inequitable outcomes than a direct hire depending on the exact mechanism underlying their use - e.g. Kramarz and Thesmar (2013) provide evidence that social networks were detrimental to corporate governance in a large sample of French public firms; Fafchamps and Moradi (2010) show that the use of referrals in the Ghanian army was detrimental to productivity. Whether these results hold more generally or if there are conditions under which we may expect networks to lead to some positive outcomes as well can only be answered by understanding the mechanisms underlying the use of referrals.

In this paper, we scrutinize whether social networks are used by employers to reduce employee moral hazard using a laboratory experiment. The advantage of the experiment relative to an empirical field study is that in the experimental setting we can rule out other explanations for the use of employee referrals such as the reduction of search costs, adverse selection and improving the match quality as potential explanations of referrals. We can also rule out explanations other than social proximity as the exact mechanism that helps to reduce worker moral hazard and we can control for referrer incentives directly. Finally, we can quantify the extent to which social networks matter in this setting. There are several novel features in our experiment. First, we use the social relationships between participants as they are in real-life, thereby incorporating a feature that is typical to field experiments. Our experiment can be considered a hybrid between a conventional lab experiment and a framed field experiment as it incorporates field context information with a standard subject pool of students (see

\footnotetext{
${ }^{3}$ For example, Munshi and Rosenzweig (2006) report that $70 \%$ of blue collar jobs in Dadar, Mumbai were found through referral (with a corresponding figure for white collar jobs of around 44\%).
} 
Harrison and List (2004)). Second, we test not just a part of the mechanism (whether workers put in more effort when they are socially connected to referrers) but also whether employers can anticipate this effect.

Our theoretical framework is described below and follows the model developed in Dhillon et al. (2013). An employer is faced with moral hazard in the workplace. She has the choice to hire anonymously through the spot market or delegate the hiring decision to a referrer who is socially connected to a set of potential workers. ${ }^{4}$ The advantage of the referrer is that the referrer and worker have some (directed) altruism towards each other via their social connection and the closer they are, the higher is the altruism. Altruism implies that the worker has some utility from exerting effort for the referrer which increases with the strength of the tie. This is the key ingredient that allows the employer to induce less opportunistic behavior by the worker. The closer the relationship between the two, the lower the chances that the worker will shirk. We use the laboratory experiment to test whether the key predictions of the model hold. First, the employer prefers to delegate the hiring decision to a referrer who potentially has a social connection to the workers. Second, the referrer should appoint a worker at a smaller social distance with a higher probability. Third, workers should be willing to work harder when they are socially closer to referrers. Finally, the mechanism through which the employer is able to prevent opportunistic behavior by employees is directed altruism on the part of referrers and workers who are socially connected to them.

The experiment assigns subjects three roles: employer, referrer, or workers. Decision making takes place over two stages. In the first stage, the employer decides whether to hire a worker via the spot market or to outsource the hiring to the referrer. When there is a successful outsourcing, the referrer is delegated the hiring decision. In either case, there is a choice between two workers who differ in the extent of social proximity to the referrer. In case the employer decides to hire via the spot market, in the second stage, one of the two workers will be randomly assigned to her. Each worker who is chosen (whether by referrer or spot market) is given a fixed budget of 30 units out of which she chooses how much to return to the

\footnotetext{
${ }^{4}$ It is assumed that she cannot choose her own friends, capturing the smaller network of the employer relative to all the employees in her company.
} 
relevant player (employer or referrer). This feature of the design captures moral hazard: the title "worker" suggests that the agent is expected to return some amount of the money she receives to the employer/referrer but neither the employer nor the referrer controls this decision. The setting is common knowledge to the four agents. In particular, the employer is aware of the workers and referrer being given information on their bilateral social relationships, but she does not receive this information.

We use two levels of social proximity. The first level of social proximity measures whether agents are directly connected or not. The second level of social proximity measures the strength of social ties via the number of friends the agents have in common (see Appendix 1 for the information that were provided on the choice screen). For our experiment we use information available via Facebook. So, for a referrer-worker pair social proximity is given by a pair $(f, c)$, where $f$ takes a value of 1 in case the referrer and worker are friends on Facebook and 0 otherwise and $c$ indicates the number of friends the referrer and the worker have in common on Facebook. If social networks are used to reduce moral hazard in the workplace then we hypothesize that: (1) The possibility that referrers can appoint close friends makes it tempting for the employers to hire via a referrer rather than via the spot market; (2) Referrers refer friends more often than non-friends and they refer the closer friends more often; and (3) Workers return on average more to referrers than to anonymous employers and return even more to socially closer referrers compared to any other referrer. Our results support these predictions unambiguously. In addition, we argue that directed altruism is the underlying mechanism for the worker returning more to friends and to close friends relative to others. We provide supportive evidence of the importance of directed altruism when social networks are salient.

This paper is related to the experimental literature on dictator games and trust games. The average returns by dictators in the literature are about a third of the pie (Engel (2011)) which is higher than the returns to the spot market that we observe. In the decision to return money to the referrer, there are three parties involved, there is only a one shot interaction and there are social networks involved. Our experimental design is able to pinpoint the two main motivations for giving on the part of workers as altruism and egalitarianism. Leider et al. (2009) use laboratory 
experiments to separate out various reasons for prosocial giving: baseline altruism, directed altruism and the prospect of future interaction. They find that directed altruism increases giving to friends by $52 \%$ relative to random strangers. In our paper, comparing giving in the spot market to giving to a friend with some common friends the figure is $54 \%$ which is reassuring for the external validity of the experiment.

Tausch et al. (2014) lists other experiments investigating the effects of social distance on giving behavior using dictator games: Charness and Gneezy (2008) shows an increase in returns when the subjects know the family name of the recipient, D'Excelle and Riedl (2010) provide evidence on the negative effect of larger social distance on giving behavior among female high school students and and Goeree et al. (2010) demonstrates the same effect with a group of household heads of a village in Nicaragua.

The paper is organized as follows: Section 4.2 introduces a simple framework to analyze the question, Section 4.3 discusses the experimental design, Section 4.4 provides the main results and Section 4.5 concludes with a discussion of the results.

\subsection{Conceptual framework}

There are 3 types of players: an employer, a referrer and $n$ workers. There are two stages. At the beginning of stage 1, the employer chooses how to hire a worker at a fixed and exogenously given wage $w$. The worker can be hired directly through the spot market or through referral. Once the worker is hired, in stage 2 she makes an effort decision $e \in[0, \bar{e}]$. It costs the worker $e$ to exert effort but she is paid $w$ regardless of effort. Effort is not observed at all by anyone other than the worker. ${ }^{5}$ We will assume however that the wage is fully enforceable, thus we capture a situation where worker moral hazard is the main concern. Hiring through the spot market is completely anonymous and the worker is chosen from among $n$

\footnotetext{
${ }^{5} \mathrm{~A}$ more plausible scenario would have some observability of effort, and the minimum level of effort may well be positive since workers cannot shirk too much without being caught. However, the results would not change qualitatively if we allowed for a positive level of observable effort.
} 
possible workers with a probability $\frac{1}{n} \cdot{ }^{6}$ If the worker is hired through the spot market, the employer makes a profit $\pi(e)$, which is increasing and concave in $e$. Alternatively, the employer can choose to delegate the hiring decision to someone within the firm (the referrer) who can use her social networks to hire a worker. The parameter $\rho$ captures the social ties between the referrer and a worker. We will assume that $\rho$ is uniformly distributed over $[0, \bar{\rho}]$ and that a higher $\rho$ signifies closer social ties between the referrer and a worker. Worker-referrer pairs are heterogeneous with respect to $\rho$. We assume that the referrer and the workers have social preferences that might be related to social proximity; hence including social proximity is important in this setting and our parameter $\rho$ captures this. If referral is used, the firm outsources the hiring decision to the referrer, at an asking price $p$. This price $p$ represents the stakes that the referee has in accepting the delegation. If the referrer is an employee in the firm and she hires a worker, the employer can hold her responsible for the decision. Ultimately the referrer stands to lose something if her referred worker puts in low effort (e.g. the referrer may lose the chance to refer again). In the model, this is captured by the price. Simultaneously, the referrer makes a bid $b$ for hiring the worker. If the referrer gains from having a socially connected worker in the workplace, she is willing to put in a positive bid. The bid captures the referrers expected benefit from referral. If the bid is higher than the price then a successful outsourcing takes place at the price $p$. This simply says that a referrer is willing to accept the hiring delegation if her gain (bid) is higher than the cost (price). If the bid is lower than the price the employer must hire through the spot market with a small cost of delay $c>0$. Subsequent to the outsourcing, the employer forfeits any returns from the worker's effort in the next stage. We make this assumption, because the gains to the employer from using referral is captured already in the price. The price represents the employer's profit from using referral vis-à-vis the spot market. The referrer makes a choice in her available network and hires someone at a social distance of $\rho$, therefore the referrer gets to choose $\rho$. The employer does not observe the choice of $\rho$ by the referrer nor does

\footnotetext{
${ }^{6}$ We ignore the possibility that the worker and the employer are connected. We capture a situation where the employer has too many vacancies to fill them with people she is connected to.
} 
she know $\bar{\rho}$, but knows that $\rho$ is uniformly distributed on an interval with lower bound 0. Similarly, the referrer when making her bid does not know $\bar{\rho}$, but knows that $\rho$ is uniformly distributed on an interval with lower bound 0 . This is because at this point, she has no information on which of her connections are available to approach for a job. Assume that $\bar{\rho} \in\{H, L\}$ and the corresponding probabilities are $q_{H}$ and $1-q_{H}$.

The referrer has non-monetary benefits $v(\rho)$ from choosing a worker who is connected to her; this captures non-monetary benefits from patronage or directed altruism towards the worker. We assume $v^{\prime}(\rho)>0, v^{\prime \prime}(\rho)<0$ and $v(0)=0$; so, if the worker is unknown to the agent selecting her, there are no patronage benefits. We also assume that patronage benefits only accrue if the choice of worker is not random. We will assume that returns from effort to the referrer, $g(e)$, are increasing and concave in effort. Thus the utility function of the referrer is denoted $U_{R}(\rho)=v(\rho)+g(e)$.

The worker's utility function is, in turn, given by $U=w-e+\alpha(0) \pi(e)$ when she is in the spot market and by $U=w-e+\alpha(\rho) U_{R}(\rho)$ when she is hired by the referrer. $\alpha$ denotes the strength of social preferences. We assume that $\alpha$ is increasing and convex in $\rho$ and $\alpha(0)>0$; the effect of social proximity on the effort decision is therefore positive and the baseline altruism is also positive. If a worker is chosen randomly, moreover, we will assume that her anticipated $\rho$ equals 0 ; this captures anonymous hiring.

Solving the game by backward induction: Suppose the worker is hired through the spot market. She chooses $e$ to maximize $w-e+\alpha(0) \pi(e)$. The first order conditions are given by $1=\alpha(0) \pi^{\prime}(e)$. By the concavity of $\pi(e)$, $e^{* *}$ denotes the optimal choice of $e$ by the worker in the spot market. Note that it is independent of $\rho$.

When referrals are used, then the worker chooses $e$ to maximize $U=$ $w-e+\alpha(\rho) U_{R}(\rho)$. Substituting for $U_{R}$ we get $U=w-e+\alpha(\rho)(v(\rho)+g(e))$. The first order conditions are given by $\alpha(\rho) g^{\prime}(e)=1$. Since $g(e)$ is concave, there is a unique maximizer to this problem denoted by $e^{*}(\rho)$. Notice that $\frac{\partial e^{*}}{\partial \rho}=-\frac{\alpha^{\prime}(\rho)}{[\alpha(\rho)]^{2} g^{\prime \prime}\left(e^{*}\right)}>0$ since $\alpha^{\prime}(\rho)>0$ and $g^{\prime \prime}(e)<0$; so $e^{*}$ is increasing in $\rho$. The referrer anticipates $e^{*}(\rho)$ and chooses $\rho$ to maximize $U_{R}(\rho)=g\left(e^{*}(\rho)\right)+v(\rho) . U_{R}(\rho)$ is increasing in $\rho$ since both $g(\cdot)$ and $v(\cdot)$ are concave while $e^{*}(\rho)$ is increasing. If $v(\rho)$ is sufficiently concave in $\rho$, then the referrer has a unique maximizer $\rho^{*}$ subject to the feasibility constraint 
$\rho^{*} \leq \bar{\rho}$. It is possible that $U_{R}$ is not concave but is convex or linear in $\rho$. In the latter two cases, there will always be a corner solution.

Recall that at the time of making the bid, the referrer does not know $\bar{\rho}$ but knows it's distribution, $\bar{\rho} \in\{H, L\}$. However we know that there is a unique maximizer $\rho^{*}$ subject to the feasibility constraint $\rho^{*} \leq \bar{\rho}$. When the constraint is not binding $\left(\rho^{*} \leq L\right)$ then regardless of $\bar{\rho}$ the referrer's expected utility at the time of the bid is simply $U_{R}\left(\rho^{*}\right)=g\left(e^{*}\left(\rho^{*}\right)\right)+v\left(\rho^{*}\right)$. When the constraint is binding for $L$ only $\left(H>\rho^{*}>L\right)$ then the expected utility is given by $E\left(U_{R}\left(\rho^{*}\right)\right)=q_{H} U_{R}\left(\rho^{*}\right)+\left(1-q_{H}\right) U_{R}(L)$. Finally, when the constraint is binding for both cases $\left(H<\rho^{*}\right)$ then we have $E\left(U_{R}\left(\rho^{*}\right)\right)=$ $U_{R}(H)$. Thus it is only when $H>\rho^{*}>L$ that we have different effort levels being chosen in equilibrium.

Since she only gets the referral if the bid is no less than the price and her bid does not affect the amount she pays (price), the referrer has a dominant strategy of setting her bid equal to the expected value of the referral. Thus her bid must be equal to $E\left(U_{R}\left(\rho^{*}\right)\right)$. It follows that the referrer's bid is increasing in $q_{H}$ whenever $H-L$ is sufficiently large and $L$ is small, i.e. $H>\rho^{*}>L$. On the other hand, if $H-L$ is small and $L$ is large, then the referrer's bid does not change with $q_{H}$.

The employer is willing to outsource for any price that satisfies $p \geq$ $\pi\left(e^{* *}\right)$. Her optimal price is $p^{*}=E\left(U_{R}\left(\rho^{*}\right)\right)$. A lower price would still suffice to guarantee that trade takes place, but does not maximize her returns from the price, while a higher price leads to no trade. Whenever the probability $q_{H}$ increases, both employers and referrers anticipate that returns will be higher whenever the difference $H-L$ is sufficiently large and the size of $L$ is small, and both the equilibrium bid and the price are higher in this case.

In order to compare $e^{*}$ and $e^{* *}$, assume that $g(e)=\pi(e)$, since there is no reason to expect that effort chosen by the worker in one case is more or less efficacious than the other. Then it is easy to see that $e^{*}>e^{* *}$. To summarize, our discussion shows that (1) When $H-L$ is sufficiently large and $L$ is not too high then the bid and the price increase as $q_{H}$ increases or as the likelihood of having a close friend available increases. This prediction implies that the employer, who does not have the choice to hire friends, would prefer to delegate the decision to the referrer who does 
have the choice of hiring friends as she can extract a price greater than the expected returns from the spot market. $(2) e^{*}(\rho)$ is increasing in $\rho$; and (3) $e^{*}>e^{* *}$.

These predictions of the solution are the basis for the hypotheses stated earlier in the introduction: (1) Employers prefer to hire via a referrer rather than via the spot market; (2) Referrers refer friends more often than nonfriends and they refer the closer friends more often (both because of patronage benefits and because they anticipate higher effort from friends); (3) Workers return on average more to referrers than to anonymous employers, they return even more to socially closer referrers compared to any other referrer. In addition, we argue that directed altruism is the underlying mechanism for the worker returning more to friends and to close friends relative to others.

\subsection{The experiment}

We conducted our referral-recruitment experiment in a laboratory using the social relationships between participants as they are in "real-life", thereby incorporating a feature that is typical to field experiments. The experimental design follows the model closely.

\section{Design}

In our setting, as in the model, there is an employer, a referrer and two workers. Decision making takes place over two stages and the decisions made determine how a fixed surplus of 30 units is divided among the four agents. We interpret the 30 units as the fixed wages discussed in the model.

In the first stage, the employer decides whether to hire a worker via the spot market or to outsource the hiring to the referrer. In case of the latter, she is asked to set the price to be paid to her by the referrer in case of a successful outsourcing. Simultaneously to the employer's decision making, the referrer has to announce the maximum price she is willing to pay to take over the task to hire a worker. In case the price charged by the employer does not exceed the maximum price the referrer is willing to pay, there is a successful outsourcing and the referrer is given the hiring task 
for the price charged; otherwise, the employer and referrer disagree on the price, and the employer is sent to the spot market.

In case the employer decides to hire via the spot market or has failed in her attempt to outsource the hiring task, in the second stage, one of the two workers will be assigned to her randomly. Without knowing whether they are assigned the job or not, both workers have to indicate how much of the 30 units they return to the employer if they are assigned the job. ${ }^{7}$ In this case, the payment to the employer equals the return of the worker who is assigned the job (minus 0.5 in case of a failure to outsource), the worker who is assigned the job receives 30 minus her return, the other worker and the referrer both receive nothing. ${ }^{8}$

In case of a successful outsourcing, in the second stage, the referrer has to choose which of the two workers to hire. Simultaneously, both workers have to indicate how much of the 30 units they return to the referrer if they are assigned the job. As the referrer has no information on the returns of the workers, she cannot condition her choice among them on such information. The only distinguishing information about the worker that the referrer has, is about her social proximity to each of the workers. Moreover, she knows that the workers know their social proximity to her, while deciding how much to return conditional on being hired. Workers do not have information on the social distance between the other worker and the referrer. In this case, the payment to the employer equals the price, the payment to the referrer equals the return by the hired worker minus the price to be paid to the employee, the hired worker receives 30 minus her return, and the other worker receives nothing.

We use two levels of social proximity. The first level of social proximity regards agents being directly connected or not. The second level of social proximity regards the number of friends agents have in common. For our experiment we use the information available via Facebook. So, for a referrer-worker pair social proximity is given by a pair $(f, c)$, where $f$ takes a value of 1 in case the referrer and worker are friends on Facebook and

\footnotetext{
${ }^{7}$ This small change helps us to increase the number of observations without deviating from the spirit of the model as each worker has a probability of being chosen for the job.

${ }^{8}$ The small penalty of 0.5 for the employer in case of a failure to outsource is introduced to make charging a reasonable price when trying to outsource incentive-compatible.
} 
0 otherwise and $c$ indicates the number of friends the referrer and worker have in common on Facebook. ${ }^{9}$ Notice that this distance is symmetric.

The setting is common knowledge to the four agents. In particular, the employer is aware of the workers and referrer being given information on their bilateral social relationships, but she does not receive this information nor does she ever learn about it later. As in the theory, the employer only has a prior on the level of friendships in the pool. Employers also never learn how much is returned to the referrer by the workers.

\section{Procedures}

For each experimental session in the lab we created two listings in Orsee (Greiner (2004)). For one of the listings three-fourth of the participants signed up; for the other the remaining one-fourth. The participants in the larger group were playing the roles of employer and workers; those in the smaller group that of referrer. The two groups were kept physically separated throughout the entire experimental session, such that referrers never saw whom they could be interacting with or could have been interacting with during the session. So, despite information on real-life social relations being provided throughout the session, we maintained the highest degree of anonymity possible.

Prior to a session, all participants in this session were asked (via email) to accept a link that would allow us (the experimenters) to retrieve information on their social relations on Facebook. Consent to share this information was a precondition to enroll in the experiment. The only information we gathered regarded the bilateral connection between any two participants in the session as summarized by their direct relation (first level of social proximity) and the number of common friends (second level of social proximity).

In total we ran six experimental sessions. All sessions took place in

\footnotetext{
${ }^{9}$ Our social proximity measure is two-dimensional, however modeling $\rho$ in one dimension saves complication and unnecessary assumptions while it still captures that different social proximity levels are comparable. We do not wish to find an exact mapping between the two, but rather make straightforward comparisons such as being a friend is closer than not being a friend for the same or unknown number of common friends, and when you are not a friend having more friends in common is strengthening the social ties.
} 
December 2012 in the BEElab, the experimental laboratory of Maastricht University. Instructions and comprehension questions were paper-based (see Appendix 1); the decision stage was computerized using zTree (Fischbacher (2007)). Four sessions were run with 24 participants; the other two sessions we had to run with 20 participants due to a low show-up. So, in total 136 students participated.

One-fourth of the participants in a session was assigned the role of employer, one-fourth that of referrer, and the remaining half were given the role of workers. These roles were kept fixed throughout the entire experimental session. The participants interacted in a sequence of 30 rounds, where every round anew they were regrouped with three other participants, such that each group consisted of one employer, one referrer and two workers. So, six groups were formed every round in four sessions and five groups in the other two sessions. In the first 15 rounds only first level social proximity information was given to the referrer-worker pairs; in the second 15 rounds first and second level social proximity information was given. After each round of play, participants received feedback on decisions as long as they were payoff-relevant. This means that employers received information on whether a deal was made (i.e., whether the bid was below the price) and knew the return from the selected worker in case hiring occurred via the spot market, referrers received information on whether a deal was made, in case a deal was made they learned the price and the return of the worker whom they selected, and workers only learned whether they were selected or not.

Payments accumulated over all rounds and were handed out immediately after the session. For each unit of payoff in the experiment, participants received 0.04 Euros. In addition, they received a show-up fee of 3 Euros, and an initial endowment of 3 Euros in experimental currency units to avoid any bankruptcy (for the referrers).

\subsection{Results}

This section consists of four subsections. After having provided descriptive information on the friendship relations among the participants, we deal consecutively with the three types of decisions in the experiment. First we 
deal with the outsourcing decisions by the employers, where we investigate if employers prefer the spot market or to outsource the hiring decision to a referrer, how often a deal is made and how bids and prices change over time. Thereafter, we consider the hiring decisions referrers make, and how (relative) social proximity to the workers affects these. Finally, we investigate the returns by the workers and how these depend on whether being hired via the spot market or via the referrer and, in case of the latter, on the social distance to the referrer.

\section{Descriptives}

Our aim in the experiment is to examine the effect of friendship on referrer decisions and worker returns while avoiding establishing such relationships superficially in the lab and use real-life relations instead. In order to obtain many friendship relations of different levels while keeping the anonymity, we restricted the subject profile to undergraduate students at the School of Business and Economics.

Table 4.1 summarizes the social proximity between participants prior to the role division. Among the 1,484 possible different pairs, 46 direct friendship relations existed. ${ }^{10}$ In 680 possible pairs the two respective participants had at least one friend in common. The average number of common friends over all possible pairs is 1.71, and this number is 4.18 when averaging over the pairs with at least one common friend.

\begin{tabular}{|c|c|c|c|c|}
\hline & \multicolumn{2}{|r|}{$c>0$} & \multicolumn{2}{|r|}{$c=0$} \\
\hline & 45 & $(3.03 \%)$ & & $(0.07 \%)$ \\
\hline$f=0$ & 635 & $(42.79 \%)$ & 803 & $(54.11 \%)$ \\
\hline
\end{tabular}

Table 4.1: Friendship relations among all possible pairs of participants prior to the role division.

Table 4.2 summarizes the same information for all possible referrerworker pairs after the roles had been decided. After the role division, there were 388 different possible referrer-worker pairs; among those there are

\footnotetext{
${ }^{10}$ These unbalanced numbers are due to the use of real-life relations data obtained through Facebook that were not subject to experimental manipulations.
} 
10 direct friendship relations. 186 possible referrer-worker pairs had at least one friend in common. The average number of common friends over all possible referrer-worker pairs is 2.14, and this number is 4.47 when restricting attention to the pairs with positive number of common friends.

\begin{tabular}{|c|c|c|}
\hline & $c>0$ & $c=0$ \\
\hline$f=1$ & $10 \quad(2.58 \%)$ & $0 \quad(0.00 \%)$ \\
\hline$f=0$ & $176 \quad(45.36 \%)$ & $202(52.06 \%)$ \\
\hline
\end{tabular}

Table 4.2: Friendship relations among all possible referrer-worker pairs.

Referrers only make hiring decisions in rounds where a deal between the employer and the referrer has been established. It is only in these cases that the friendship relation of the referrer with the two workers matters. Out of the 68 participants who were assigned the role of a worker, only 9 of them ever matched, in a successful outsourcing, with a referrer with whom she shares a direct friendship relation. Such a matching, in a successful outsourcing, between a worker and a referrer who is her friend occurred in total 31 times over all 30 rounds.

\section{Outsourcing by employers}

Employers have two options to choose from, either to hire from the spot market directly or to outsource the hiring to a referrer. If employers expect workers to return more to the referrer, then they may opt for outsourcing to exploit this difference. This comes only at a slight risk due to the small amount employer needs to pay if her offer is declined. We find that, despite the small cost in case of a failure to set a deal, employers prefer to hire via the referrer rather than via the spot market. Over 30 rounds 34 employers made in total 1,020 hiring decisions, and in 831 of them (81\%) a deal is offered to a referrer. ${ }^{11}$ This preference to outsource is rather robust over time. $^{12}$

\footnotetext{
${ }^{11}$ Percentages by which employers opted for outsourcing averaged by session are 90 , $75,89,76,85$ and 75 .

${ }^{12}$ Over the six consecutive bundles of five rounds, all sessions combined, the respective percentages by which employers opted for outsourcing are $73,87,77,82,85$ and 85 .
} 
In case the employer makes the attempt to outsource the hiring by offering a deal to the referrer, whether a deal is reached depends on the referrer's bid (which is her revealed maximum price that she is willing to pay to take over the responsibility to hire). Out of the 1,020 hiring decisions, 397 $(39 \%)$ resulted in a deal between the employer and the referrer. Figure 4.1 shows the percentage of successful outsourcings with respect to all hiring decisions for each session. In order to better picture a possible time-trend, the graph presents moving averages over clusters of 10 rounds.

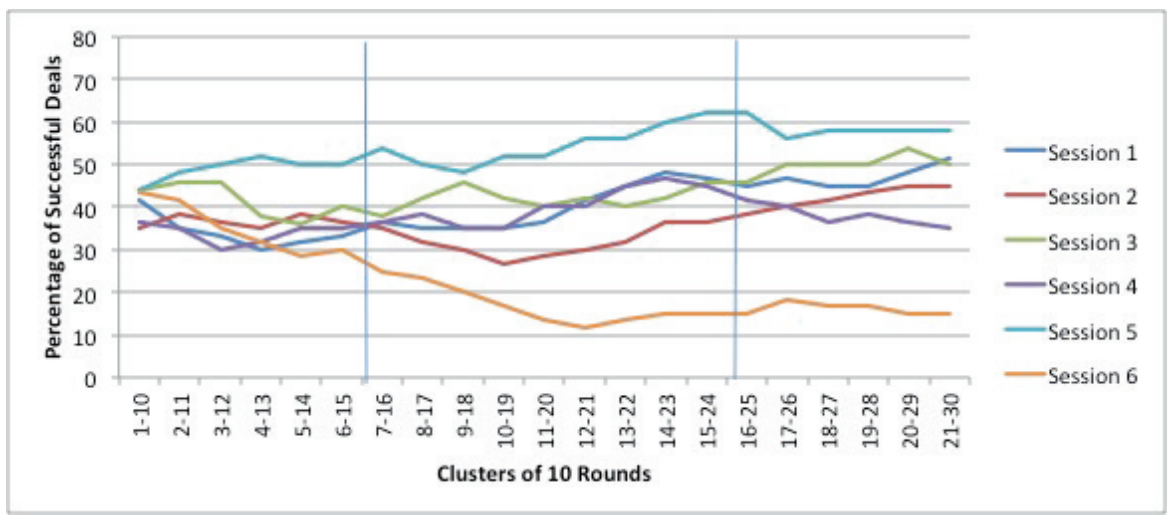

Figure 4.1: Moving averages over clusters of 10 rounds of the percentage of successful outsourcings per session.

The figure suggests that heterogeneity across sessions grows over time. Before the first vertical line, the graph is based only on the first fifteen rounds where subjects have no information about the second level of social proximity. After the second vertical line, it is only based on the last fifteen rounds, where referrers and workers receive information also on the second level of social proximity. Between the two lines, the data is based on a mixture of these two informational variations.

Between the first and the second fifteen rounds, where subjects do not know and do know about the number of common friends respectively, there is no significant difference between gross percentage of deals ( $p=0.2489$; two-sided Wilcoxon signed-rank test on session averages). When allowing for a learning effect and considering only the last five rounds under the two different information conditions, we find a significant increase in the 
number of deals $(p=0.0345)$.

Whether a deal is established depends on the prices and the bids. Figure 4.2 shows the prices and bids by rounds averaged over sessions. ${ }^{13}$ The average price is based on the instances where employers decide to outsource the hiring; so, given that employers try to outsource in $81 \%$ of the time, the average price in each round is based on 28 employer decisions on average. As referrers do not know about the employers' intention to outsource at the moment of setting their bids, the average bid in each round is based on 34 referrer decisions. We see that both bids and prices are declining over time and follow each other closely.

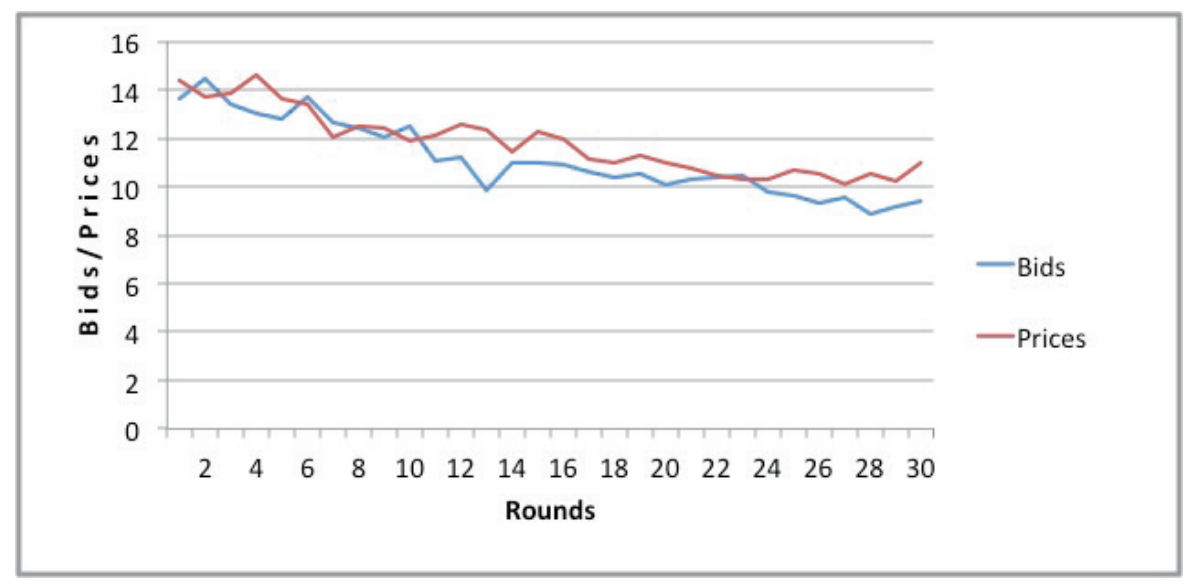

Figure 4.2: Average referrer bids and employer prices over time.

Referrers are expected to adjust their bids to the returns they receive from the workers. In case the returns are below the bid such an adjustment prevents potential losses; in case returns are above it such an adjustment increases the opportunity to make a profit. Figure 4.3 shows the trend of bids and returns to the referrer. The graph suggests that the (relatively) low returns to the referrers drive down the bids referrers make. Still, referrers bid above the returns from the workers in almost all rounds, suggesting that there are positive non-monetary benefits to hiring friends.

Employers, on the other hand, are expected to adjust their prices to

\footnotetext{
${ }^{13}$ Graphs of the individual sessions do not look much different.
} 


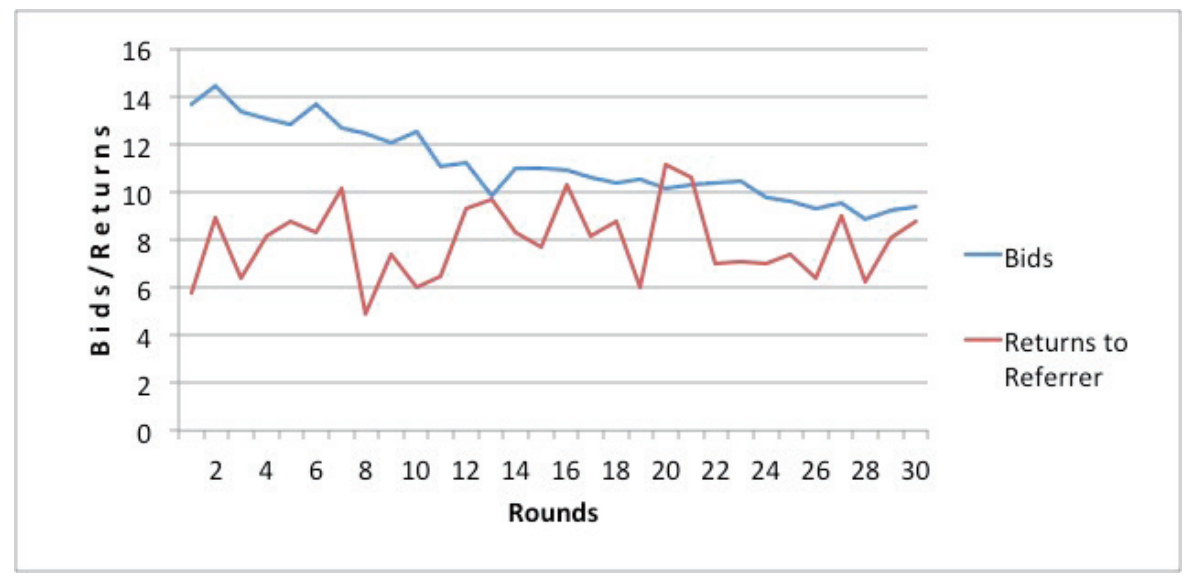

Figure 4.3: Average referrer bids and worker returns to referrers over time.

the bids from referrers and returns they receive from the spot market. Figure 4.4 shows the trend of prices and returns from the spot market to the employer. Although employers keep prices far above spot market returns, both quantities show a decreasing trend. Overall, prices seem to be more responsive to bids (recall Figure 4.2) than to spot market returns. The high prices charged lead us to think that employers do not choose to outsource in order to involve referrers in the sharing of the surplus, but mainly for the sake of self-interest. ${ }^{14}$

\section{Hiring by referrer}

When there is a successful outsourcing, a referrer is randomly matched with two workers, either of whom may be a friend or not. Before deciding whom of the two workers to hire, the referrer receives information on her social proximity to each of them. If this choice is between a friend and a nonfriend, we find that referrers choose more often for the friend: 7 referrers were together 29 times in the position to choose between a friend and a nonfriend and 22 times they decided to hire the friend (this is significant at

\footnotetext{
${ }^{14}$ Note here that all employers in our data set have experienced at least one spot market return in the first five rounds and 32 out of the 34 employers even experienced two or more spot market returns throughout the first five rounds.
} 


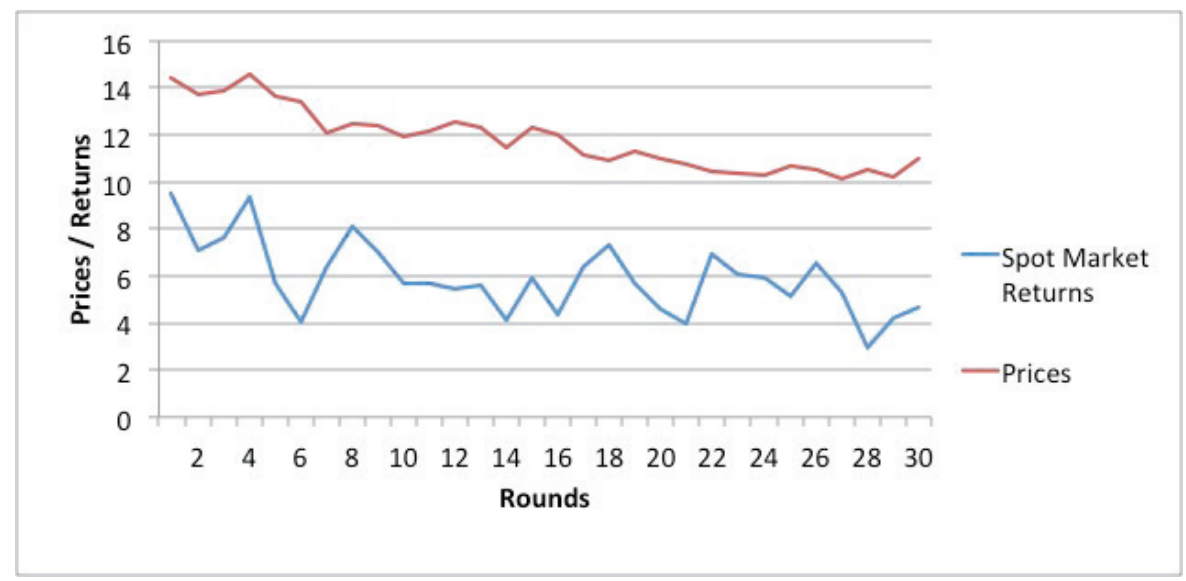

Figure 4.4: Average employer prices and worker returns to employer via spot market over time.

$p=0.0208$; two-sided Wilcoxon signed-rank test on individual percentages; note here that different referrers in the same session never directly interact, hence we believe we can safely regard their decisions as independent).

It is not only the direct friendship relation, but also the number of common friends that plays a role in the hiring decision of the referrer. We find that when a worker has more friends in common with the referrer, she is more likely to be chosen. In the last fifteen rounds, where referrers have information on both levels of social proximity, referrers hire the worker with the higher number of common friends in 72.79 percent of the 136 occasions (This is significant at $p=0.0277$ for the test based on session percentages). Restricting attention to those 119 cases where the referrer is matched with two non-friend workers, this percentage is $73.11(p=0.0277)$. If this choice is between a non-friend worker with zero common friends and a non-friend with a positive number of common friends, this percentage is 73.86 in the 88 cases $(p=0.0269)$; when both non-friend workers share at least one common friend, this percentage is $70.97 \%$ in the 31 cases $(p=0.0796)$.

We randomly label one of the two workers as worker 1 . Table 4.3 presents the results of a regression with the probability that worker 1 is selected as dependent variable and the main explanatory variable is how many more friends she has in common with the referrer compared to the 


\begin{tabular}{|c|c|c|c|}
\hline & $\begin{array}{c}\text { All data } \\
\text { (1) }\end{array}$ & $\begin{array}{c}c_{i}>0 \\
\text { and } \\
c_{j}=0 \\
(2)\end{array}$ & $\begin{array}{c}c_{1}>0 \\
\text { and } \\
c_{2}>0 \\
(3)\end{array}$ \\
\hline$c_{1}-c_{2}$ & $\begin{array}{l}0.02^{* * *} \\
(0.01)\end{array}$ & $\begin{array}{c}0.02^{* *} \\
(0.01)\end{array}$ & $\begin{array}{c}0.01 \\
(0.01)\end{array}$ \\
\hline Round & $\begin{array}{c}0.01 \\
(0.01)\end{array}$ & $\begin{array}{c}0.01 \\
(0.01)\end{array}$ & $\begin{array}{c}0.01 \\
(0.02)\end{array}$ \\
\hline Constant & $\begin{array}{c}0.40^{*} \\
(0.20)\end{array}$ & $\begin{array}{c}0.21 \\
(0.25)\end{array}$ & $\begin{array}{c}0.13 \\
(0.51)\end{array}$ \\
\hline Observations & 194 & 88 & 44 \\
\hline R-squared & 0.05 & 0.08 & 0.05 \\
\hline
\end{tabular}

Table 4.3: Probability that worker 1 is selected. Both workers are not friends of the referrer. $c_{1}$ and $c_{2}$ stand for the number of friends the referrer has in common with worker 1 and worker 2 respectively. Robust standard errors (clustered on individual level) in parentheses. ${ }^{* * *} p<0.01,{ }^{* *} p<0.05,{ }^{*} p<0.1$.

other worker. ${ }^{15}$ As information on the number of common friend is only given in the last fifteen rounds, only these rounds are considered in the regression. The table presents the result for three different selections of the data: (1) when both workers are non-friends (i.e. neither of the workers is friends with the referrer), (2) when both workers are non-friends and one of them shares a positive number of common friends while the other one does not have any friend in common, and (3) when both workers are non-friends and both have at least one friend in common with the referrer.

The results in the table indicate that referrers generally prefer to hire the worker who has more friends in common with her, which supports the earlier findings on basis of the nonparametric tests. If both workers have at least one friend in common with the referrer, this result is not significant, unlike in the earlier nonparametric tests. This is likely to be due to the limited number of observations in which a referrer is matched with two

\footnotetext{
${ }^{15}$ In this regression, we avoid comparing two levels of social proximity if both dimensions are unequal, since such a comparison needs further information about how people compare these levels. Therefore we chose to run the regressions for friends and nonfriends separately, not in interaction. Due to limited number of friends data, only the regression for non-friends is presented.
} 
workers who are both non-friends and share an unequal positive number of common friends with her.

\section{Returns by workers}

Table 4.4 provides the average returns by workers to referrers and in the spot market for each sessions. We see that the overall average return to a referrer is significantly higher than the average return in spot market ( $p=0.0747$; Wilcoxon signed-rank on session level). Possible explanations for this difference include reciprocity, egalitarian taste, or social proximity. A detailed description and discussion of these motives is provided in the final section.

\begin{tabular}{|c|c|c|c|c|c|c|}
\hline \multirow[b]{2}{*}{ Session } & \multicolumn{3}{|c|}{ To referrer } & \multicolumn{3}{|c|}{ To spot market } \\
\hline & $1-30$ & $1-15$ & $16-30$ & $1-30$ & $1-15$ & $16-30$ \\
\hline 1 & 7.10 & 7.02 & 7.15 & 4.20 & 4.84 & 3.35 \\
\hline 2 & 10.02 & 9.55 & 10.43 & 7.39 & 7.22 & 7.58 \\
\hline 3 & 5.18 & 5.79 & 4.65 & 5.93 & 6.18 & 5.65 \\
\hline 4 & 8.58 & 9.17 & 8.04 & 7.59 & 7.86 & 7.30 \\
\hline 5 & 8.50 & 8.41 & 8.57 & 4.46 & 5.12 & 3.52 \\
\hline 6 & 4.40 & 4.33 & 4.54 & 4.14 & 4.28 & 4.02 \\
\hline All & 7.48 & 7.41 & 7.55 & 5.65 & 5.94 & 5.34 \\
\hline
\end{tabular}

Table 4.4: Average returns by workers in the different informational conditions over different clusters of rounds.

In order to be able to disentangle the importance of social proximity, we categorize the possible relationship situations between a worker and a referrer into five different type-classes, based on first and second levels of social proximity. Type $(f=1, c>0)$ refers to workers who are matched with a referrer that she has a friendship relation with and with whom she has a positive number of friends in common. As there were no workerreferrer pairs who had a friendship relation but no common friends in our experiment, the class of Type $(f=1, c=0)$ workers is empty. Type $(f=$ $0, c>0)$ refers to workers who are matched with a referrer that she has no friendship relation with, but does have a positive number of friends in common. Finally, Type $(f=0, c=0)$ refers to workers who have maximal 
social distance in the pool of participants captured in our data. These four types are only relevant once a successful outsourcing of the hiring process is reached. Moreover, full type information is revealed to relevant parties only in the last fifteen rounds; in the first fifteen rounds the first two typeclasses and the latter two are not distinguishable. The last type is the spot market, which refers to a worker who is not matched with a referrer but hired by the employer via the spot market. Table 4.5 summarizes the average returns of the different types when all workers have full information about their type (last fifteen rounds), with, in parentheses, the standard deviation and number of observations. ${ }^{16}$

\begin{tabular}{|c|c|c|c|c|}
\hline & & $c>0$ & & $c=0$ \\
\hline$f=1$ & 8.24 & $(7.31,17)$ & & $(-, 0)$ \\
\hline$f=0$ & 9.33 & $(6.73,184)$ & 6.00 & $(6.36,221)$ \\
\hline
\end{tabular}

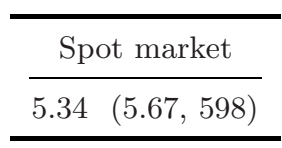

Table 4.5: Average returns by workers in the different informational conditions.

Table 4.6 present the result of an OLS and Tobit regression of the returns from the workers in the last fifteen rounds on the types just described relative to the omitted spot market type. The regression results indicate that workers do not return significantly more to a non-friend referrer without common friends than they return in the spot market; as such these referrers are considered total strangers and treated as such. Unlike for workers of type $(f=1, c>0)$, this lack of significance is not due to a poor number of observations (see Table 4.5). However, when the referrer is not a total stranger to the worker, as expressed by a nonzero number of common friends, the worker returns a significantly higher amount than in the spot market.

Further, the difference between types $(f=0, c>0)$ and $(f=0, c=0)$ is significant $(p=0.0023)$. We argue that social proximity is the main driver for this difference. If the main driver of positive returns by the worker was

\footnotetext{
${ }^{16}$ To compare these returns to reciprocal behavior in related famous game situations: the average return in trust games is usually about $37 \%$ of the investment (Johnson and Mislin (2011)) which would suggest a return of 11.1 at the spot market and the average return in dictator games is about $28 \%$ of the endowment (Engel (2011)) which corresponds to a return of 8.49 at the spot market.
} 


\begin{tabular}{|c|c|c|}
\hline & OLS & Tobit \\
\hline Type $(f=1, c>0)$ & $\begin{array}{c}2.99 \\
(3.02)\end{array}$ & $\begin{array}{c}2.56 \\
(4.24)\end{array}$ \\
\hline Type $(f=0, c>0)$ & $\begin{array}{l}4.00^{* * *} \\
(0.95)\end{array}$ & $\begin{array}{l}4.81^{* * *} \\
(1.16)\end{array}$ \\
\hline Type $(f=0, c=0)$ & $\begin{array}{c}0.66 \\
(0.85)\end{array}$ & $\begin{array}{c}0.55 \\
(1.16)\end{array}$ \\
\hline Round & $\begin{array}{c}-0.07^{* *} \\
(0.03)\end{array}$ & $\begin{array}{c}-0.09^{* * *} \\
(0.03)\end{array}$ \\
\hline Constant & $\begin{array}{l}6.93^{* * *} \\
(0.93)\end{array}$ & $\begin{array}{l}6.11^{* * *} \\
(1.19)\end{array}$ \\
\hline $\begin{array}{l}\text { Observations } \\
\text { R-squared }\end{array}$ & $\begin{array}{c}1,020 \\
0.06\end{array}$ & 1,020 \\
\hline
\end{tabular}

Table 4.6: Returns by the various types of workers. Robust standard errors (clustered on individual level) in parentheses. ${ }^{* * *} p<0.01,{ }^{* *} p<0.05,{ }^{*} p<0.1$.

purely returning a favor regardless of the social ties, then one would expect also a higher return by a worker of type $(f=0, c=0)$ since the favor is the same. Likewise, if the main driver of positive returns was egalitarian preferences, a higher return would be expected for type $(f=0, c=0)$ as well, just because of the awareness that the surplus is divided among three, rather than two, individuals.

Table 4.7 presents the results of the regressions that aim to unravel how the effect of friendship on returns interacts with the number of common friends. We see from the regressions over the data of the first fifteen rounds, that workers return more to a non-friend referrer than they return in the spot market. Notice here that in these first fifteen rounds no information is given on the number of friends workers have in common with the referrer and, hence, they cannot assess perfectly their social proximity to the referrer.

There is no significant difference in returns to friend and non-friend referrers ( $p=0.9421$ in OLS; $p=0.9197$ in Tobit). Like earlier, this lack of significance may be attributed to the low number of direct friendship relations among worker-referrer pairs. In total there are only nine workers who are ever matched with a referrer who is a friend. If we only consider the average return by these nine workers to referrers who are friends and 


\begin{tabular}{|c|c|c|c|c|}
\hline & \multicolumn{2}{|c|}{ Rounds 1-15 } & \multicolumn{2}{|c|}{ Rounds $16-30$} \\
\hline & OLS & Tobit & OLS & Tobit \\
\hline Type $(f=1, \bullet)$ & $\begin{array}{c}1.60 \\
(2.52)\end{array}$ & $\begin{array}{c}1.41 \\
(3.20)\end{array}$ & $\begin{array}{l}10.50^{* * *} \\
(3.19)\end{array}$ & $\begin{array}{l}14.57^{* * *} \\
(4.50)\end{array}$ \\
\hline Type $(f=0, \bullet)$ & $\begin{array}{c}1.42^{* *} \\
(0.54)\end{array}$ & $\begin{array}{l}1.74^{* * *} \\
(0.63)\end{array}$ & $\begin{array}{c}1.59^{* *} \\
(0.77)\end{array}$ & $\begin{array}{c}1.82^{*} \\
(0.99)\end{array}$ \\
\hline Type $(f=1, \bullet) \times c$ & & & $\begin{array}{c}-0.23^{* * *} \\
(0.05)\end{array}$ & $\begin{array}{c}-0.44^{* * *} \\
(0.11)\end{array}$ \\
\hline Type $(f=0, \bullet) \times c$ & & & $\begin{array}{l}0.38^{* * *} \\
(0.10)\end{array}$ & $\begin{array}{l}0.46^{* * *} \\
(0.13)\end{array}$ \\
\hline Round & $\begin{array}{c}-0.11^{* *} \\
(0.04)\end{array}$ & $\begin{array}{c}-0.13^{* *} \\
(0.05)\end{array}$ & $\begin{array}{c}-0.06^{* *} \\
(0.03)\end{array}$ & $\begin{array}{c}-0.08^{* *} \\
(0.03)\end{array}$ \\
\hline Constant & $\begin{array}{l}6.85^{* * *} \\
(0.66)\end{array}$ & $\begin{array}{l}6.18^{* * *} \\
(0.84)\end{array}$ & $\begin{array}{l}6.78^{* * *} \\
(0.92)\end{array}$ & $\begin{array}{l}5.87^{* * *} \\
(1.18)\end{array}$ \\
\hline $\begin{array}{l}\text { Observations } \\
\text { R-squared }\end{array}$ & $\begin{array}{c}1,020 \\
0.02\end{array}$ & 1,020 & $\begin{array}{c}1,020 \\
0.06\end{array}$ & 1,020 \\
\hline
\end{tabular}

Table 4.7: Relation of returns to the number of common friends. Robust standard errors (clustered on individual level) in parentheses. ${ }^{* * *} p<0.01,{ }^{* *} p<0.05$, ${ }^{*} p<0.1$.

referrers who are non-friends, we still do not find any significant difference between returns to friends in non-friends by means of a nonparametric test $(p=0.2123) .^{17}$

In the regressions over the last fifteen rounds we see that the return to non-friends is increasing in the number of common friends, while to friends the returns are decreasing in this number. The numbers in the table indicate that up to about fifteen common friends more is returned to a friend and beyond this number more is returned to a non-friend. Though, the negative impact of the number of common friend on returns to friends should be taken with some reservation. During the last fifteen rounds, only seven workers have been matched with a referrer who is a friend (in 17 decision situations). Those seven individuals mostly adopt a fixed return to friends and none of them was ever matched with at least two different

\footnotetext{
${ }^{17}$ Notice that there is no direct interaction between workers nor they learn about each other's payoffs or relations to the referrers, hence we can safely treat their returns as independent.
} 
referrers that are friends and with whom a different number of common friends is shared. A decent within-subject analysis is therefore not possible.

\subsection{Discussion and conclusion}

In this section we discuss the main findings and the motives behind the behavior of the participants. Firstly, we are interested in understanding why workers return anything at all when they are in a position to keep the full surplus to themselves. Possible explanations are reciprocity, egalitarian preferences, baseline altruism, directed altruism, or motivation by future prospects.

A reciprocal individual responds to actions she perceives to be kind in a kind manner and to actions she perceives to be hostile in a hostile manner. When a referrer hires a worker, this may be perceived by the worker as a kind gesture as the referrer actively chooses one worker over the other while risking a loss by placing a bid. The worker may want to return this favor. Instead, in the spot market, the employer does not risk a loss and the worker is not selected by decision; reciprocity should not prevail in this information state.

Egalitarian preferences of workers is another possible explanation. An egalitarian individual attempts to produce equality even at a cost to herself (Dawes et al. (2007)). A perfectly egalitarian individual will return 15 in the spot market (the endowment is only shared between the worker and the employer), and return 20 if she is hired by a referrer (the endowment is shared between the worker, the referrer and the employer). Even if we do not observe this perfectly egalitarian behavior, some workers may simply return more to the referrer to be relatively more equal.

Leider et al. (2009) mention three more possible motives. First, baseline altruism, which entails being nice unconditionally (even to strangers). Although the presence of this factor cannot be rejected, it cannot explain the differences in workers' returns across the different informational conditions. Second, directed altruism, which entails being nicer to socially closer people. According to this notion different types should return differently and returns should be responsive to the number of common friends. Third, motivation by future prospects. Since decisions take place in anonymity, 
workers are rematched to referrers every round anew or hiring may take place via the spot market, there is no scope for building a reputation relationships during the session and this factor appears irrelevant.

Hence, only three of the five factors have potential to be of explanatory value for behavior observed throughout our experiment: reciprocity, egalitarianism and directed altruism.

Average returns to referrers are found to be higher than average returns in the spot market. If this difference were to be attributed to purely reciprocating a favor or egalitarianism, then we should also see a difference between average returns to non-friend referrers with zero common friends and average returns in the spot market. However, we did not find such a difference (and this is not due to a lack of observations). This supports the earlier claim that social proximity is the main driving force behind observed differences.

However, in the first fifteen rounds (when workers do not know their exact social proximity to the referrer), workers return more to a non-friend referrer than they return in the spot market. This can be explained by reciprocity and egalitarian preferences. It appears that in the absence of exact social proximity information, workers base their decisions on one of these other factors.

Additional support of the role of social proximity is found in the hiring decisions by the referrers as well as the outsourcing decision of employers. Employers prefer to outsource in the vast majority of cases, possibly anticipating higher returns from workers when they are socially more connected to the referrer relative to herself, although this anticipation can also occur due to reciprocity or egalitarian concerns. Referrers tend to hire friends over non-friends, and tend to hire workers with more common friends when neither of them is a direct friend. Moreover, workers return significantly more when they have more friends in common with a non-friend referrer.

In conclusion, social ties generally induce higher returns and hiring decisions on basis of social ties lead to a selection of the more returning worker. The decisions to outsource and to exploit the social ties of referrers to workers by the employers therefore leads to an increase in the joint payoff of the employer and the referrer and justifies the use of job referrals. 



\section{Chapter 5}

\section{Workplace Referrals and Gift Exchange}

\section{$5.1 \quad$ Introduction}

The notion that firms can exploit the social preferences of their employees to increase profits is not new. ${ }^{1}$ Akerlof (1982) theoretically shows that it is useful for a firm to give "gifts" to employees which increase goodwill towards the firm and enhance worker productivity. Extensive experimental literature has provided rich insights into worker-firm relations (see e.g. Fehr, Kirchsteiger, and Riedl (1993), a survey by Casoria and Riedl (2013) and another survey by Fehr, Goette, and Zehnder (2009)).

When the hiring decision is outsourced to a referrer, the referrer acts as an intermediary between the employer and the worker. In the previous chapter we showed that the decision to outsource recruitment to the referrer is thus based on exploiting an asymmetric social relationship. In this chapter, we are particularly interested in a different form of asymmetry: even when the worker and the referrer are unconnected socially, it may still be worthwhile for the employer to outsource the recruitment (or work allocation) decision to a referrer who can be identified as the person who personally offers the job to a specific worker, rather than the worker being

\footnotetext{
${ }^{1}$ This chapter is based on a paper jointly written by Amrita Dhillon, Ronald Peeters and Ayşe Müge Yüksel.
} 
chosen as part of an anonymous recruitment drive (e.g. online). ${ }^{2}$

We examine the intricacies of the gift exchange mechanism in the setting of an employer who is seeking to recruit workers, or induce employees to work harder. In particular we test how the ability to attribute volitional choice in the offer of a job to the worker can increase positive reciprocity even in the absence of social networks connecting the referrer and the worker. We show that the simple ability to be able to pinpoint who is responsible for the offer is sufficient to induce better behavior from the worker.

We run a laboratory experiment where participants are randomly allotted to the role of employer, referrer and worker. Employers can choose to hire someone via anonymous hiring (a lottery) or to outsource the decision on hiring to a referrer in the firm. The employer posts a price at which she is willing to outsource the hiring decision to the referrer. Simultaneously, the referrer posts a bid for the outsourcing. When the bid is higher than the price, a successful outsourcing takes place at the price posted by the employer. The wage to the potential workers is fixed throughout the experiment. However, the worker only receives the wage if she is hired, whether anonymously or through a referral. We vary the information available to workers: some worker are uninformed, they do not know whether they are randomly selected or whether they are selected through referrer choice. Others are informed that they are selected by a referrer. Employer-workerreferrer sets are matched randomly every round so there is no possibility of repeated interaction. In the last 15 rounds the informed workers also get information on the price paid by the referrer to the employer.

We present a novel motivation for the use of workplace referrals in labor markets: the attribution of a favor backed by good intentions to the referrer increases the chances that the worker will reciprocate positively for the benefit of the firm. Since the employer hires a larger number of workers, the causal attribution of an offer of employment as a gift is less likely to occur for an employer while if the choice of worker is outsourced to a referrer in the firm, the perception of a volitional choice increases. We find that

\footnotetext{
${ }^{2}$ Charness (2004) shows that the mechanism wages are determined, either randomly or by volitional choice, has an impact on the effort levels chosen by the workers. We investigate a similar effect of the hiring mechanism on the workers' effort levels
} 
there is a difference of 4 percentage points in the returns of workers who are able to causally attribute a specific person as being responsible for the recruitment decision. Even if the wage offered is the same, we find that the worker reciprocates positively to the outsourcing. Egalitarian motives are other incentives we investigate that support the higher effort levels chosen by the worker when she knows she is hired through referral.

The experimental design is very similar to our previous experiment described in Chapter 4. We ask similar questions about the motivations of employers, referrers and workers. However this time we are not investigating the effect of social ties but rather the ability to attribute the hiring decision to one person. One addition of this experiment is that here we also have the opportunity to test if the workers are influenced by the stakes for the referrers. The price the referrer needs to pay to be able to outsource the hiring is revealed to some workers in the second half of the experiment. The last major difference is the personality test we asked participants to fill in at the end of the experiment. This personality test enables us to pinpoint the characteristics of those people who exert more effort when they know that hiring is outsourced to a referrer. This gives us suggestions about what might be the motivation behind such behavior.

\subsection{The experiment}

We conducted our referral-recruitment experiment in a laboratory where workers are in different information states about the hiring process. We are mainly interested in learning how and why these information states about the hiring process shape workers' returns and thus the decision to whether outsource the hiring or not. The experimental design follows the model closely.

\section{Design}

In our setting, there is an employer, a referrer and two workers. Decision making takes place over two stages and how a fixed surplus of 30 units is divided among the four agents will be determined.

In the first stage, the employer decides whether to hire a worker via 
the spot market or to outsource the hiring to the referrer. In case she tries to outsource the hiring, she is asked to set the price to be paid to her by the referrer in case of a successful outsourcing. Simultaneously, the referrer needs to announce the maximum price she is willing to pay to accept the task to hire a worker. In case the price charged by the employer does not exceed the maximum price the referrer is willing to pay, there is a successful outsourcing and the referrer is given the task of hiring for the price charged. If the employer and referrer disagree on the price, the employer is sent to the spot market.

In case the employer opts for hiring via the spot market or has failed in her attempt to outsource the hiring task, in the second stage, one of the two workers will be randomly assigned to her. Before learning whether they are assigned the job or not, both workers have to indicate how much of the 30 units they return to the employer if they are assigned the job. ${ }^{3}$ At this point workers do not even know that they are in the spot market, therefore we call them both uninformed workers. In this case, the payment to the employer equals the return of the worker that is randomly assigned the job (minus 0.5 in case of a failure to outsource), the worker that is assigned the job receives 30 units minus her return, the other worker and the referrer both receive nothing. ${ }^{4}$

In case of a successful outsourcing, in the second stage, the referrer has to hire one of the two workers. One of them is the informed worker who knows that hiring is outsourced to a referrer; the other is the uninformed worker who does not know if she is at spot market or if she is returning to a referrer (see Appendix 2 for the choice screen). Workers are randomly assigned to referrers and to the roles of informed or uninformed workers every round. Simultaneously, both workers have to indicate how much of the 30 units they return to the referrer if they are assigned the job. As the referrer has no information on the returns of the workers, she cannot condition her choice among them on such information. The only distinguishing characteristic of the worker from referrer's viewpoint, is the informational

\footnotetext{
${ }^{3}$ This small change helps us to increase the number of observations without deviating from the spirit of the model.

${ }^{4}$ The small penalty of 0.5 for the employer in case of a failure to outsource is introduced to incentivize charging a reasonable price when trying to outsource.
} 
difference between the workers. In this case, the payment to the employer equals the price, the payment to the referrer equals the return by the hired worker minus the price to be paid to the employee, the hired worker receives 30 minus her return, and the other worker receives nothing.

Every round, each worker is assigned as an informed or an uninformed worker. When a worker is assigned as an informed worker, she knows that the hiring process is outsourced to a referrer. In addition, in the last 15 rounds of the experiment, the exact price at which the referrer and the employer settled the deal is revealed to the informed worker before she makes her decision on how much of the 30 units to return. Uninformed workers do not know in any round if there is a deal between the employer and the referrer, neither has she any price information. The setting is common knowledge to the four agents. At the end of each session, only the own payoff relevant information is revealed to the participants; for example, the employer never learns how much is returned to the referrer by the workers.

\section{Procedures}

For each experimental session we created a session in Orsee (Greiner (2003)) and recruited among all students from our participant pool. In total we ran six sessions. All sessions took place in June 2012 in the BEElab, the experimental laboratory of Maastricht University. Instructions and comprehension questions were paper-based (see Appendix 2); the decision stage was computerized using zTree (Fischbacher (2007)). Six sessions were run with 24 participants, so in total 144 students participated.

Half of the participants in each session were assigned the role of workers, one-fourth that of referrer, and the remaining one-fourth were given the role of employers. These roles were kept fixed throughout the experimental session. The participants interacted for 30 rounds, where every round anew they were regrouped with three other participants, such that each group consisted of one employer, one referrer and two workers. So, six groups were randomly composed in each round.

In the first 15 rounds workers did not know about the price the referrer will pay to the employer when a deal is made; in the second 15 rounds price 
information was given to the informed workers. After each round of play, participants received feedback on decisions as long as they were payoffrelevant. This means that employers received information on whether a deal was made (i.e., whether the bid was below the price) and knew the return from the selected worker in case hiring occurred via the spot market, referrers received information on whether a deal was made and in case a deal was made, they learned the price and the return of the worker whom they selected, and workers only learned whether they were selected or not. Payments accumulated over all rounds and were handed out immediately after the session. For each unit of payoff in the experiment, participants received 0.04 Euros. In addition, they received a show-up fee of 3 Euros, and an initial endowment of 3 Euros in experimental currency units to avoid any bankruptcy (for the referrers). Participants earned 14.94 Euros on average.

After the experiment, participants were asked to complete a questionnaire. The first part of this questionnaire asks about age, sex and nationality. The second part of the questionnaire is a self-report test (retrieved from Rensselaer Polytechnic Institute website) on the "Big Five" personality dimensions based on Goldberg (1993). We used only those questions that concern three personality traits that are relevant for our purposes. Answers to the questions in the questionnaire were not subject to any monetary incentives.

\section{Hypotheses}

In summary, our main claim is that job referrals as opposed to anonymous hiring works as a gift exchange and workers reciprocate being hired by exerting higher levels of effort. Additionally, we claim that egalitarian motives are prevalent. In our experimental setting we test the following hypotheses: (1) The employer, who does not have the choice to hire informed workers, would prefer to outsource the decision to the referrer who does have the choice of hiring informed workers (hiring directly) as she can extract a price greater than the expected returns from the spot market. (2) Informed workers exert more effort than uninformed workers do at all times. (3) When informed workers observe the price the referrer needs to 
pay to the employer, this should not lead to a change in behavior as the referrer's good intentions were already known. Reciprocal behavior of the worker should not respond to the observed price, as the risk the referrer takes increases with the price she agrees to pay but the gift given to the worker does not. (4) If egalitarianism is a prevalent concern among the workers then they should respond negatively (by decreasing returns) to prices above 10, since this deal will sure disrupt a possible equal outcome for all.

\subsection{Results}

In total 144 persons participated. Participants were undergraduate and graduate students of Maastricht University from various studies, though mainly students from the economics and business programmes participated. With $53 \%$ of the participants being females, the sex ratio was quite balanced. Of the 144 participants, 36 participants were assigned the role of employer, 36 the role of referrer and 72 the role of a worker.

This section consists of three subsections. First we deal with the outsourcing decisions and deals between employers and referrers, where we investigate if employers prefer the spot market or outsourcing the hiring decision to a referrer, how often a deal is made and how bids and prices change over time. Thereafter, we consider the hiring decisions referrers make. We explore if a worker is more likely to be chosen by a referrer if the referrer knows that this worker is aware of the returned units to flow to the referrer. Finally, we investigate the amount workers return in the two different information states. An explanation of the workers behavior, partly on basis of the personal traits elicited in the post-experimental questionnaire, is relegated to the discussion.

\section{Outsourcing by employers}

Employers have to decide either to hire from the spot market directly or to outsource the hiring to a referrer. If employers expect workers to return more to the referrer, then they may opt for outsourcing to exploit this difference. This comes only at a slight cost, because there is a small amount 
employer needs to pay if her offer is declined. Despite this small cost in case of a failure, employers still prefer to hire via the referrer rather than via the spot market. Over 30 rounds, 36 employers made in total 1,080 hiring decisions, and in 786 of them $(73 \%)$ a deal is offered to a referrer. ${ }^{5}$ This preference to outsource is robust over time. ${ }^{6}$

In case the employer makes the attempt to outsource the hiring by offering a deal to the referrer, whether a deal is reached depends on the referrer's bid (which is her revealed maximum price that she is willing to pay to take over the responsibility to hire). Out of 1,080 hiring decisions, 345 $(32 \%)$ resulted in a deal between the employer and the referrer. ${ }^{7}$ Figure 5.1 shows the percentage of successful outsourcings with respect to all hiring decisions for each session. Moving average of clusters of 10 rounds are presented here to picture possible trends over time better.

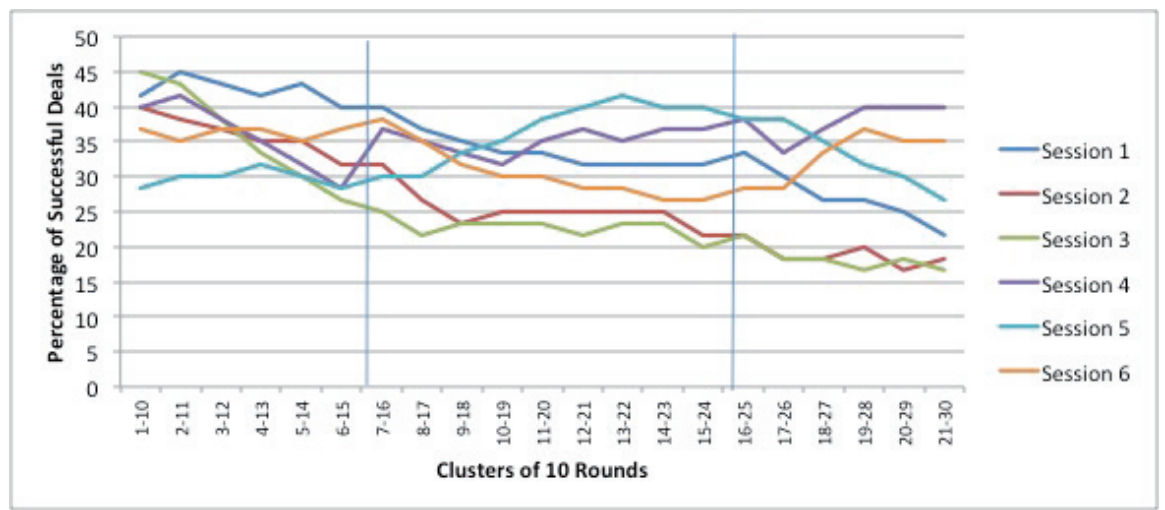

Figure 5.1: Moving averages over clusters of 10 rounds of the percentage of successful outsourcings per session.

The figure indicates that heterogeneity across sessions grows over time. Before the first vertical line, the graph refers to the first fifteen rounds

\footnotetext{
${ }^{5}$ Percentages by which employers opted for outsourcing averaged by session are 66 , $75,73,85,68$ and 70 .

${ }^{6}$ Over the six consecutive bundles of five rounds the respective percentages by which employers opted for outsourcing are 73, 79, 70, 71, 73 and 71 .

${ }^{7}$ Notice that this ratio is less than the accepted deals in the previous chapter since here the referrers does not have the incentive of possibly hiring a friend.
} 
where informed workers have no information about the price of the deal; that is, workers do not know how much the referrer has to return to the employer. After the second vertical line, it refers to the last fifteen rounds, where informed workers possess information on the price that the referrer has to transfer to the employer. Between the two lines, data from these two informational variations are mixed.

Between first and second fifteen rounds, where workers do not know and know about the price of the deal respectively, there is no significant difference between gross percentage of deals ( $p=0.1159$; two-sided Wilcoxon signed-rank test on session averages).

Whether a deal is established depends on the prices and the bids. Figure 5.2 shows the prices and bids by rounds averaged over all six sessions. ${ }^{8}$ The average price is based on the instances where employers decide to outsource the hiring; so, given that employers try to outsource in $73 \%$ of the time, the average price in each round is based on 26 employer decisions on average. As referrers do not know about the employers' intention to outsource at the moment of setting their bids, the average bid in each round is based on all referrers' decisions. We see that bids are declining over time, but a bit slower in the second half of the session. Prices are decreasing in the first half and settle down afterwards. As such, in the second half, employer prices are not responsive to referrer bids.

Adjusting their bids to the returns they receive from the workers would benefit the referrers. In case the returns are above the bid such an adjustment increases the opportunity to make a profit, and in case the returns are below it such an adjustment prevent potential losses. Figure 5.3 shows the trend of referrers' bids and the returns to the referrer. The graph suggests that indeed referrers' bids may be responding to the (relatively) low returns of the workers.

Employers, on the other hand, are expected to adjust their prices to the referrers bids and the spot market returns. Figure 5.4 shows the trend of prices and returns from the spot market to the employer over 30 rounds. Although employer prices seem to follow the decreasing trend in returns in the first half, in the second half of the experiment employers discontinue translating the further fall in returns into a further fall in their prices. In

\footnotetext{
${ }^{8}$ Graphs of the individual sessions do not look much different.
} 


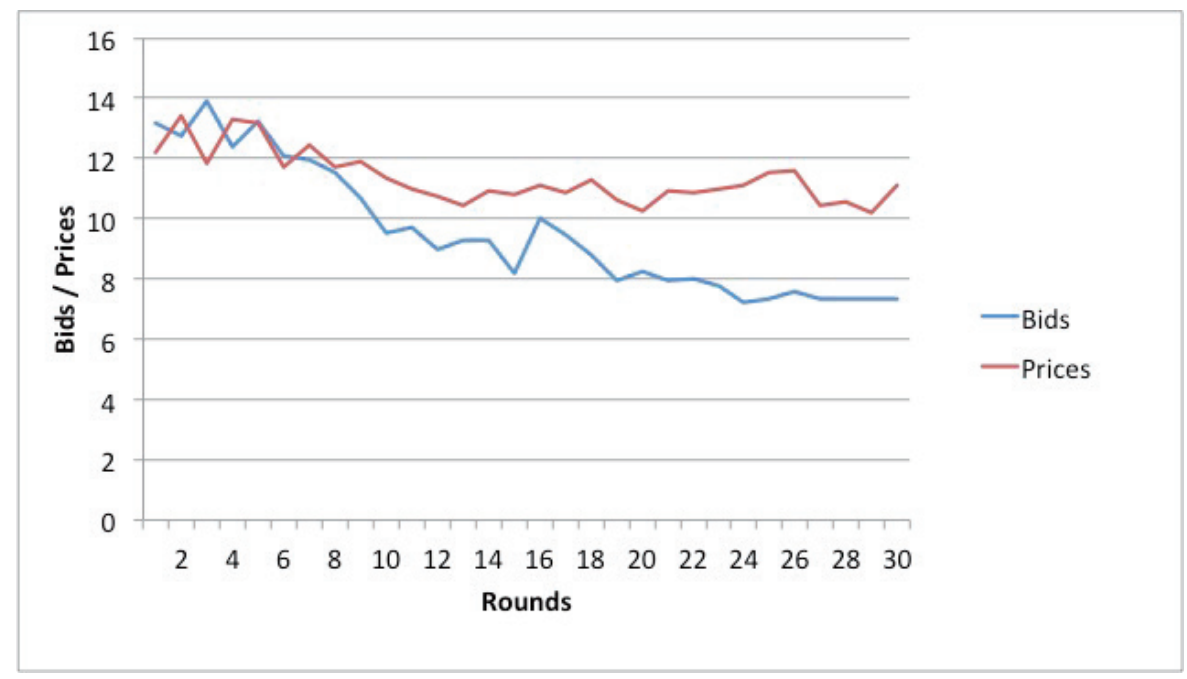

Figure 5.2: Average referrer bids and employer prices over time.

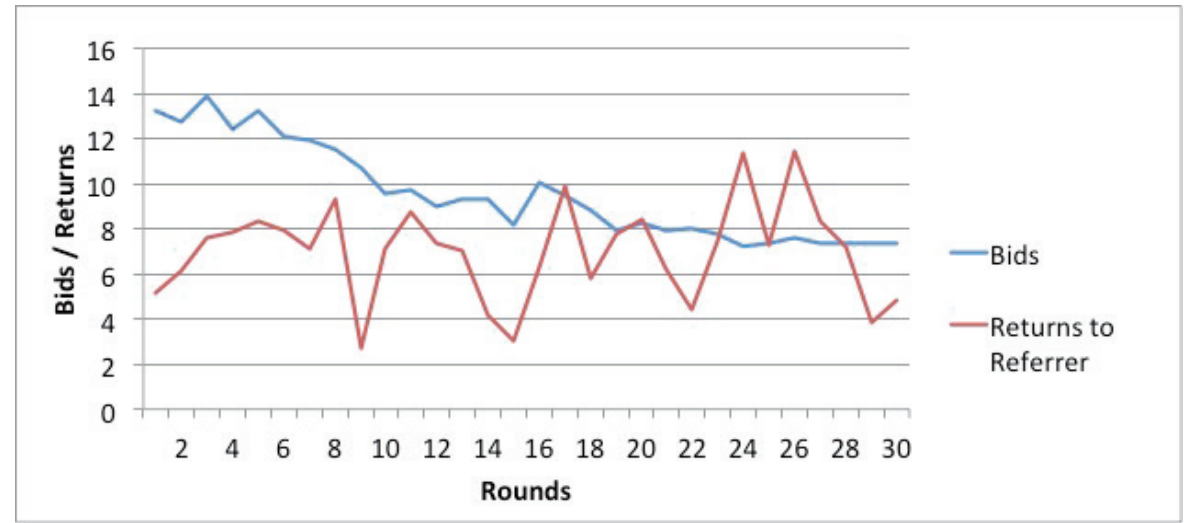

Figure 5.3: Average referrer bids and worker returns to referrers over time.

any case, employers keeping the prices far above spot market returns. This leads us to think that employers do not choose to outsource in order to share the surplus with the referrers, but mainly due to self-interest. ${ }^{9}$

\footnotetext{
${ }^{9}$ Note here that all employers in our data set have experienced at least one spot market return in the first five rounds and 33 out of the 36 employers even experienced two or more spot market returns throughout the first five rounds.
} 


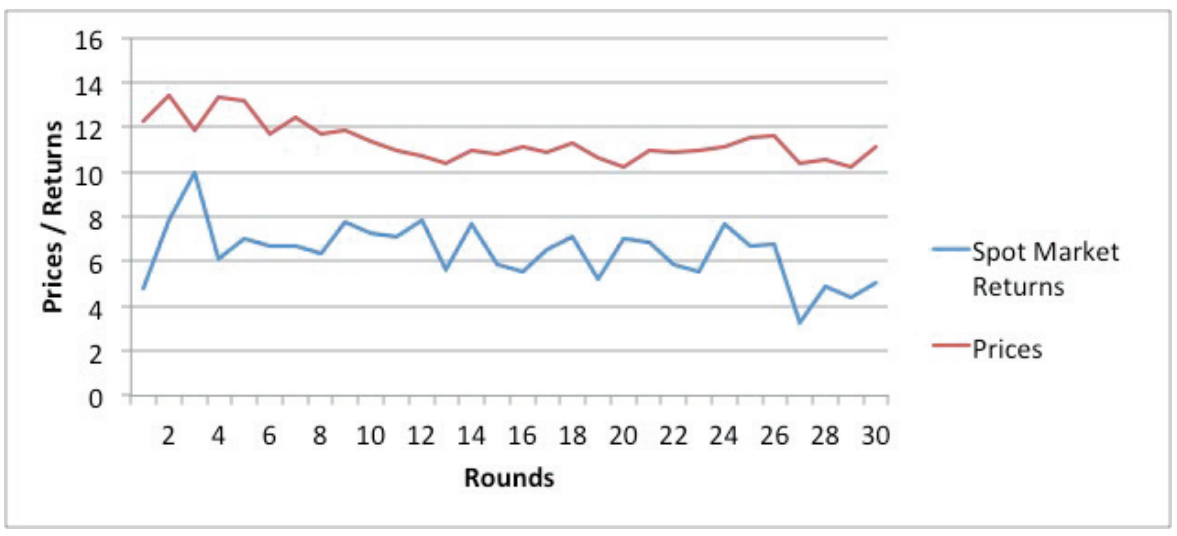

Figure 5.4: Average employer prices and worker returns to employer via spot market over time.

\section{Hiring by referrer}

When there is a successful outsourcing, a referrer is randomly matched with two workers. One of them is an informed worker who knows that the selection whom to hire is a deliberate decision by a referrer (who in exchange pays a price to an employer). The other worker does not know if a referrer is involved in the hiring process or if she is in a spot market; this worker will be referred to as an uninformed worker. The referrer makes a decision which of the two workers to hire.

In our experiment, referrers choose slightly more often the informed worker. In the 345 decision instances, the 36 referrers choose 189 times for the informed worker. Despite the fraction of such choices being just $55 \%$, this revealed preference for the informed worker is significant at $p=0.0277$ (Wilcoxon sign rank test on session percentages). For each referrer we calculate the ratio of instances in which the informed worker was chosen. Of the 36 referrers, 21 hire an informed worker more often than an uninformed worker and 10 choose more often for the uninformed worker. As there is no direct interaction between the referrers, we may consider the calculated ratios as independent observations and find that they are significantly different from fifty percent $(p=0.0229)$. So, referrers are not choosing randomly but deliberately choose informed workers more often. 
Finally, we explore eventual differences between referrers' choices in the first and second halves of the experiment. We find that the choice ratios for the informed worker in the second half of the experiment are not significantly different to those in the first half of the experiment $(p=0.6735$; two-sided Wilcoxon signed-rank test on choice ratios by every individual referrer). It can be claimed that the referrers are not anticipating a change in any direction in worker returns from first to the second half.

\section{Returns by workers}

Figure 5.5 presents the cumulative distribution of the returns by informed and uninformed workers. The figure shows that the returns by uninformed workers are first-order stochastically dominated by those of the informed workers.

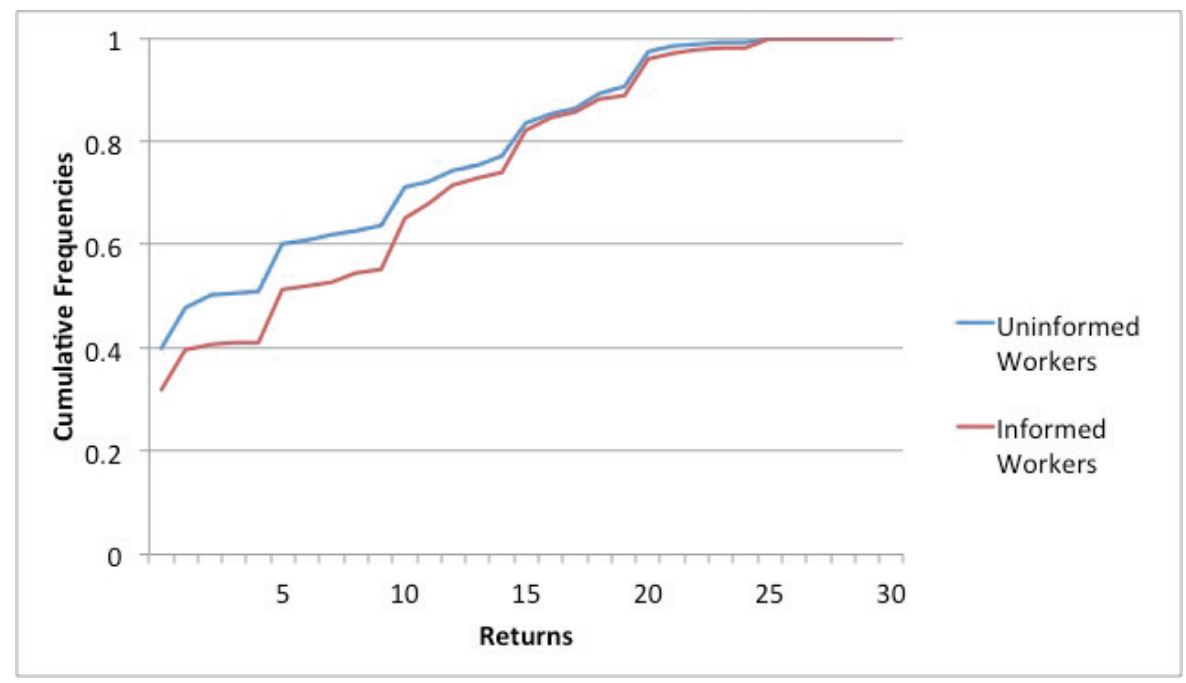

Figure 5.5: Cumulative distribution of returns by informed and uninformed workers.

Table 5.1 presents the average returns by the workers in the different information states during different phases in the experiment.

Overall, informed workers return on average 7.73 (25.77\% of the surplus) 


\begin{tabular}{lcccc}
\hline Worker & & $1-30$ & $1-15$ & $16-30$ \\
\cline { 1 - 2 } \cline { 4 - 5 } Informed & & 7.73 & 7.28 & 8.27 \\
Uninformed & & $(7.60,345)$ & $(7.08,187)$ & $(8.16,158)$ \\
& & $(7.50,1815)$ & $(7.43,893)$ & $(7.57,922)$ \\
\hline
\end{tabular}

Table 5.1: Average returns by workers in the different information states over different clusters of rounds. Standard deviations and the number of observations are presented in parentheses.

while uninformed workers return on average $6.55(21.83 \%) .{ }^{10}$ The numbers in the table indicate that during all prominent phases of the experiment the returns of the informed workers dominate those of the uniformed workers. To test for the significance of this finding, for each participant with the role of a worker we calculate the average amount she returned when in each of the two information states. ${ }^{11}$ On basis of the resulting 72 pairs of returns, we find that workers return significantly more when they are sure that a referrer is involved ( $p=0.0005$; two-sided Wilcoxon signed-rank). This effect is also present when restricting to any of the other two phases as captured in the table $(p=0.0089, p=0.0013$ resp.).

For informed workers, we find that revelation of the price referrers are at stake for has no significant impact on their returns by comparing their average returns in the first half to that in the second half by nonparametric tests on individual level $(p=0.2618)$ or on session level $(p=0.4631)$. No change is observed in the uninformed workers' returns either by comparing their average returns in both halves by nonparametric tests on individual

\footnotetext{
${ }^{10}$ To compare these returns to reciprocal behavior in related game settings: the average return in trust games is usually about $37 \%$ of the investment, which would suggest a return of 11.1 (Johnson and Mislin (2011)); the average return in dictator games is about $28 \%$ of the endowment, which corresponds to a return of 8.49 (Engel (2011)). However, in our experiment a worker is either sure the surplus is divided among three agents or she is unsure whether it is divided among two or three agents. Therefore a direct comparison of the results in our experiment to these related game settings have to be digested with care.

${ }^{11}$ As workers do not directly interact (their payoffs are strategically independent) and never get feedback on each others returns, their decisions can safely be treated as independent.
} 
level $(p=0.6352)$ or on session level $(p=0.1159)$. We conclude that the workers are not responsive to revelation of prices but it still needs to be investigated if informed workers are sensitive to the revealed price itself.

Figure 5.6 shows the averages prices that informed workers observed and their returns. We see that the average returns has a decreasing trend during the first half (which is also seen in the table) and an increasing trend during the second half coming closer to the average price. Due to the little amount of variation in average prices (for every round the average price of all sessions is between 9.00 and 10.34), it is not visible whether returns respond to prices.

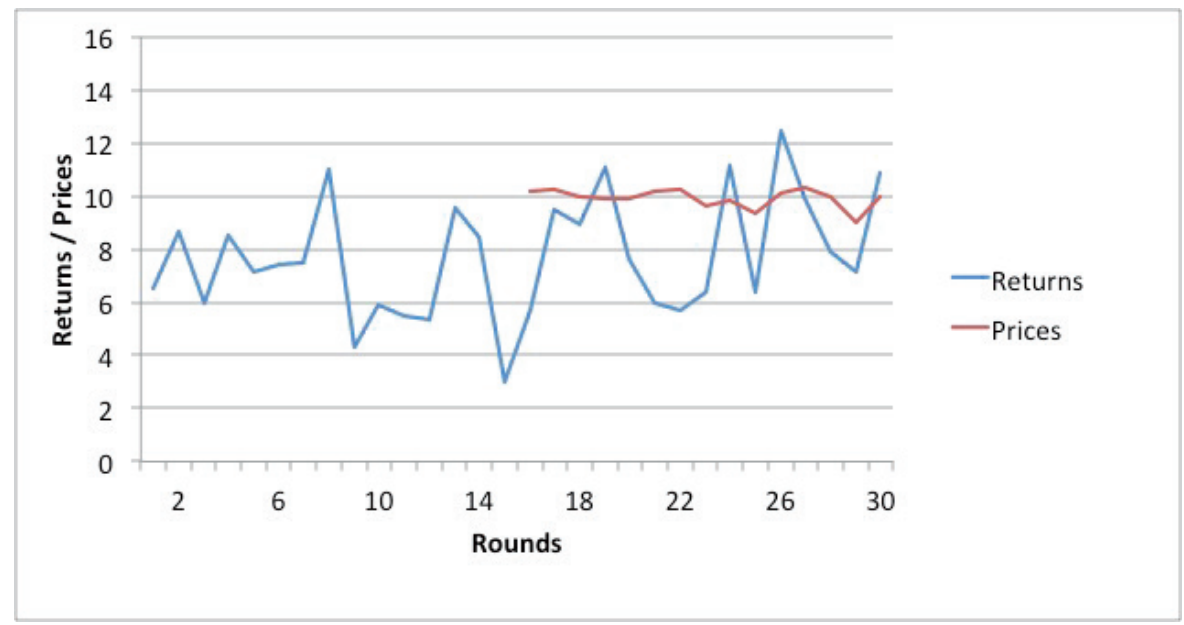

Figure 5.6: Average prices and informed worker returns over time.

To explore the responsiveness of returns to prices observed, we regress the returns of informed workers on price and round. The result is presented in the first column of Table 5.2, and reveals that there is no significant effect of prices on returns.

If informed workers are driven by egalitarian preferences, they may respond differently to prices below 10 compared to prices above this level. ${ }^{12}$ The second column in the table presents the result of the same regression when restricting attention to the observation where the price is 10 or higher.

\footnotetext{
${ }^{12} \mathrm{An}$ explanation of this follows in the discussion section.
} 


\begin{tabular}{|c|c|c|}
\hline & All prices & price $\geq 10$ \\
\hline Price & $\begin{array}{c}-0.44 \\
(0.41)\end{array}$ & $\begin{array}{c}-1.21^{* *} \\
(0.45)\end{array}$ \\
\hline Round & $\begin{array}{c}0.14 \\
(0.14)\end{array}$ & $\begin{array}{c}0.19 \\
(0.18)\end{array}$ \\
\hline Constant & $\begin{array}{c}9.43^{*} \\
(5.58)\end{array}$ & $\begin{array}{l}17.38^{* *} \\
(7.12)\end{array}$ \\
\hline Observations & 158 & 115 \\
\hline R-squared & 0.02 & 0.07 \\
\hline
\end{tabular}

Table 5.2: Returns by the informed workers. Robust standard errors (clustered on individual level) in parentheses. ${ }^{* * *} p<0.01,{ }^{* *} p<0.05,{ }^{*} p<0.1$.

We see that for prices of 10 or higher, a further increase in price has even a significant negative effect on the return of the informed worker.

\subsection{Discussion and conclusion}

In this section we discuss the main findings and motives behind the behaviors of the participants. Firstly, we investigate why workers return anything positive when they can keep everything to themselves. As we randomly rematch employers, referrers and workers every round anew, and no identity information is ever given, future interaction prospects and social proximity effects are negligible in our experiment. This leaves us with two motives that deserve a deeper assessment: reciprocity and egalitarianism. We repeat the same definitions for those concepts from the previous chapter.

A reciprocal individual responds to actions she perceives to be kind in a kind manner, and to actions she perceives to be hostile in a hostile manner (Rabin (1993), Segal and Sobel (2007), Dufwenberg and Kirchsteiger (2004), Falk and Fischbacher (2006), Fehr and Schmidt (2006)). When a referrer hires a worker, this may be perceived by the informed worker as a kind gesture as the referrer deliberately chooses one worker over the other while risking a loss by placing a bid. An informed worker may want to return the favor. An uninformed worker, on the other hand, does not know if she is chosen deliberately by a referrer who risks making a loss or randomly through the spot market, therefore less reciprocal behavior should prevail 
in this information state.

When a worker can attribute the hiring to the volitional choice of a referrer, she reciprocates, therefore we observe higher returns from informed workers compared to uninformed workers. On the other hand, the worker perceives to be hired as a gift but not so much the risk the referrer takes to be able to do the hiring. The referrer might have higher stakes but this does not change the size of the gift for the worker and we do not observe any additional reciprocity when the stakes are higher.

Egalitarian preferences of workers is another possible explanation of positive returns by workers. An egalitarian individual attempts to produce equality even at a cost to herself (Dawes et al. (2007)). In the setting implemented, a perfectly egalitarian informed worker is expected to return 20 since the surplus will be shared among the worker, the referrer and the employer. The return from a perfectly egalitarian uninformed worker depends on her beliefs about the likelihood she is hired through the spot market or via a referrer. In any case a perfectly egalitarian uninformed worker will return an amount between 15 and 20. Even if we do not observe this perfectly egalitarian behavior, an informed worker is expected to return more than an uninformed one, just to be relatively more equal.

The finding that for prices of 10 or more returns are decreasing in the price can be convincingly explained on basis of egalitarianism. For prices beyond 10, an equal division of the surplus is impossible; an extremely egalitarian informed worker may punish the referrer for accepting a deal that obstructs an egalitarian outcome. ${ }^{13}$

Egalitarian and reciprocal motives drives workers to exert higher efforts in the existence of a referrer. Therefore employers tend to outsource the hiring often and the referrers mostly pick the worker who is aware of this outsourcing process hence the volitional choice of who will be hired.

Finally, we regress the individual differences in returns between the informed state and the uninformed state on the three personality traits

\footnotetext{
${ }^{13}$ An alternative argument is when the price is too high, it may not be perceived as a gift any more. When a worker sees high prices, this means high expected returns from the worker and may cause a pressure on her. It is as if the employer and the referrer makes a very bad deal for the worker, or in other words it is the worker who has to pay for the gift now. However this motive yet lacks empirical evidence.
} 
from the Big Five that we retrieved in a post-experimental questionnaire: conscientiousness, agreeableness and neuroticism. Due to different motives possibly affecting participants' behavior in different manners across the two different informational variations in the first and second half of the experiment, Table 5.3 presents the result for each half of the experiment separately.

\begin{tabular}{|c|c|c|}
\hline & $1-15$ & $26-30$ \\
\hline Conscientiousness & $\begin{array}{c}-0.39^{* *} \\
(0.19)\end{array}$ & $\begin{array}{r}-0.36^{*} \\
(0.18)\end{array}$ \\
\hline Agreeableness & $\begin{array}{c}0.17 \\
(0.16)\end{array}$ & $\begin{array}{l}0.35^{* *} \\
(0.17)\end{array}$ \\
\hline Neuroticism & $\begin{array}{c}-0.18 \\
(0.16)\end{array}$ & $\begin{array}{c}-0.16 \\
(0.18)\end{array}$ \\
\hline Constant & $\begin{array}{l}10.76 \\
(7.81)\end{array}$ & $\begin{array}{c}4.94 \\
(8.69)\end{array}$ \\
\hline Observations & 66 & 63 \\
\hline R-squared & 0.08 & 0.013 \\
\hline
\end{tabular}

Table 5.3: Difference in return between workers in the informed and uninformed state. Robust standard errors (clustered on individual level) in parentheses. ${ }^{* * *} p<$ $0.01,{ }^{* *} p<0.05,{ }^{*} p<0.1$.

We see that a high conscientiousness score is a good predictor of returning more equally in the informed state and the uninformed while a high score on agreeableness is a good predictor for a larger difference in returns between these two information states, though only significantly in the second half of the experiment. Neuroticism has an insignificant negative effect. These findings support our earlier explanations.

Firstly, Gerlitz (2008) claims that higher scores of conscientiousness can be associated with weaker preferences for unequal distributions. If egalitarian preferences are one of the drivers for the gap in returns between informed and uninformed workers, then we should observe a smaller difference for those individuals with weaker egalitarian preferences. After all, informed workers are sure that the surplus is distributed among three individuals, while uninformed workers are unsure whether the surplus is going to be divided among two or three individuals. Individuals with higher 
scores of conscientiousness, whom can be expected to have a stronger preference for unequal distribution, indeed have less difference in returns in the two different information states. This supports our claim that egalitarian preferences have an impact on the return gap.

Secondly, Ashton et al. (1998) find that empathy/attachement relate positively with agreeableness. People with high agreeableness scores would empathize with the referrer about the price she needs to pay, but only when they know that there is a referrer and more so when they know the price. Hence the significant positive effect of agreeableness in the second half of the experiment seems consistent with our suggestion to explain the difference in returns by informed and uninformed workers by goodwill towards the referrer, hence the firm. 


\section{Appendix 1}

\section{Instructions}

\section{Welcome}

You are about to participate in a session on interactive decision-making. Thank you for agreeing to take part. The session should last 60 to 90 minutes.

You should have already turned off all mobile phones, smart phones, mp3 players and all such devices by now. If not, please do so immediately. These devices must remain switched off throughout the session. Place them in your bag or on the floor besides you. Do not have them in your pocket or on the table in front of you.

The entire session, including all interaction between you and other participants, will take place through the computer. You are not allowed to talk or to communicate with other participants in any other way during the session.

You are asked to abide by these rules throughout the session. Should you fail to do so, we will have to exclude you from this (and future) session(s) and you will not receive any compensation for this session.

We will start with a brief instruction period. Please read these instructions carefully. They are identical for all participants in this session with whom you will interact. If you have any questions about these instructions or at any other time during the experiment, then please raise your hand. One of the experimenters will come to answer your question. 


\section{Compensation for participation in this session}

In addition to the 3 Euros participation fee, what you will earn from this session will depend on your decisions, the decisions of others and chance. In the instructions and all decision tasks that follow, payoffs are reported in Experimental Currency Units (ECUs). You will receive an initial endowment of $75 \mathrm{ECU}$ which will cover some loss that might occur during the experiment. Just like a profit is automatically added to your total payoff at the end of a round, a loss will be automatically deducted. If at the end of the experiment your total payoff is negative we will ask you to donate this amount to a charity organization of choice. This situation is not likely to occur and under your control. At the end of the experiment, the total amount you have earned will be converted into Euros using the following conversion rate:

$1 \mathrm{ECU}=0.04$ Euros.

The payment takes place in cash at the end of the experiment. Your decisions in the experiment will remain anonymous.

\section{Instructions}

In the beginning of the experiment, you will be assigned one of three possible roles: employer, referee or worker. You will keep this role throughout the entire session in which the decision situation explained below is repeated for 30 rounds.

Every round anew, new groups are formed consisting of one employer, one referee and two workers. You will never be informed about identities of the people you are interacting with: neither during nor after the experiment.

\section{Employer}

First the employer decides whether s/he wants to hire a random worker from the spot market or to hire one via the referee.

When the employer chooses to hire a random worker from the spot market, one of the workers is randomly assigned the job. This worker is given an amount of $30 \mathrm{ECU}$ and has to decide how many of this $30 \mathrm{ECU}$ to return 
to the employer.

If the employer wants to hire via the referee, $\mathrm{s} /$ he has to ask a price between 0 and $30 \mathrm{ECU}$ at which $\mathrm{s} / \mathrm{he}$ is willing to outsource the hiring decision. In case the price-offer is accepted, the referee is given the task to hire a worker and will collect the return, but has to pay the price to the employer. In case the price-offer is rejected, no deal is made and the employer will be assigned a random worker from the spot market and collects the return from this worker. However, in this case, the employer loses 0.5 ECU for the delay.

\section{Referee}

The referee (whom does not know which way the employer likes to hire a worker, nor the offered price in case s/he wants to hire via the referee), is asked to indicate the maximum price - the bid - at which s/he is willing to accept the task to hire a worker. Afterwards s/he learns whether a priceoffer has been made by the employer. The offer results in a successful deal in case the price asked does not exceed the bid.

In case no successful deal is made, the referee is not assigned the task and does not have to make any further decision this round.

In case a successful deal is made, the referee has to choose to hire one of two possible workers: Worker 1 or Worker 2. Once the deal is realized, the referee observes his/her friendship-connection on Facebook to each of the workers. In the first 15 rounds the information released is whether a worker is a friend on Facebook or not; in the remaining 15 rounds the referee also observes how many friends s/he has in common with the workers on Facebook. ${ }^{1}$ The hired worker decides how much of the 30 ECU to return. The referee chooses to hire one of the workers before s/he sees how much they would return.

\footnotetext{
${ }^{1}$ Remark: Some Facebook-users use security options that do not allow us a perfect counting. As a result, the actual number of common friend may be larger than the number that is presented.
} 


\section{Worker}

In case a worker is randomly hired through the spot market (either because the employer prefers so or because the employer has not been successful in making a deal with the referee), both workers in the group are asked how much of the 30 ECU they want to return in case they are hired.

In case a deal is realized between the employer and the referee, both workers observe their friendship-connection on Facebook to the referee. In the first 15 rounds the information released is whether the referee is a friend on Facebook or not; in the remaining 15 rounds each worker also observes how many friends s/he has in common with the referee on Facebook (see Footnote 1). Both workers are asked how much of the 30 ECU they want to return in case they are hired.

The workers do not know each other's Facebook-relationship to the referee.

\section{Additional informational details}

If the employer wants to hire via the referee, the employer only learns if a deal is made or not. That is, $\mathrm{s} /$ he learns whether the bid of the referee is below the price or not, but s/he will never learn the precise bid. In case of a successful deal, the employer will not learn which worker is hired by the referee and how much this worker has returned.

In case the worker is not hired via the referee, the return goes to the employer and the referee will not learn about the amount returned.

In case the worker is hired by the referee, the amount that $\mathrm{s} /$ he returns goes to the referee, who in turn pays a price to the employer (and the price is not known by this worker).

Notice that a worker decides how much to return before knowing whether $\mathrm{s} /$ he is hired or not. At the end of the round the worker learns if $\mathrm{s} /$ he is hired for the job.

Also notice that when the referee does the hiring, s/he does not see how much each worker returns before s/he makes a choice between them. Similarly the employer does not see any returns before s/he makes a decision to go to the spot market or to hire via the referee. 


\section{Earnings}

Employer:

- If s/he chooses to hire a random worker from the spot market:

Earnings $=$ return

- If s/he offers the task to the referee and the offer is accepted:

Earnings $=$ price

- If $\mathrm{s} /$ he offers the task to the referee and the offer is rejected (and a random worker from the spot market is assigned the job):

Earnings $=$ return -0.5

Referee:

- If the employer hires a worker from the spot market (either directly or after an unsuccessful deal):

Earnings $=0$

- If a deal is made with the employer:

Earnings $=$ return - price

Worker:

- If the worker is hired for the job (either randomly selected from the spot market, or chosen by the referee):

Earnings $=30$ - return

- If the worker is not hired:

Earnings $=0$

The earnings (in ECU) are accumulated over (all 30) rounds and transferred to Euros at the end of the experiment (at the exchange rate given on the first page).

\section{Hypothetical examples for demonstration purposes}

\section{Example 1}

Suppose the employer wants to hire via the referee and asks a price of 20 (price $=20$ ), while the referee indicates to be willing to pay a price of 15 at maximum (bid=15). Then, no deal is realized between the employer and the referee, and the employer will be hiring from the spot market. This means that a randomly selected worker is assigned the job. Suppose this worker returns 6 of the $30 \mathrm{ECU}$. Then the earnings of the employer are 5.5 
ECU, that of the referee 0 ECU and that of the worker 24 ECU.

\section{Example 2}

Suppose the employer wants to hire via the spot market directly, while the referee indicates to accept all prices up to $7(\mathrm{bid}=7)$. The referee learns that no offer is made and that the employer is hiring from the spot market. Like in the previous example, a randomly selected worker is assigned the job. Suppose this worker returns 14 of the $30 \mathrm{ECU}$. Then the earnings of the employer are $14 \mathrm{ECU}$, that of the referee $0 \mathrm{ECU}$ and that of the worker 16 ECU.

\section{Example 3}

Suppose the employer wants to hire via the referee and asks a price of 12 (price=12), while the referee indicates to accept all prices up to 16 (bid=16). As the bid is not lower than the price, a deal is made between the employer and the referee at a price of 12 . As a result, the referee will be hiring a worker and will collect the return. Suppose that Worker 1 and the referee are friends on Facebook, this information will be revealed to both of them now. Suppose that Worker 2 and the referee are not friends on Facebook, this information will be revealed to both of them now. Suppose that Worker 1 indicates to return 20 of the 30 ECU and Worker 2 indicates to return 16 in case being hired. Suppose the referee (who cannot observe the returns of the two workers) hires Worker 2. Then the earnings of the employer are $12 \mathrm{ECU}$, that of the referee is $4 \mathrm{ECU}$ and that of Worker 2 is 14 ECU; Worker 1 receives 0 ECU.

\section{True or False?}

After reading the instructions, before proceeding with the experiment you should be able to tell if the following sentences are true or false. Please write down your answers on this sheet. You will be approached by the experimenter and the answers will be checked.

1. If I am a worker, when I return more I increase my chances of being hired in that round. 
2. Every round I will keep the same role, but I will be rematched with others to form a new group.

3. If I am a referee, when there is a deal I need to return the price to the employer.

4. If I am an employer and a deal is made, I will receive the price from the referee for sure.

\section{Experiment screen}

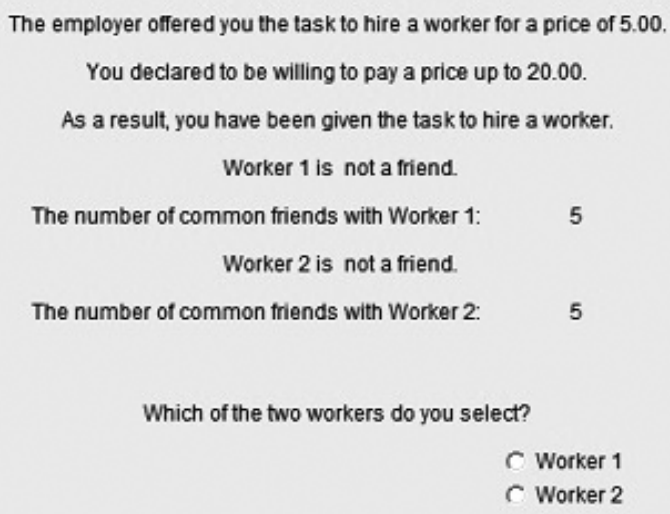

Figure A1.1: Information on social proximity given to subjects on the choice screen 



\section{Appendix 2}

\section{Instructions}

\section{Welcome}

You are about to participate in a session on interactive decision-making. Thank you for agreeing to take part. The session should last 60 to 90 minutes.

You should have already turned off all mobile phones, smart phones, mp3 players and all such devices by now. If not, please do so immediately. These devices must remain switched off throughout the session. Place them in your bag or on the floor besides you. Do not have them in your pocket or on the table in front of you.

The entire session, including all interaction between you and other participants, will take place through the computer. You are not allowed to talk or to communicate with other participants in any other way during the session. You are asked to abide by these rules throughout the session. Should you fail to do so, we will have to exclude you from this (and future) session(s) and you will not receive any compensation for this session.

We will start with a brief instruction period. Please read these instructions carefully. They are identical for all participants in this session with whom you will interact. If you have any questions about these instructions or at any other time during the experiment, then please raise your hand. One of the experimenters will come to answer your question. 


\section{Compensation for participation in this session}

In addition to the 3 Euros participation fee, what you will earn from this session will depend on your decisions, the decisions of others and chance. In the instructions and all decision tasks that follow, payoffs are reported in Experimental Currency Units (ECUs). You will receive an initial endowment of $75 \mathrm{ECU}$ which will cover some loss that might occur during the experiment. Just like a profit is automatically added to your total payoff at the end of a round, a loss will be automatically deducted. If at the end of the experiment your total payoff is negative we will ask you to donate this amount to a charity organization of choice. This situation is not likely to occur and under your control. At the end of the experiment, the total amount you have earned will be converted into Euros using the following conversion rate:

$1 \mathrm{ECU}=0.04$ Euros.

The payment takes place in cash at the end of the experiment. Your decisions in the experiment will remain anonymous.

\section{Instructions}

In the beginning of the experiment, you will be randomly assigned one of three possible roles: employer, referee or worker. You will keep this role throughout the entire session in which the decision situation explained below is repeated for 30 rounds.

Every round anew, new groups are formed consisting of one employer, one referee and two workers. You will never be informed about identities of the people you are interacting with: neither during nor after the experiment.

\section{Employer}

First the employer decides whether s/he wants to hire a random worker from the spot market or to hire one via the referee.

When the employer chooses to hire a random worker from the spot market, one of the workers is randomly assigned the job. This worker is given an amount of $30 \mathrm{ECU}$ and has to decide how many of this $30 \mathrm{ECU}$ to return 
to the employer.

If the employer wants to hire via the referee, $\mathrm{s} /$ he has to ask a price between 0 and $30 \mathrm{ECU}$ at which $\mathrm{s} / \mathrm{he}$ is willing to outsource the hiring decision. In case the price-offer is accepted, the referee is given the task to hire a worker and will collect the return, but has to pay the price to the employer. In case the price-offer is rejected, no deal is made and the employer will be assigned a random worker from the spot market and collects the return from this worker. However, in this case, the employer loses 0.5 ECU for the delay.

\section{Referee}

The referee (whom does not know which way the employer likes to hire a worker, nor the offered price in case s/he wants to hire via the referee), is asked to indicate the maximum price - the bid - at which s/he is willing to accept the task to hire a worker. Afterwards s/he learns whether a priceoffer has been made by the employer. The offer results in a successful deal in case the price asked does not exceed the bid.

In case no successful deal is made, the referee is not assigned the task and does not have to make any further decision this round.

In case a successful deal is made, the referee has to choose to hire one of two possible workers: one who is informed that hiring is done via a referee that paid a price to do the hiring (the price being unknown in the first 15 rounds and known in the remaining 15 rounds) or one who does not know whether s/he is randomly hired through the spot market or is hired by the referee. In either case, the hired worker decides how much of the 30 ECU to return. The worker that is informed about being hired via the referee knows that the return goes to the referee (whom in turn pays a price to the employer); the worker that is unaware on how $\mathrm{s} /$ he got the job does not know whether $\mathrm{s} /$ he returns to the employer or the referee.

The referee chooses to hire one of the workers before s/he sees how much they would return. 


\section{Worker}

In case a worker is randomly hired through the spot market (either because the employer prefers so or because the employer has not been successful in making a deal with the referee), both workers in the group are asked how much of the 30 ECU they want to return in case they are hired.

In case a deal is realized between the employer and the referee, one of the workers is informed that if $\mathrm{s} / \mathrm{he}$ is hired it is because the referee has chosen her/him (the referee knows that only this worker is informed); the other worker is not informed. Both workers are asked how much of the $30 \mathrm{ECU}$ they want to return in case they are hired.

\section{Additional informational details}

If the employer wants to hire via the referee, the employer only learns if a deal is made or not. That is, $\mathrm{s} /$ he learns whether the bid of the referee is below the price or not, but s/he will never learn the precise bid. In case of a successful deal, the employer will not learn which worker is hired by the referee and how much this worker has returned.

In case the worker is not hired via the referee, the return goes to the employer and the referee will not learn about the amount returned.

A worker who is informed about being hired by the referee if hired, knows that the amount that $\mathrm{s} /$ he returns goes to the referee, who in turn pays a price to the employer (and in the first 15 rounds the price is not known by this worker; in the remaining 15 rounds it is). In case a worker is not given this information, s/he does not know whether the return goes to the employer or to the referee.

Notice that a worker decides how much to return before knowing whether $\mathrm{s} /$ he is hired or not. At the end of the round the worker learns if $\mathrm{s} /$ he is hired for the job.

Also notice that when the referee does the hiring, s/he does not see how much each worker returns before s/he makes a choice between them. Similarly the employer do not see any returns before $\mathrm{s} /$ he makes a decision to go to the spot market or hire via referee. 


\section{Earnings}

Employer:

- If s/he chooses to hire a random worker from the spot market:

Earnings $=$ return

- If $\mathrm{s} /$ he offers the task to the referee and the offer is accepted:

Earnings $=$ price

- If $\mathrm{s} /$ he offers the task to the referee and the offer is rejected (and a random worker from the spot market is assigned the job):

Earnings $=$ return -0.5

Referee:

- If the employer hires a worker from the spot market (either directly or after an unsuccessful deal):

Earnings $=0$

- If a deal is made with the employer:

Earnings $=$ return - price

Worker:

- If the worker is hired for the job (either randomly selected from the spot market, or chosen by the referee):

Earnings $=30$ - return

- If the worker is not hired:

Earnings $=0$

The earnings (in ECU) are accumulated over (all 30) rounds and transferred to Euros at the end of the experiment (at the exchange rate given on the first page).

\section{Hypothetical examples for demonstration purposes}

\section{Example 1}

Suppose the employer wants to hire via the referee and asks a price of 20 (price $=20$ ), while the referee indicates to be willing to pay a price of 15 at maximum (bid=15). Then, no deal is realized between the employer and the referee, and the employer will be hiring from the spot market. This means that a randomly selected worker is assigned the job. This worker does not know whether s/he is hired via the spot market (in which case the 
return goes to the employer) or via the referee (in which case the return goes to the referee). Suppose this worker returns 6 of the 30 ECU. Then the earnings of the employer are 5.5 ECU, that of the referee 0 ECU and that of the worker 24 ECU.

\section{Example 2}

Suppose the employer wants to hire via the spot market directly, while the referee indicates to accept all prices up to $7(\mathrm{bid}=7)$. The referee learns that no offer is made and that the employer is hiring from the spot market. Like in the previous example, a randomly selected worker is assigned the job who does not know whether s/he is hired via the spot market or via the referee. Suppose this worker returns 14 of the 30 ECU. Then the earnings of the employer are $14 \mathrm{ECU}$, that of the referee $0 \mathrm{ECU}$ and that of the worker 16 ECU.

\section{Example 3}

Suppose the employer wants to hire via the referee and asks a price of 12 (price $=12$ ), while the referee indicates to accept all prices up to 16 (bid=16). As the bid is not lower than the price, a deal is made between the employer and the referee at a price of 12. As a result, the referee will be hiring a worker and will collect the return. Suppose the referee hires the worker that does not know a deal has been made between the employer and the referee, and that this worker returns 20 of the $30 \mathrm{ECU}$, while the worker who knows that a deal has been made between the employer and the referee indicates to return 16 in case being hired. Then the earnings of the employer are $12 \mathrm{ECU}$, that of the referee $8 \mathrm{ECU}$ and that of the hired worker $10 \mathrm{ECU}$; the worker that is not hired receives 0 ECU.

\section{True or False?}

After reading the instructions, before proceeding with the experiment you should be able to tell if the following sentences are true or false. Please write down your answers on this sheet. You will be approached by the experimenter and the answers will be checked. 
1. If I am a worker, when I return more I increase my chances of being hired in that round.

2. If I am a worker, when I return more I increase my chances of being hired in the next rounds.

3. If I am a referee, when there is a deal I need to return the price to the employer.

4. If I am an employer and a deal is made, I will receive the price from the referee for sure.

\section{Experiment screen}

The employer offered you the task to hire a worker for a price of 10.00 .

You declared to be willing to pay a price up to 20.00 .

As a result, you have been given the task to hire a worker.

Which of the two workers do you select?

$C$ the worker that knows s/he is hired via you

$C$ the worker that is left unaware

Figure A2.1: Information on social proximity given to subjects on the choice screen 



\section{Bibliography}

[1] Akerlof G (1982). Labor contracts as partial gift exchange. The Quarterly Journal of Economics 97(4): 543-569.

[2] Ashton M, S Paunonena, E Helmesa and D Jacksona (1998). Kin altruism, reciprocal altruism, and the Big Five personality factors. Evolution and Human Behavior 19(4): 243 ?255.

[3] Aumann R (1959). Acceptable points in general cooperative n-person games. In: A Tucker and R Luce (eds.) Contributions to the theory of games IV. Princeton: Princeton University Press: 287-324.

[4] Bandiera O, I Barankay and I Rasul (2009). Social connections and incentives in the workplace: Evidence from personnel data. Econometrica 77(4): 1047-1094.

[5] Beaman L and J Magruder (2012). Who gets the job referral? Evidence from a social networks experiment. American Economic Review 102(7): 3574-3593.

[6] Bernheim B, B Peleg and M Whinston (1987). Coalition-proof Nash equilibria I: Concepts. Journal of Economic Theory 42 (1): 1-12.

[7] Besley T and S Coate (1997). An economic model of representative democracy. Quarterly Journal of Economics 112 (1): 85-114.

[8] Casoria F and A Riedl (2013). Experimental labor markets and policy considerations: Incomplete contracts and macroeconomic aspects. Journal of Economic Surveys 27(3): 398-420.

[9] Charness G. (2004). Attribution and reciprocity in an experimental labor market. Journal of Labor Economics 22(3): 665-688. 
[10] Charness G and U Gneezy (2008). What's in a name? Anonymity and social distance in dictator and ultimatum games. Journal of Economic Behavior and Organization, 68(1) : 29-35.

[11] Cox G (1987). Electoral equilibrium under alternative voting institutions. American Journal of Political Science 31 (1): 82-108.

[12] Dawes C, J Fowler, T Johnson, R McElreath, and O Smirnov (2007). Egalitarian motives in humans. Nature 446(7137): 794-796.

[13] D'Excelle B and A Riedl (2010). Directed Generosity and Network Formation: Network Dimension Matters, IZA Discussion Paper No. 5356, December 2010.

[14] Dhillon A, V Iversen and G Torsvik (2013). Employee referral, social proximity and worker discipline: Theory and evidence from India. CESifo Working Paper Series No. 4309.

[15] Downs A (1957). An Economic Theory of Democracy. New York: Harper and Row.

[16] Dufwenberg and Kirchsteiger (2004). A Theory of sequential reciprocity. Games and Economic Behavior 47(2): 268-298.

[17] Dustmann C, A Glitz and U Schoenberg (2011). Referral-based job search networks. Norface Discussion Paper Series 2011012, Norface Research Programme on Migration, Department of Economics, University College London.

[18] Duverger M (1954). Political Parties. New York: Wiley.

[19] Eguia J (2010). The origin of parties: Theory, and evidence from the United States Congress 1789-1797. SSRN working paper 1650683.

[20] Engel C (2011). Dictator games: A meta study. Experimental Economics 14(4): 583-610.

[21] Fafchamps M and A Moradi (2010). Referral and job performance: evidence from the Ghanaian army. Mimeo, Department of Economics, University of Oxford.

[22] Falk and Fischbacher (2006). A theory of reciprocity. Games and Economic Behavior 54(2): 293-315. 
[23] Faye, J P (1996). Le sicle des idologies .Paris: A. Colin.

[24] Feddersen T (1992). A voting model implying Duverger's law and positive turnout. American Journal of Political Science 36 (4): $938-62$.

[25] Fehr E, G Kirchsteiger and A Riedl (1993). Does fairness prevent market clearing? An experimental investigation. The Quarterly Journal of Economics 108(2): 437-459.

[26] Fehr E and K Schmidt (2006). The economics of fairness, reciprocity and altruism - Experimental evidence and new theories. Handbook of the Economics of Giving, Altruism and Reciprocity: Chapter 8: 615-691.

[27] Fehr E, L Goette and C Zehnder (2009). A behavioral account of the labor market: The role of fairness concerns. Annual Review of Economics 1(1): 355-384.

[28] Fey M (1997). Stability and coordination in Duverger's law: A formal model of preelection polls and strategic voting. American Political Science Review 91 (1): 135-147.

[29] Fischbacher U (2007). zTree: Zurich toolbox for ready-made economic experiments. Experimental Economics 10(2): 171-178.

[30] Gerlitz J-Y (2008). Personality and distributive justice: The impact of the Big Five on preferences for justice ideologies. Working paper.

[31] Goeree J, M A McConnell, T Mitchell, T Tromp and L Yarif (2010). The 1/d law of giving. American Economic Journal: MicroEconomics, 2(1) : 183-203.

[32] Goldberg R (1993). The structure of phenotypic personality traits. American Psychologist 48(1): 26-34.

[33] Granovetter (1995). Getting a Job: A Study of Contacts and Careers, 2nd edition, Chicago University Press.

[34] Greiner B (2004). An online recruitment system for economic experiments. In: K Kremer and V Macho (eds.): Forschung und 
wissenschaftliches Rechnen 2003. GWDG Bericht 63, Göttingen: Ges. für Wiss. Datenverarbeitung: 79-93.

[35] Gupta B, F-C Lai, D Pal, J Sarkar and C-M Yu (2004). Where to locate in a circular city? International Journal of Industrial Organization 22 (6): 759-782.

[36] Harrison GW and JA List (2004). Field experiments. Journal of Economic Literature 42(4): 1009-1055.

[37] Heath R (2011). Why do firms hire using referrals?: Evidence from Bangladeshi garmet factories. Dissertation. Yale University.

[38] Hotelling H (1929). Stability in competition. Economic Journal 39 (153): 41-57.

[39] Jackson M and B Moselle (2002). Coalition and party formation in a legislative voting game. Journal of Economic Theory 103 (1): 49-87.

[40] Johnson N and A Mislin (2011). Trust games: A meta analysis. Journal of Economic Psychology 32(5): 865-889.

[41] Kaminski M (2006). A general equilibrium model of multi-party competition. Social Choice and Welfare 26 (2): 333-361.

[42] Kramarz F and Thesmar (2013). Social networks in the boardroom. Journal of the European Economic Association 11(4): 780-807.

[43] Kugler A (2003). Employee referrals and efficiency wages. Labour Economics 10(5): 531-556.

[44] Leider S, M Möbius, T Rosenblat and Q-A Do (2009). Directed altruism and enforced reciprocity in social networks. Quarterly Journal of Economics 124(4): 1815-1851.

[45] Levy G (2004). A model of political parties. Journal of Economic Theory 115 (2): 250-277.

[46] Lijphart A (1990). The political consequences of electoral laws, 194585. American Political Science Review 84 (2): 481-496.

[47] Montgomery J (1991). Social networks and labor-market outcomes: Toward an economic analysis. American Economic Review 81(5): 1408-1418. 
[48] Morelli M (2004). Party formation and policy outcomes under different electoral systems. Review of Economic Studies 71 (3): 829-853.

[49] Munshi K and M Rosenzweig (2006). Traditional institutions meet the modern world: Caste, gender, and schooling choice in a globalizing economy. American Economic Review 96(4): 1225-1252.

[50] Nozick R (1997). The characteristic features of extremism. Socratic puzzles: 296-299.

[51] Osborne M and A Slivinski (1996). A model of political competition with citizen-candidates. Quarterly Journal of Economics 111 (1): 65-96.

[52] Osborne M and R Tourky (2008). Party formation in single-issue politics. Journal of the European Economic Association 6 (5): 974-1005.

[53] Palfrey T (1989). A mathematical proof of Duverger's law. In: Ordeshook P (ed.) Models of Strategic Choice in Politics. Ann Arbor: University of Michigan Press: 69-91.

[54] Persson T and G Tabellini (2000). Political Economics: Explaining Economic Policy. Cambridge: MIT Press.

[55] Rabin M (1993). Incorporating fairness into game theory and economics. American Economic Review 83(5): 1281-1302

[56] Rae D (1971). The Political Consequences of Electoral Laws (2nd edition). New Haven: Yale University Press.

[57] Riker W (1982). The two-party system and Duverger's law: An essay on the history of political science. American Political Science Review 76 (4): 753-766.

[58] Rivière A (1998). Citizen candidacy, party formation, and Duverger's law. Mimeo: Université Libre de Bruxelles.

[59] Salop S (1979). Monopolistic competition with outside goods. The Bell Journal of Economics 10 (1): 141-156.

[60] Segal and Sobel (2007). Tit for tat: Foundations of preferences for reciprocity in strategic settings. Journal of Economic Theory 136(1): 197-216. 
[61] Snyder J Jr. and M Ting (2002). An informational rationale for political parties. American Journal of Political Science 46 (1): 90-110.

[62] Taagepera R and M Shugart (1989). Seats and Votes: The Effects and Determinants of Electoral Systems. New Haven: Yale University Press.

[63] Tausch F, J Potters and A Riedl (2013). Preferences for redistribution and pensions. What can we learn from experiments?. Journal of Pension Economics and Finance, 12, pp 298-325.

[64] Verwys C. The Big Five Personality Dimensions. Personality Psychology lecture notes on Rensselaer Polytechnic Institute website. Retrieved from http://homepages.rpi.edu/ verwyc/BIGFIVEOH.html Retrieved on June 2012. 


\section{Valorization}

In this chapter we discuss what we learn from this research, how it can be applied and create value from knowledge for the society. Two distinct parts of the thesis in different fields of economics will be handled separately.

\section{On political economy}

Why in the Netherlands there are so many political parties where in the US we only speak of Republicans and Democrats? Because the US has a winner-takes-all approach in the elections and the Netherlands favors a proportional representation. We know since decades that the former approach leads to two major parties and the latter leads to the formation of many political parties with diverse agendas. We just do not exactly know why.

In our attempt to explain this observation, we challenge the assumptions on how political ideology works. People are very much used to thinking of political agendas as a piece of line with rightists at the right and leftists at the left, which is the only way political agendas have ever been presented to them. Coming back to our discussion in the introduction, a political ideology cannot be observed directly but only in its consequences. We do not have to stick to this piece of line, in the end it is only an assumption.

A model of political agendas as a piece of line tells you that there are two types of extremes and that those two are furthest away from each other. Here is what Clint Eastwood mentions about extreme political ideologies: "Extremism is so easy. You've got your position, and that's it. It doesn't take much thought. And when you go far enough to the right you meet the 
same idiots coming around from the left." Offensive it might be, however it demonstrates the fact that we perceive two extremes not as exact opposites, but as rather similar ones.

We claim that established views on political ideology so far might not be accurate. We introduce a new circular model and explain the observations above about the number of parties, with only standard assumptions. This will help us for a better understanding of society, political dynamics and outcomes of voting processes. It comes in two stages: firstly on an academic level and afterwards on a societal level. In chapter 2, we develop a new model that will be adopted by other scholars and lead to discoveries of new insights on elections, party or coalition formation. This model has also technical superiorities and we believe it will accelerate the research progress in this area. In chapter 3 we provide necessary tools to work with this circular model and explain why a certain equilibrium notion we create is the most suitable one in this setting. Even if they do not immediately adopt this new model, if we can get the academic audience question the validity of their existing assumptions on political ideology this would be a drastic contribution to the science.

Once the academic audience is convinced, it is very important that this circular way of interpreting political ideology is publicized by media and used in their electoral analyses. This will improve the accuracy of their predictions and provide the voting body a better understanding of the choices they make. Policy analysts, media and non-governmental organizations can beneficially utilize this new model. Elections are a useful tool for democracy, yet elections alone do not constitute democracy. In so many ways electoral design can restrict or even shape the outcome, some of these effects listed in the introduction. In Turkey, as an illustration, the electoral rule was legislated by a military government after a coup in 1980 and today still there is a 10 percent threshold of all the votes to have a seat in the parliament. Introduced as a tool of suppression, this rule has also caused a serious minority conflict for decades. Through this thesis we serve as a reminder for nations that the design of the electoral rule is crucial and every country should question if its electoral system fits to its changing dynamics and investigate if the current electoral model fits the values of the country and enables the public to be represented, rather than serving 
for the incumbent governments.

\section{On behavioral economics}

Lean Six Sigma, a renowned methodology that relies on team efforts for continuous improvement, states underutilization of people and talent to be one of the eight wastes that needs to be removed for a successful management. Companies are looking for ways to create value by finding a good match for their talent needs and provide incentives for people to work for them by employer branding. Innovative solutions in talent acquisition and employee motivation are very much demanded by business owners, managers and HR specialists and mostly provided by online services or professional headhunting agencies.

With technological advancement and growing opportunities in social media, hiring is not what it used to be. Providing behavioral resumes based on big five personality test (JobFig), big data analysis for understanding which strategies are more effective for an employer for recruiting (Dice - open web), active search engines for finding passive candidates online (Talent bin by Monster), combining social media reports with applicant's resume is now the new reality of job markets.

Employee referrals, which means existing employees refer their connections for open positions in their company, however has been the choice of employers for many years and it still is for one very simple reason: it works. It has evolved hand in hand with social network revolution and today there are Facebook applications that help employers identify potential candidates among employees' Facebook friends or tools to rate employees on their referral performance (Jobvite).

Job referrals has some indisputable benefits. By homophily or assortative matching arguments, your employee networks provides an invaluable pool for new hires. It functions as a screening mechanism and reduces the uncertainty about a candidate's talent or labor productivity. Through better knowledge of both sides, employees can increase the quality of the match between workplace and new employees. Referrals reduce search cost.

When it comes to blue collar jobs, those benefits seems to be much less as these are manual jobs requiring comparatively less training, talent or 
creativity. For these kind of jobs employers are seeking for trustworthiness and to avoid absenteeism and moral hazard such as putting in low levels of effort. This thesis demonstrates that job referrals also pays off when hiring for blue collar jobs where talent is not particularly emphasized. The role of job referrals is not limited to those of a disciplining and a monitoring device. This work shows that social proximity, which is a natural component of job referrals, encourages altruistic behavior between workers and help overcome moral hazard issues.

This work also serves as a guide for designing a successful referral scheme in companies for blue collar jobs. We list the most important elements that needs to be taken into account in the scheme. Our points are simple and effective.

Social proximity is crucial. It is more effective when employees invite their siblings, cousins, close friends rather than acquaintances. This is an important distinction from white collar jobs where the focus is on talent and weak links when utilized effectively is as important as strong links. An advantage of social proximity is that thanks to high prevalence of social networks, it is easily traceable. This thesis also presents that all the research for linking social proximity information to social media sites are of great importance.

The referral scheme itself should be clear to referrers and candidates. The volitional choice of the referrer should be emphasized in order for the employment opportunity to be perceived as a gift by the new hire. The new hire will reciprocate to the gift by higher effort and lower moral hazard. High stakes for the referrer are not necessary, in fact it can be detrimental for the process if stakes are too high. If the referrer receives a lot of compensation, the new hire may doubt the incentives of the referrer and might interpret the offer as purely selfish. On the other hand if the referrer has a high stake when the new hire underperforms, the new hire might think that it is not much of a gift as she is placed in an uncomfortable position.

In order to provide best fitting advice to companies on hiring strategies we need to understand the mechanisms underlying the success of job referrals. Our work yields useful insights that are directly applicable to the design of hiring schemes for blue collar jobs. Innovation in talent acquisition 
for white collar jobs while expanding in the direction of wider utilization of social networks in hiring, can also benefit from our findings by gaining a better understanding of the effects of social ties on workplace behavior. The concepts discussed here such as gift exchange mechanism, directed altruism and egalitarian concerns are applicable to the hiring process for both types of jobs. 



\section{Short Curriculum Vitae}

Ayse Muge Yuksel was born in Izmir, Turkey in 1985. After obtaining her Bachelor of Science degree in Mathematics at Bilkent University in 2006, she received her Master of Arts degree in Economics at the same university in 2009. Her work and training were focused on Mathematical Economics and Game Theory. She joined Maastricht University Department of Economics as a full time lecturer in 2008 and she started her doctoral studies there in 2009. During her PhD, Ayse was also a Visiting Scholar at Princeton University where she met one of her coauthors. Her interests expanded in the directions of political economy and behavioral economics; she followed courses in Jerusalem, Princeton, and Singapore. Currently she is working at Saudi Basic Industries Corporation. 
